University of Tennessee Health Science Center

UTHSC Digital Commons

\title{
$5-2011$
}

\section{The Treatment of Breast Cancer Tumor Growth and Metastasis With an Anti-MMP9 DNAzyme}

Miranda A. Hallett

University of Tennessee Health Science Center

Follow this and additional works at: https://dc.uthsc.edu/dissertations

\section{Recommended Citation}

Hallett, Miranda A. , "The Treatment of Breast Cancer Tumor Growth and Metastasis With an Anti-MMP9 DNAzyme" (2011). Theses and Dissertations (ETD). Paper 110. http://dx.doi.org/10.21007/ etd.cghs.2011.0124.

This Dissertation is brought to you for free and open access by the College of Graduate Health Sciences at UTHSC Digital Commons. It has been accepted for inclusion in Theses and Dissertations (ETD) by an authorized administrator of UTHSC Digital Commons. For more information, please contact jwelch30@uthsc.edu. 


\title{
The Treatment of Breast Cancer Tumor Growth and Metastasis With an Anti- MMP9 DNAzyme
}

\begin{abstract}
BACKGROUND: Tumor cell proliferation, invasion and metastasis are known to be mediated, at least in part, through degradation of basement membrane by neutral metalloproteinases (MMP) produced by tumor and stromal cells. MMP-9 is known to play a significant role in breast tumor cell invasion and metastasis via degradation of ECM components and activation of cytokines and chemokines. MMP-9 is known to cleave type IV collagen, one of the most abundant collagens of the extracellular matrix. Our lab has found that the fully processed $(68 \mathrm{kDa})$ form of MMP-9 generated in tumor and stromal cells is also capable of cleaving type I collagen molecule with similar characteristics of MMP-1. This observation raises questions regarding the significance of each MMP in tumor cell invasion and metastases. Thus, in combating tumor growth and invasion, understanding the mechanism of substrate specificity and design of a novel therapeutic compound that is capable of specifically down regulating MMP-9 expression are of interest.
\end{abstract}

METHOD: DNAzymes are catalytic oligonucleotides that bind to and cleave specific mRNA, resulting in a decreased protein expression. The safety and efficacy of anti-MMP-9 DNAzyme (AM9D) in vivo was determined by injecting ${ }^{35}$ S-labeled AM9D ( ${ }^{35}$ S-AM9D) into the tail vein of healthy and MMTV-PyMT transgenic mice and the amount of ${ }^{35} \mathrm{~S}-\mathrm{AM} 9 \mathrm{D}$ accumulated in different tissues was measured as a function of time. The effect of AM9D treatment on breast tumor progression was tested by four once-weekly intratumoral injections of two concentrations of AM9D into mammary tumors of MMTVPyMT transgenic mice at early stages of tumor development. The tumor sizes were measured at the end of the experiments. The effect of AM9D treatment on early stage experimental metastasis and survival was evaluated by injecting FVB female mice with $1 \times 10^{6}$ luciferase labeled mammary tumor epithelial cells (luc-MTEC) isolated from MMTV-PyMT mice and treating the animals with AM9D, control DNAzyme, or PBS for 3 weeks or up to 10 weeks, respectively.

The mechanism of substrate specificity of $68 \mathrm{kDa}$ MMP-9 was determined by generating a series of truncated and site directed mutant forms of MMP-9. Specific amino acid residue in sequence ${ }^{444}$ PRPEPEPRPPTTT ${ }^{456}$ in the hinge region responsible for substrate selectivity of the enzyme was then identified by alanine-scanning site directed mutagenesis. The charged amino acid residues ( $\operatorname{Arg}^{445}$, $\mathrm{Glu}^{447}$, $\mathrm{Glu}^{449}$, and $\mathrm{Arg}^{451}$ ) were individually replaced by Ala and the proteolytic activity of the mutant enzymes toward Mca-PLGL(Dpa)AR-NH2, gelatin, and type I collagen was determined.

RESULTS: Treatment of MDA-MB-231 breast cancer cell line with AM9D in vitro resulted in decreased invasion potential of the cells and intratumoral treatment of MMTV-PyMT mice in vivo resulted in delayed rate of tumor growth and retarded final tumor volume by up to $51 \%$. This decrease in tumor growth was correlated with decreased MMP-9 protein production within the treated tumor tissues. Tumors treated with AM9D were also less vascular compared to control and untreated tumors. Furthermore, DNAzyme administered IV is distributed to major organs including lung, without showing any organ toxicity. Intravenous administration of AM9D and control DNAzyme in animals bearing luc-MTECs were able to decrease the number of gross lung macro metastasis. In addition, AM9D treatment increased progression-free survival but did not have an effect on overall survival of animals inoculated with luc-MTECs compared to control DNAzyme and PBS treatment. These data indicate that AM9D can be used individually or as an adjuvant to current chemotherapy for breast cancer.

To further illuminate the role of MMP-9 in tumor growth and metastases the mechanism of substrate 
specificity of the enzyme was studied. Site directed and deletion mutagenesis revealed that interaction of $\mathrm{Glu}^{415}$ in the active site with $\mathrm{Glu}^{447}$ and/or $\mathrm{Arg}^{451}$ in the hinge region makes the active site rigid, preventing full length MMP-9 from cleaving type I collagen. Disruption of this interaction, on the other hand, provides the flexibility necessary for the enzyme's active site to change conformation and be able to bind and cleave type I collagen substrate.

CONCLUSION: Given that MMP-9 is capable of cleaving type I collagen and its down regulation hinders the development of breast cancer in an animal model, AM9D could prove useful as an adjuvant therapy against breast carcinoma cell invasion.

Document Type

Dissertation

Degree Name

Doctor of Philosophy (PhD)

Program

Biomedical Sciences

Research Advisor

Tayebeh Pourmotabbed, Ph.D.

Keywords

Breast Cancer, DNAzyme, Metastasis, MMP-9 
THE TREATMENT OF BREAST CANCER TUMOR GROWTH AND METASTASIS WITH AN ANTI-MMP9 DNAZYME

\author{
A Dissertation \\ Presented for \\ The Graduate Studies Council \\ The University of Tennessee \\ Health Science Center
}

\begin{abstract}
In Partial Fulfillment
Of the Requirements for the Degree

Doctor of Philosophy

From The University of Tennessee
\end{abstract}

By

Miranda A. Hallett

May 2011 
Copyright (C) 2011 by Miranda A. Hallett. All rights reserved. 


\section{DEDICATION}

This dissertation is dedicated to my family and friends who provided me with strength, prayer and encouragement in obtaining this degree. A special dedication is extended to my mother who is the epitome of a strong woman. To my father who taught me a conversation without words is the most important conversation. Also, for being there to encourage me through the toughest of times, even when there were dogs in the room. 


\section{ACKNOWLEDGEMENTS}

First and foremost, I owe all praise to my Lord and savior Jesus Christ. I would like to thank my advisor Tayebeh Pourmotabbed for the opportunity to work in her lab and the training I received. Also, thanks to my committee members Yi Lu, Ph.D, R.K. Rao, Ph.D, Tiffany Seagroves, Ph.D, and Trevor Sweatman, Ph.D for providing excellent insights, ideas, and guidance during my research.

My gratitude is also extended to past and present members of the Pourmotabbed laboratory, Pooja Dalal, Bin Teng, Jiang "Julia” Liang Shen, Mohammad Shokouh-Amiri, Ipsit "Raja" Chakrabari, and Isita Chakrabari for their support and help. In addition, I would like to thank members of the Seagroves and Christopher Duntsch laboratories for guidance. Appreciation is also extended to Dr. Sweatman for devoting his time and laboratory to completion of a portion of my project. A special thanks is extended to Pooja Dalal for always reminding me to eat, pray, and love. Additionally, I would like to thank other members of the Microbiology Immunology and Biochemistry department for offering input, guidance, and support. 


\begin{abstract}
BACKGROUND: Tumor cell proliferation, invasion and metastasis are known to be mediated, at least in part, through degradation of basement membrane by neutral metalloproteinases (MMP) produced by tumor and stromal cells. MMP-9 is known to play a significant role in breast tumor cell invasion and metastasis via degradation of ECM components and activation of cytokines and chemokines. MMP-9 is known to cleave type IV collagen, one of the most abundant collagens of the extracellular matrix. Our lab has found that the fully processed $(68 \mathrm{kDa})$ form of MMP-9 generated in tumor and stromal cells is also capable of cleaving type I collagen molecule with similar characteristics of MMP-1. This observation raises questions regarding the significance of each MMP in tumor cell invasion and metastases. Thus, in combating tumor growth and invasion, understanding the mechanism of substrate specificity and design of a novel therapeutic compound that is capable of specifically down regulating MMP-9 expression are of interest.
\end{abstract}

METHOD: DNAzymes are catalytic oligonucleotides that bind to and cleave specific mRNA, resulting in a decreased protein expression. The safety and efficacy of anti-MMP-9 DNAzyme (AM9D) in vivo was determined by injecting ${ }^{35} \mathrm{~S}$-labeled AM9D $\left({ }^{35}\right.$ S-AM9D) into the tail vein of healthy and MMTV-PyMT transgenic mice and the amount of ${ }^{35} \mathrm{~S}$-AM9D accumulated in different tissues was measured as a function of time. The effect of AM9D treatment on breast tumor progression was tested by four once-weekly intratumoral injections of two concentrations of AM9D into mammary tumors of MMTV-PyMT transgenic mice at early stages of tumor development. The tumor sizes were measured at the end of the experiments. The effect of AM9D treatment on early stage experimental metastasis and survival was evaluated by injecting FVB female mice with $1 \times 10^{6}$ luciferase labeled mammary tumor epithelial cells (luc-MTEC) isolated from MMTV-PyMT mice and treating the animals with AM9D, control DNAzyme, or PBS for 3 weeks or up to 10 weeks, respectively.

The mechanism of substrate specificity of $68 \mathrm{kDa}$ MMP-9 was determined by generating a series of truncated and site directed mutant forms of MMP-9. Specific amino acid residue in sequence ${ }^{444}$ PRPEPEPRPPTTT ${ }^{456}$ in the hinge region responsible for substrate selectivity of the enzyme was then identified by alanine-scanning site directed mutagenesis. The charged amino acid residues $\left(\mathrm{Arg}^{445}, \mathrm{Glu}^{447}, \mathrm{Glu}^{449}\right.$, and $\mathrm{Arg}^{451}$ ) were individually replaced by Ala and the proteolytic activity of the mutant enzymes toward Mca-PLGL(Dpa)AR-NH2, gelatin, and type I collagen was determined.

RESULTS: Treatment of MDA-MB-231 breast cancer cell line with AM9D in vitro resulted in decreased invasion potential of the cells and intratumoral treatment of MMTV-PyMT mice in vivo resulted in delayed rate of tumor growth and retarded final tumor volume by up to $51 \%$. This decrease in tumor growth was correlated with decreased MMP-9 protein production within the treated tumor tissues. Tumors treated with AM9D were also less vascular compared to control and untreated tumors. Furthermore, DNAzyme administered IV is distributed to major organs including lung, 
without showing any organ toxicity. Intravenous administration of AM9D and control DNAzyme in animals bearing luc-MTECs were able to decrease the number of gross lung macro metastasis. In addition, AM9D treatment increased progression-free survival but did not have an effect on overall survival of animals inoculated with luc-MTECs compared to control DNAzyme and PBS treatment. These data indicate that AM9D can be used individually or as an adjuvant to current chemotherapy for breast cancer.

To further illuminate the role of MMP-9 in tumor growth and metastases the mechanism of substrate specificity of the enzyme was studied. Site directed and deletion mutagenesis revealed that interaction of $\mathrm{Glu}^{415}$ in the active site with $\mathrm{Glu}^{447}$ and/or $\mathrm{Arg}^{451}$ in the hinge region makes the active site rigid, preventing full length MMP-9 from cleaving type I collagen. Disruption of this interaction, on the other hand, provides the flexibility necessary for the enzyme's active site to change conformation and be able to bind and cleave type I collagen substrate.

CONCLUSION: Given that MMP-9 is capable of cleaving type I collagen and its down regulation hinders the development of breast cancer in an animal model, AM9D could prove useful as an adjuvant therapy against breast carcinoma cell invasion. 


\section{TABLE OF CONTENTS}

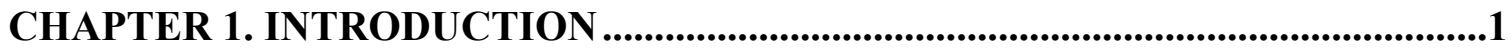

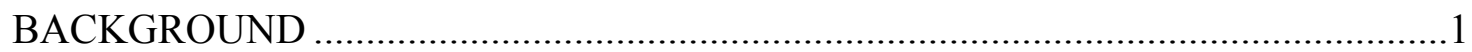

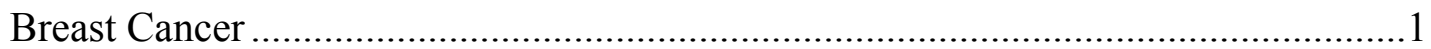

Matrix Metalloproteinases (MMP) ..................................................................

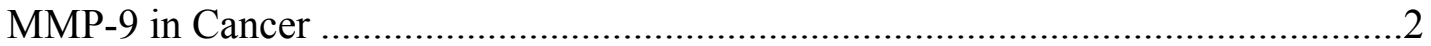

DNAzymes as Novel Treatments for Cancer........................................................4

Design and In Vitro Efficacy of Anti-MMP-9 DNAzyme (AM9D)...........................

RESEARCH OBJECTIVES AND SPECIFIC AIMS …..........................................

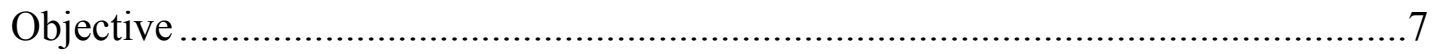

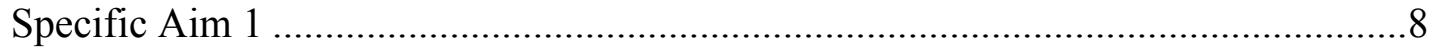

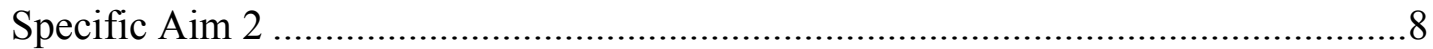

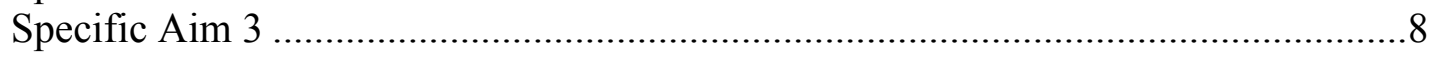

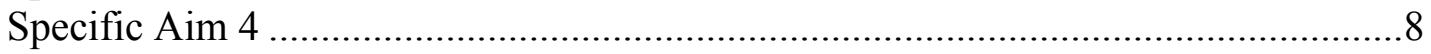

CHAPTER 2. TREATMENT OF TUMOR GROWTH WITH AM9D ....................10

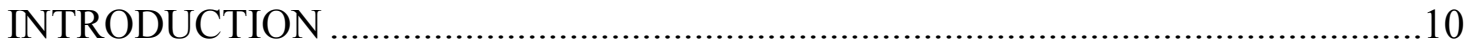

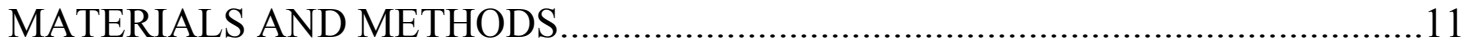

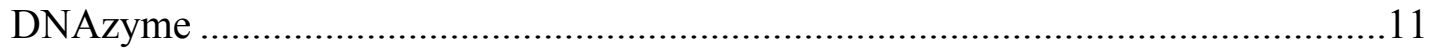

MMTV-PyMT Transgenic Mammary Tumor Model ............................................11

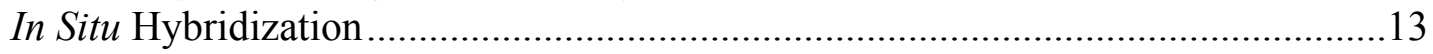

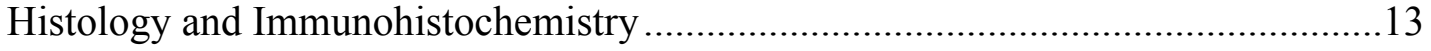

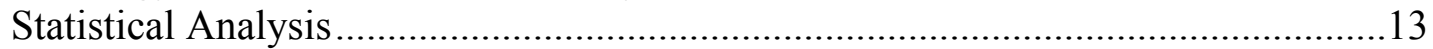

RESULTS .......................................................................................................... 14

MMP-9 Is Expressed in Mammary Tumors of MMTV-PyMT Mice .......................14

DNAzyme In Vivo Stability ........................................................................... 14

Effect of AM9D Treatment on Final Tumor Load ................................................16

Effect of AM9D on Angiogenesis and Apoptosis ...............................................16

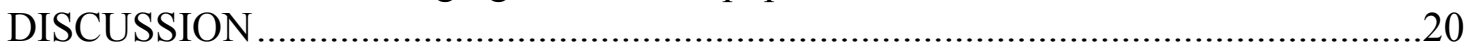

\section{CHAPTER 3. DISTRIBUTION, CLEARANCE, AND CYTOTOXICITY OF}

DNAZYME .......................................................................................................................21

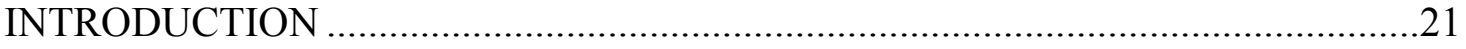

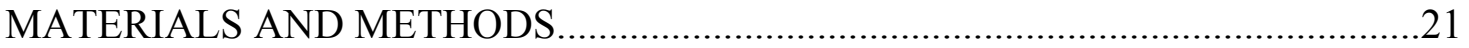

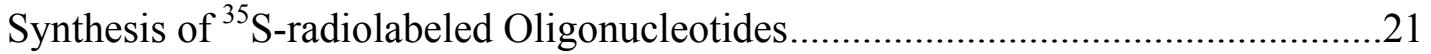

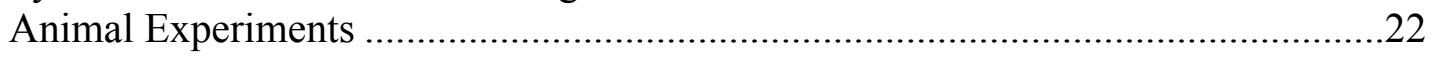

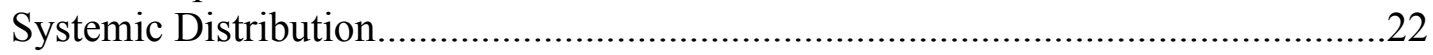

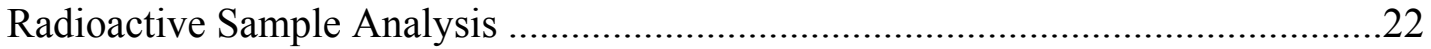

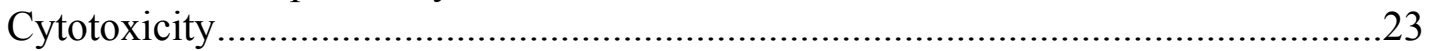

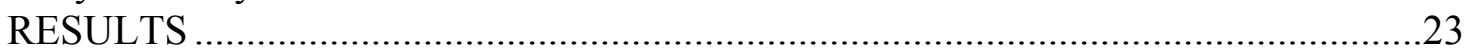

Kinetics of DNAzyme in Normal Mice ..........................................................23

Kinetics of DNAzyme in Mammary Tumor bearing Mice....................................27

Cytotoxicity of Intravenous Injection of AM9D in Healthy Mice ............................30

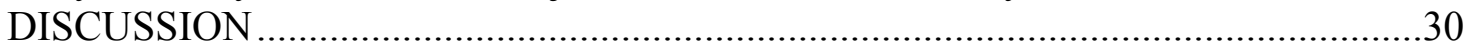


CHAPTER 4. AM9D TREATMENT OF EXPERIMENTAL METASTASIS...........35

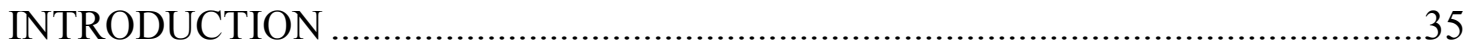

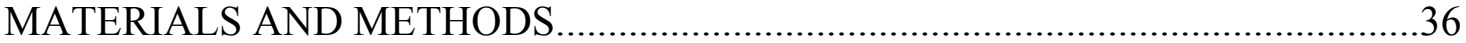

Establishing eIF1 alpha-Luciferase2 Mammary Tumor Epithelial Cells

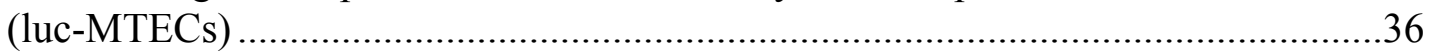

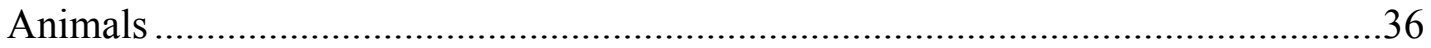

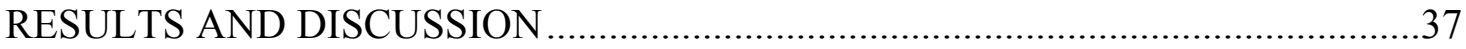

Effect of AM9D Treatment on Early Stage Experimental Metastasis.......................37

Effect of Long Term AM9D Treatment on Lung Tumor Load in Experimental

Metastasis and on Survival ..................................................................................4

CHAPTER 5. MMP-9 TRESSPASSES ON MMP-1'S TURF ..................................46

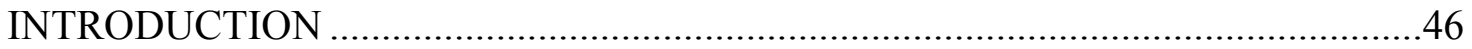

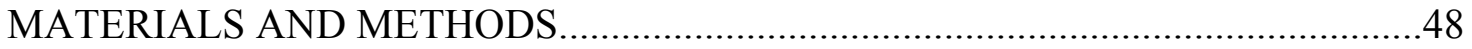

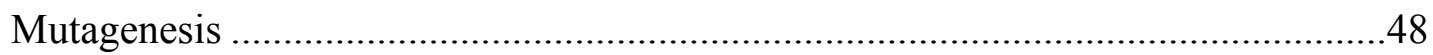

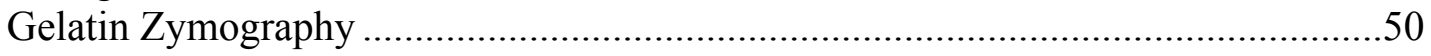

Determination of Kcat/Km Values for the Fluorogenic Peptide Substrate

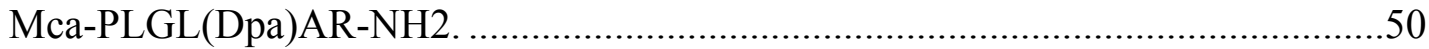

Kinetic Analysis of Type I Collagenolytic Activity ...............................................50

Analysis of Gelatinolytic Activity of the Enzymes ...............................................51

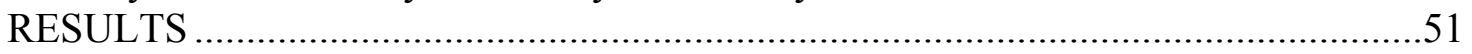

Expression, Purification, and Activation of Deletion Mutant Enzymes ...................51

Characterization of Deletion Mutants MMP-9 …..................................................51

$\mathrm{Glu}^{447}$ and $\mathrm{Arg}^{451}$ Residues in the Hinge Region Play a Role in Type I

Collagenolytic Activity of MMP-9 .........................................................................54

Interaction Between Glu ${ }^{415}$ and $\mathrm{Glu}^{447}$ and/or $\mathrm{Arg}^{451}$ Dictates Substrate

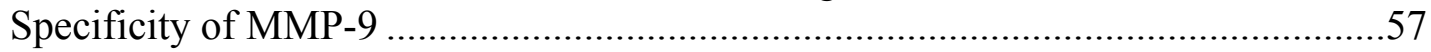

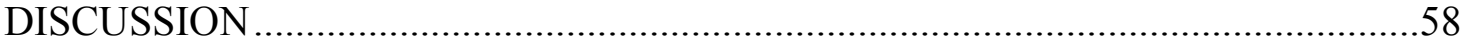

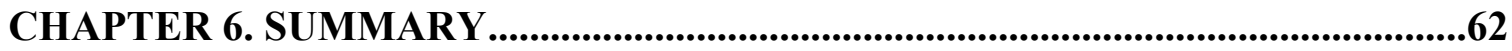

CHAPTER 7. AM9D: FROM PRECLINIC TO CLINIC .......................................64

AM9D FOR BREAST CANCER PATIENTS ............................................................64

AM9D AS AN ADJUVANT TO SURGERY .......................................................65

FUTURE AM9D PRECLINICAL STUDIES .........................................................65

LIST OF REFERENCES ........................................................................................................67

APPENDIX. DEVELOPMENT OF AM9D MATERIALS AND METHODS ..........77

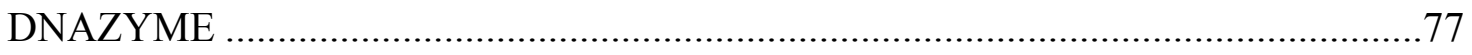

IN VITRO TRANSCRIPTION AND CLEAVAGE ANALYSIS OF MMP-9 RNA

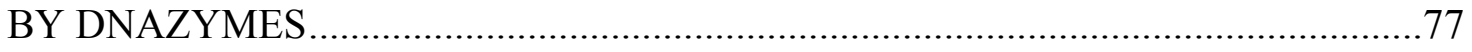

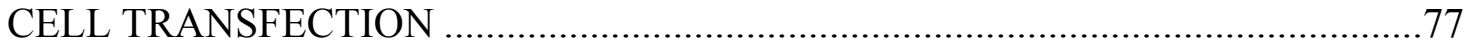

ANALYSIS OF MMP-9 MRNA AND PROTEIN PRODUCTION IN AM9D

TRANSFECTED CELLS ........................................................................................ 78 
CELL INVASION ASSAY

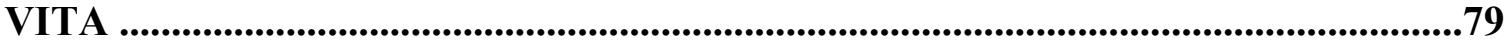




\section{LIST OF TABLES}

Table 3-1. Tissue distribution of $\left[{ }^{35} \mathrm{~S}\right]$-DNAzyme in normal mice presented in average percentage of total DNAzyme. ................................................25

Table 3-2. Rate of $\left[{ }^{35} \mathrm{~S}\right]-\mathrm{DNAzyme}$ initial and final clearance in normal mice. ...........27

Table 3-3. Tissue distribution of $\left[{ }^{35} \mathrm{~S}\right]$-DNAzyme in MMTV-PyMT mice presented in average percentage of total DNAzyme...........................................29

Table 3-4. Rate of $\left[{ }^{35} \mathrm{~S}\right]-\mathrm{DNAzyme}$ initial and final clearance in mice with

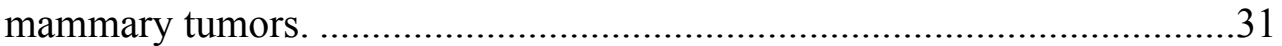

Table 5-1. Proteolytic activity of deletion mutant enzymes......................................53

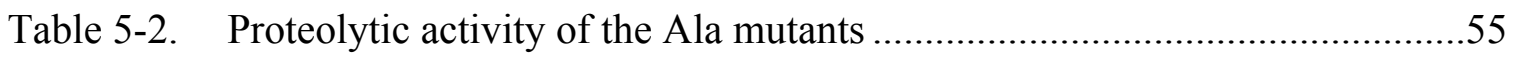

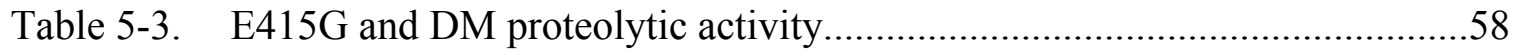




\section{LIST OF FIGURES}

Figure 1-1. Structural domains of matrix metalloproteinases. ......................................

Figure 1-2. Composition of the $10-23$ catalytic motifs..............................................

Figure 1-3. Efficacy of anti-MMP-9 DNAzyme (AM9D) in vitro................................6

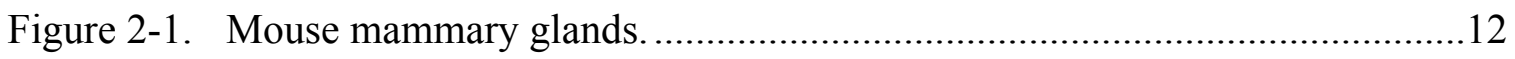

Figure 2-2. MMP-9 in MMTV-PyMT mice mammary tumors....................................14

Figure 2-3. Stability of DNAzyme in mammary tumors......................................... 15

Figure 2-4. Effect of AM9D on the rate of tumor growth and final mean tumor volume.

Figure 2-5. Effect of AM9D on MMP-9 protein expression in MMTV-PyMT mammary tumors. ........................................................................ 18

Figure 2-6. Fluorescent in situ hybridization....................................................... 18

Figure 2-7. AM9D reduces tumor vasculature. ........................................................ 19

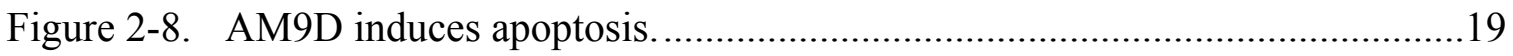

Figure 3-1. Distribution and elimination profile of $\left[{ }^{35} \mathrm{~S}\right]$-DNAzyme in normal mice.....24

Figure 3-2. Distribution profile of $\left[{ }^{35} \mathrm{~S}\right]$-DNAzyme in additional organs of normal

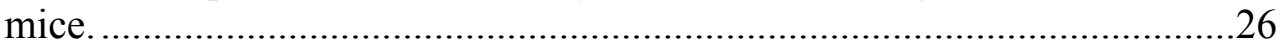

Figure 3-3. Distribution profile of $\left[{ }^{35} \mathrm{~S}\right]$-DNAzyme in MMTV-PyMT mice.................28

Figure 3-4. Distribution of $\left[{ }^{35} \mathrm{~S}\right]-\mathrm{DNAzyme}$ in MMTV-PyMT mammary tumors. ........31

Figure 3-5. Pathology of organs from mice injected with AM9D, control DNAzyme, or PBS.

Figure 4-1. Representative lungs images extracted from two mice in the PBS treated group at early stage experimental metastasis..........................................38

Figure 4-2. Macro and micro metastasis in lungs from early stage experimental metastasis.

Figure 4-3. CpG regions in AM9D and control DNAzyme.

Figure 4-4. Mouse body weights measured during experimental metastasis 
Figure 4-5. Analysis of mice organ pathology.

Figure 4-6. Effect of various treatments on mice lung tumor burden.

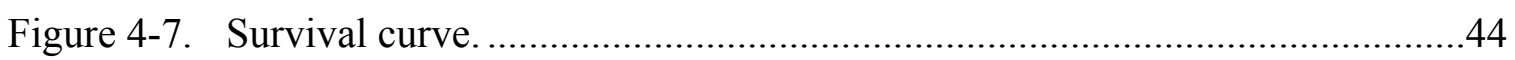

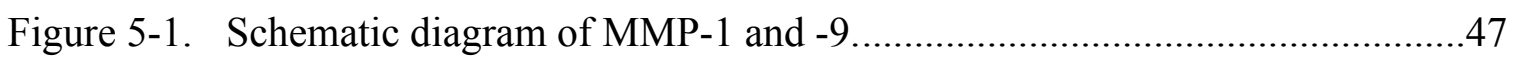

Figure 5-2. MMP-9 recombinant deletion mutants. ..................................................52

Figure 5-3. Gelatin- gel zymography of purified mutant enzymes. ..............................53

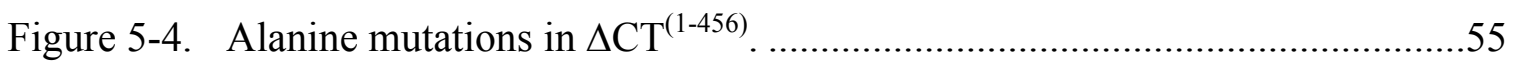

Figure 5-5. Gelatin- gel zymography of purified site directed mutant enzymes.............56

Figure 5-6. Schematic diagram and gelatinolytic activities of E415G and DM............57

Figure 5-7. Schematic diagram of MMP-9 mutants with type I collagenolytic activity. 60 


\section{LIST OF ABBREVIATIONS}

$\alpha$-SMA

$\triangle \mathrm{CT}$

${ }^{35} \mathrm{~S}$

AM9D

AS

CpG-ODN

DNAzyme

ECM

Luc-MTEC

MMP

MMP-9

MMTV-PyMT

MTEC

RT

WT
Alpha-Smooth Muscle Actin

Carboxyl Terminal Truncated

Radioactive Sulfur

Anti-MMP-9 DNAzyme

Active Site

Synthetic CpG Containing Oligodeoxynucleotide

Catalytic Deoxyribonucleotide

Extracellular Matrix

Luciferase Labeled Mammary Tumor Epithelial Cells

Matrix Metalloproteinase

Matrix Metalloproteinase-9

Mouse Mammary Tumor Virus - Polyoma Middle T antigen

Mammary Tumor Epithelial Cells

Room Temperature

Wild-Type 


\title{
CHAPTER 1. INTRODUCTION
}

\author{
BACKGROUND
}

\section{Breast Cancer}

Breast cancer is one of the leading causes of cancer deaths in women, second only to lung cancer [1]. Breast cancer is divided into three subtypes based on the tumor cells expression of estrogen receptor (ER), progesterone receptor (PR), and/or HER2. The aforementioned subtypes of breast cancer are known as luminal A (ER or $\mathrm{PR}^{+} / \mathrm{HER} 2$ ), luminal B $\left(\mathrm{ER}\right.$ or $\left.\mathrm{PR}^{+} / \mathrm{HER}^{+}\right)$, and triple negative (ER $\left./ \mathrm{PR}^{-} / \mathrm{HER} 2^{-}\right)$[2]. The American Cancer Society estimated that in 2010 there would be 207,090 new cases of invasive and 57,010 new cases of non-invasive breast cancer diagnosed in women. In 2010, about 39,840 women were expected to die as a result of breast cancer. The spread of cancer cells to distant organs, metastasis, is responsible for the majority of morbidity and mortality [3-5]. In the case of breast cancer, metastasis affects the lungs, regional lymph nodes and bone, while less frequently affecting brain and liver [6]. This metastasis and eventual tumor growth at distant sites depends on interaction between tumor cells, stromal cells, and the host microenvironment [7]. Since the main event separating those that survive breast cancer and those who fall victim to breast cancer is metastasis, it is as important to develop therapeutic strategies against the metastatic process as for any other process in the breast cancer spectrum.

It has been widely hypothesized that metastasis occurs when cells from the primary tumor undergo sequential steps to make them more adaptable to seed tumors in distant organs. These sequential steps include the transition of epithelial cells to mesenchymal like cells (epithelial to mesenchymal transition; EMT), degradation of the extracellular membrane (ECM), intravasation, extravasation, and finally transition back to epithelial like cells (mesenchymal to epithelial transition; MET) [8]. This transition has been shown to involve matrix metalloproteinases (MMP) produced by tumor and stromal cells [9]. These enzymes enable the invasion of carcinoma cells into adjacent normal tissue by degrading the extracellular (ECM) and basement membrane components.

\section{Matrix Metalloproteinases (MMP)}

MMPs are a family of over 24 proteolytic enzymes and essential regulators of cells microenvironment [10]. These enzymes are secreted as catalytically latent species, which are processed to their activated forms in vivo by other proteinases [11]. Most human MMPs are categorized into five main subclasses based on their substrate specificity, collagenases (MMP1, MMP8, and MMP13), stromelysin (MMP3, MMP10, MMP11, MMP7 and MMP26), gelatinases (MMP2 and MMP9), membrane type MMPs (MMP14, MMP15, MMP16, MMP17, MMP24, and MMP25) [10, 11] and metalloelastase (MMP-12) [12]. MMPs cleave virtually all components of the ECM and 
overlap in their substrate specificity. Collagenases can cleave native fibrillar collagen types I, II, and III [13]. Although less well studied, the collagenases can also cleave collagen types VII and X as well as gelatin, aggrecan, entactin, and tenascin [14]. Stromylysins digest native collagen types III, IV, V, IX, X, and XI, as well as, tenascin, gelatin, aggrecan, and many other substrates [14]. Gelatinases digest elastin, aggrecan, and collagen types IV, V, and XI [14]. They also act synergistically with interstitial collagenase in the degradation of fibrillar collagens. Recent studies have shown that MMP-2 can cleave native type I collagen in the same position as MMP-1 [15], and MMP-9 cleaves $\alpha 2$ chains of type I collagen [16]. Finally, a few of the MT-MMP substrates are collagens type I, II, and III, gelatin, casein, fibronectin, laminin, vitronectin, and entactin [14].

As evidenced by their substrate specificity, MMPs play a significant role in normal and pathological conditions that involve matrix degradation and remodeling [17]. This includes, but is not limited to, wound healing, post partum involution, congestive heart failure, rheumatoid arthritis, osteoarthritis, and cancer (reviewed in [18-22]). In cancer, degradation of the ECM by MMPs not only enhances tumor invasion, but also affects tumor cell behavior and leads to cancer progression [10].

Metastasis, a multi step process, involves dissemination of cells from the primary tumor to distant organs or tissues and the formation of secondary tumors. Expression of MMPs apparently leads to dissociation of cell-cell and cell-ECM adhesion through the processing of cadherins, thereby leading to EMT initiation [8, 23, 24]. This transition can lead to increased extracellular proteolytic activity further promoting migration. MMPs are also capable of affecting cell regulatory signaling, directly or indirectly, within the extracellular microenvironment, which ultimately affects the cells intracellular signaling [25]. This is achieved by their role in the bioavailability of multiple growth factors and cytokines $[10,25]$. MMPs also cleave insulin-like growth factors and release transmembrane precursors of growth factors, including TGF- $\beta$, which aids in proliferation [10]. Thus, MMPs are important through their ability to affect tumor initiation and growth via cell adhesion independency, evasion of apoptosis, disruption of proper cell division, and as mediators of metastasis during late stage malignancy [25].

\section{MMP-9 in Cancer}

It has been suggested that the production of MMPs in general and MMP-9 in particular is one of the most important factors for migration of tumor cells into the bloodstream or lymphatic vessels, or into adjacent normal tissues [26, 27]. MMP-9 (gelatinase B) has been shown to be closely associated with invasion and metastasis [28, 29]. MMP-9 degrades type IV collagen, one of the most abundant collagens in the ECM [22], and is involved in angiogenesis and proliferation. With the use of multistage pancreatic carcinogenesis in a transgenic RIP1-Tag2 mouse model, MMP-9 was shown to be up-regulated in angiogenic islets, leading to an increase in the bioavailability of VEGF [30]. Xu, et al. evidenced that MMP-9's cleavage of type IV collagen exposes an otherwise hidden HUIV26 cryptic site which is important in angiogenesis and tumor 
growth in vivo [31]. Rao, et al. have demonstrated the down regulation of MMP-9 increased $\beta 1$-integrin which leads to ERK activation and apoptosis through one of two mechanisms: (1) release of cytochrome $\mathrm{C}$ into the cytosol and/or (2) increase in NF-kB activation, which both lead to subsequent activation of caspase 3 [32]. Although few cell types express MMP-9 constitutively, the majority of human metastatic tumor cells (i.e. melanoma, fibrosarcoma, breast adenocarcinoma, glioma, etc.) that have been tested consistently show elevated MMP-9 activity compared with benign control cells [33-36]. In addition, tumor cells stably expressing the MMP-9 cDNA have been shown to metastasize in nude mice [37]. Furthermore, inhibition of MMP-9 activity has been demonstrated to block the invasive behavior of breast carcinoma cells, MDA-MB-231 [38]. Thus, inhibition of MMP-9 expression can be used as a therapeutic modality to decrease growth and invasion of tumor cells.

Analyses of the primary structures of MMPs revealed that these proteins could be divided into several distinct domains with apparent specific functions (Figure 1-1). A typical secreted MMP has three major domains: $\mathrm{NH}_{2}$-terminal prodomain, central catalytic domain, and $\mathrm{COOH}$-terminal hemopexin-like domain $[18,27]$. The characterization of MMP-9 revealed two additional domains, one with homology to the gelatin-binding region of fibronectin and the other with a collagen-like sequence [39]. The fibronectin-like gelatin binding domain has been shown to be important for the gelatinolytic and type V collagenolytic activity of the enzyme [40]. Structural similarities among MMP members have made it very difficult to develop specific synthetic inhibitor for MMP-9 as a potential cancer therapeutic agent. The lack of specificity of most active site directed MMP inhibitors that entered clinical trials made

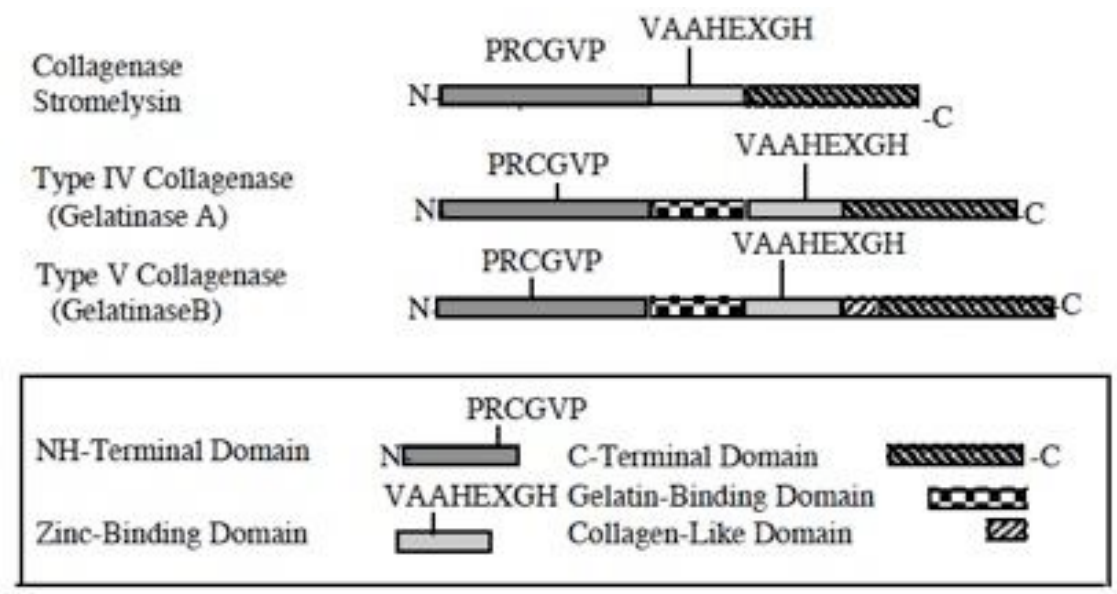

Figure 1-1. Structural domains of matrix metalloproteinases.

This is a schematic diagram showing the main structural domains of Collagenases (MMP-1) and Gelatinases (Gelatinase B, MMP-9; Gelatinase A, MMP-2). Gelatinases contain two additional domains compared to collagenases, the gelatin-binding domain and the collagen-like domain. 
them more harmful than helpful [41]. For example, Batimastat, the first synthetic MMP inhibitor studied in humans, showed reduced growth of primary tumor, onset of distant metastases, and even prolonged survival of animals with pancreatic, orthotopic colon, or orthotopic liver tumor [42-44]. In addition, Marimastat, a derivative of Batimastat significantly increased progression-free survival in the patients with inoperable gastric cancer, without improving overall survival [45]. Despite favorable results of these synthetic MMP inhibitors in animal systems and human clinical trials, they lead to significant side effects, which include but are not limited to fatigue, anorexia, nausea, vomiting, asthenia, and inflammatory polyarthritis [46, 47]. These multiple side effects associated with usage of the non-specific MMP inhibitors in clinical trials are comprehensible since as stated above, MMPs are required for normal physiological processes such as cell growth and remodeling, ovulation, and wound healing. In addition, two MMP members, MMP-3 and -8, have been identified as cancer anti-targets because their down regulation results in initiation of the disease or deleterious alteration in disease progression [27]. In order to over come this problem, the mechanism of substrate specificity of MMP-9 must be identified and considered in the design of the specific inhibitor to be used for cancer therapy.

The role of the hemopexin-like carboxyl terminal domain of MMP-9 is of interest, since we have recently shown that it dictates substrate specificity of the enzyme (please see below). The role and significance of collagen-like and hemopexin-like carboxyl terminal domains in substrate specificity of MMP-9 has been investigated in Chapter 5 .

\section{DNAzymes as Novel Treatments for Cancer}

Over the past few years, DNAzymes have been used in vitro to selectively inhibit or modify specific mRNA levels in mammalian cell cultures [48]. DNAzymes are catalytic DNA molecules that in the absence of proteins bind to and cleave specific mRNA sequences, which results in the decreased expression of the encoded protein [49] (Figure 1-2).

DNAzymes have emerged as novel, highly selective inhibitors or modulators of gene expression [50]. Khachigian and colleagues have reported that the DNAzymes targeting early growth response factor-1 (Egr-1) mRNA inhibits neointimal formation after balloon injury to the rat carotid artery wall and reduce intimal thickening after stenting pig coronary arteries. DNAzyme targeting c-Jun caused repair of injured rat carotid arteries [51]. Upregulation of Aurora kinase A has been shown to be important in carcinogenesis of prostate cancer. DZ2, an Aurora kinase A specific DNAzyme was shown to strongly inhibit Aurora kinase A in a prostate cancer cell line in vitro and inhibit tumor growth of human prostate cancer xenografts in nude mice [52]. Finally, a DNAzyme targeting vascular endothelial growth factor receptor 2 (VEGFR2) significantly inhibited the growth of breast tumors derived from xenografting MDA-MB-435 cells into nude mice by inducing apoptosis [53]. These data demonstrate that these small nucleotide mRNA cleaving sequences can potentially be designed and administered to target specific genes with relative lack of toxicity. DNAzymes have 


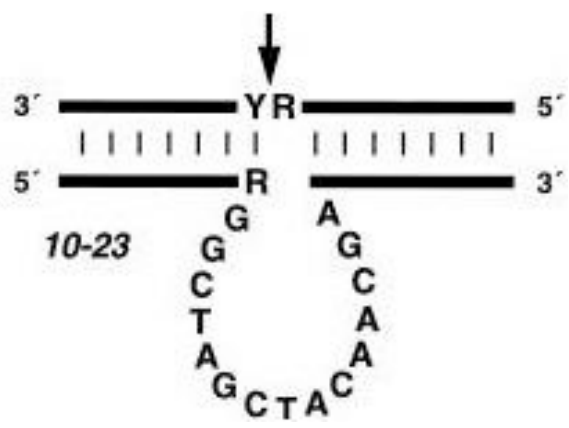

Figure 1-2. Composition of the 10-23 catalytic motifs.

The DNA enzyme (bottom strand) binds the RNA substrate (top strand) through Watson-Crick pairing. Cleavage occurs at the position indicated by the arrow. $\mathrm{R}=\mathrm{Purine}$ (A or $\mathrm{G}$ ); Y=Pyrimidine (U or C). Reprinted with permission from Santoro SW, Joyce GF (1997). A general purpose RNA-cleaving DNA enzyme. Proc Natl Acad Sci US A 94: 4262-4266.

excellent potential as a biotherapy against matrix metalloproteinases.

As stated above, since DNAzyme molecules can be designed to target a specific gene with relative lack of toxicity, it is expected that specific down regulation of MMP-9 by DNAzyme will prevent tumor cell invasion and metastasis while generating a minimum side effect.

\section{Design and In Vitro Efficacy of Anti-MMP-9 DNAzyme (AM9D)}

To test whether down regulation of MMP-9 by an MMP-9 mRNA targeted DNAzyme could be used as a treatment strategy for cancer, Dr. Hasegawa, a postdoctoral fellow in our laboratory, designed several anti-MMP-9 DNAzymes (AM9D) according to putative DNAzyme target sites in the predicted secondary structure of MMP-9 mRNA and selected the most efficient AM9D with respect to its activity toward RNA substrate. As shown in Figure 1-3a, only AM9D-2 (lane 3) and AM9D-5 (lane 6) were able to efficiently cleave over $85 \%$ of the RNA substrate in $2 \mathrm{~h}$ at $37{ }^{\circ} \mathrm{C}$ as determined by the density of the RNA fragment products. These reactions were time dependent as a longer incubation of the RNA substrate with the AM9D-2 and AM9D-5 led to complete cleavage of the RNA molecule (data not shown). The AM9D-1, scrambled control, and sense control DNAzymes (lanes 2, 7 and 8, respectively) at the same concentration did not have any activity toward the RNA substrate. AM9D-3 and -4 (lanes 4 and 5) were able to cleave only $\sim 25 \%$ of the RNA substrate. AM9D-5 (referred to in this body of work as AM9D) and scrambled control DNAzyme was used for further studies. 

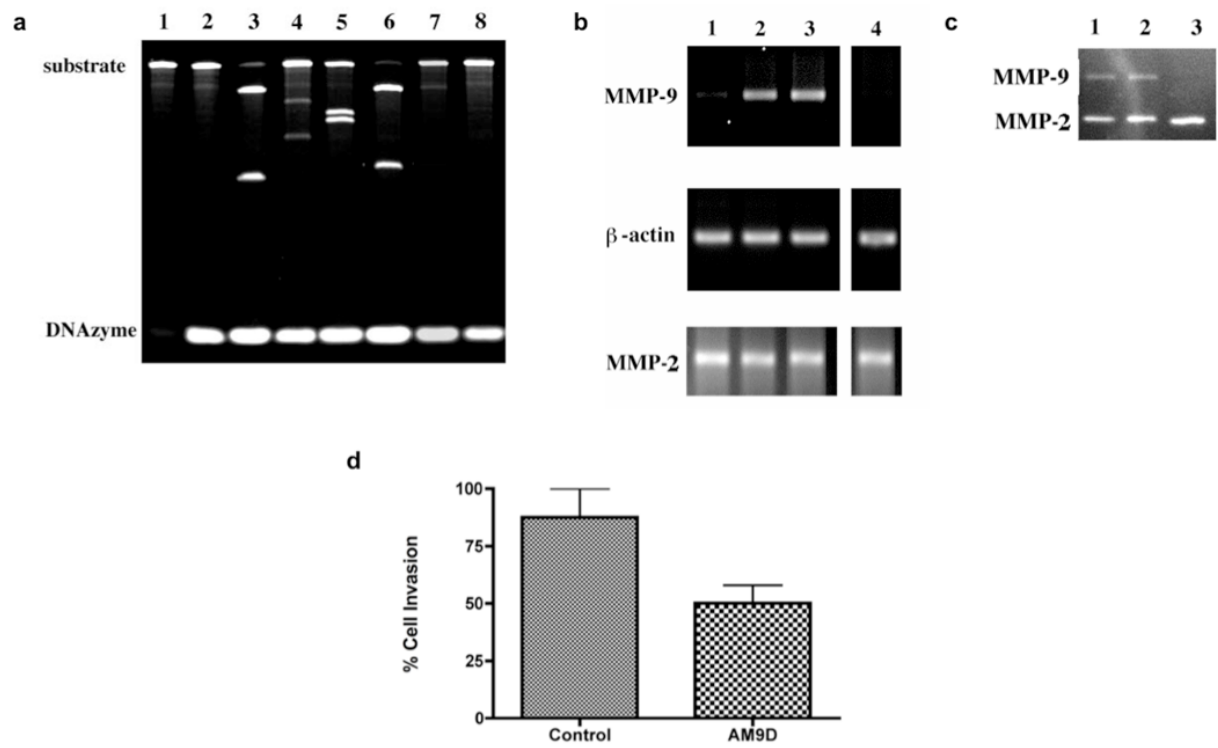

Figure 1-3. Efficacy of anti-MMP-9 DNAzyme (AM9D) in vitro.

(a) Urea-Polyacrylamide gel electrophoresis of cleaved MMP-9-RNA by DNAzyme. Anti MMP-9 DNAzymes, scrambled, or sense control DNAzymes $(12.5 \mu \mathrm{M})$ were incubated with MMP-9 RNA substrate $(764 \mathrm{nt}, 0.48 \mu \mathrm{M})$ for $2 \mathrm{~h}$ at $37{ }^{\circ} \mathrm{C}$ and the products were analyzed by polyacrylamide-urea gel. Lane 1, RNA substrate alone; lane 2, AM9D-1; lane 3, AM9D-2; lane 4, AM9D-3; lane 5, AM9D-4; lane 6, AM9D-5; lane 7, Scrambled control; and lane 8, Sense control DNAzymes. The RNA bands were visualized by Ethidium Bromide staining. The lowest molecular weight bands are DNAzyme. (b) AM9D reduced MMP-9 mRNA level. MMP-9 stably transfected COS-7 cells (COS-7 NG) were transfected with Oregon Green 488 labeled DNAzymes. Positively transfected cells were identified by flow cytometry. Total RNA was isolated and MMP-9, MMP-2, and $\beta$-actin mRNA were amplified by RTPCR. The PCR products were subjected to agarose gel and visualized by Ethidium Bromide staining. Lane 1, AM9D-5; lane 2, control DNAzyme; lane 3, Cells treated with DOTAP transfection reagent only and lane 4, the PCR product from parental COS-7 cells (non-transfected with MMP-9). (c) AM9D decreased MMP-9 production. Culture media from MMP-9 stably transfected COS-7 cells (COS-7 NG) treated with DOTAP alone (lane 1), control DNAzyme (lane 2), and AM9D-5 (lane 3) were separated on gelatin zymogram gel. As shown, AM9D-5 down regulates production of MMP-9 in COS-7 NG cells. (d) AM9D decreased the invasive behavior of human MDA-MB-231 breast cancer cells. The percentage ratio of carcinoma cells invading the Matrigel Matrix after treatment with AM9D-5 against that of cells treated with control DNAzyme after $24 \mathrm{~h}$. The AM9D-5 transfected cells showed a $43 \%$ reduction in cell invasion compared to control DNAzyme transfected cells. 
To assess the effect of AM9D-5 on MMP-9 production in vitro, monkey kidney cells lacking MMP-9 (COS-7 cells, Figure 1-3b, lane 4) were stably transfected with MMP-9 cDNA to constitutively express the protein. The effect of AM9D-5 on the production of MMP-9 in the stably transfected cells (COS-7 NG) was then examined by transiently transfecting the cells with different amounts of either control DNAzyme or AM9D-5 using Gene PORTER (Genlantis, San Diego, CA). Twenty-four h after transfection, the cells were harvested, total RNA was extracted, and condition media were examined for the presence of MMP-9 mRNA and protein by RT-PCR (Figure 1-3b) and by gelatin gel zymography (Figure 1-3c), respectively. As demonstrated in Figure $1-3 b$ and c, AM9D-5 was able to significantly reduce the level of the MMP-9 mRNA (Figure 1-3b, lane 1) and protein as evidenced by the low enzyme activity in AM9D-5 treated COS-7 NG cells (Figure 1-3c, lane 3) compared to non-treated and control DNAzyme treated cells (Figure 1-3c, lanes 1 and 2, respectively).

To demonstrate the specificity of AM9D toward MMP-9 mRNA its activity toward MMP-2 mRNA, a closely related enzyme to MMP-9, was determined. COS-7 cells constitutively express MMP-2 (Figure 1-3b and c). Stably transfecting COS-7 cells with MMP-9 cDNA (COS-7 NG) and treating the cells with AM9D-5 did not have any effect on MMP-2 mRNA (Figure 1-3b) or protein (Figure 1-3c) expression levels. This data clearly demonstrates that the AM9D-5 is very specific and it only affects the MMP-9 production in cells.

To determine the effect of decreased MMP-9 mRNA expression on the invasive behavior of cancer cells, MDA-MB-231 highly invasive breast cancer cells were transiently transfected with fluorescently labeled AM9D-5 or control DNAzyme, FACS sorted and the invasive behavior of the sorted cells was determined using ECMatrix ${ }^{\mathrm{TM}}$ (Millipore, Billerica, MA) invasion chamber. The mean invasion potential of MDA-MB-231 cells decreased by $43 \%$ when transfected with AM9D-5 compared to control DNAzyme treated cells (Figure 1-3d). These data indicate that MMP-9 significantly contributes to the invasive behavior of MDA-MB-231 tumor cells and provides evidence that AM9D treatment significantly and specifically reduces MMP-9 production and suppresses the invasive behavior of breast tumor cells in vitro. Thus, AM9D may be a useful anti-tumorigenic and anti-metastatic agent in vivo.

\section{RESEARCH OBJECTIVES AND SPECIFIC AIMS}

\section{Objective}

The objective of this proposal was to evaluate the efficacy of an MMP-9 targeted DNAzyme as a therapy in treating breast carcinoma and preventing lung metastasis. If anti-MMP-9 DNAzyme (AM9D) therapy is proven useful in reducing tumor growth and preventing metastasis in an animal model of breast cancer, this will be an important step in the preclinical development of a new biotherapy with excellent potential for expanding the standard of care for breast cancer patients. 


\section{Specific Aim 1}

The first aim of this body of work was to test the efficacy of anti-MMP-9 DNAzyme oligonucleotides on tumor growth in MMTV-PyMT transgenic mice. This was accomplished by intratumorally injecting control DNAzyme or AM9D into mammary tumors once a week, for 4 weeks, at an early palpable tumor size. Tumor sizes were measured weekly and the animals were sacrificed at a selected time point (one week after the $4^{\text {th }}$ injection). The efficacy of MMP-9 downregulation by AM9D on the rate of tumor growth, final tumor load, development of new vasculature, and tumor cell survival was evaluated.

\section{Specific Aim 2}

The second aim of this body of work was to determine the distribution, clearance, and cytotoxicity of AM9D. This was accomplished by intravenously injecting ${ }^{35}$ S-labeled DNAzyme ([ $\left.{ }^{35} \mathrm{~S}\right]$-DNAzyme) molecule into normal and tumor-bearing MMTV-PyMT mice, sacrificing mice at various time points ( $2 \mathrm{~h}-7$ days), and determining the amount of DNAzyme in organs and mammary tumors. To determine organ toxicity by DNAzyme in general and the anti-MMP-9 DNAzyme (AM9D) in particular, mice were injected with PBS or escalating concentrations $(200 \mu \mathrm{g}, 650 \mu \mathrm{g}$, or $1500 \mu \mathrm{g}$ ) of AM9D or control DNAzyme. Mice were sacrificed on day 7 post treatment and a Pathologist evaluated major organs for any signs of toxicity.

\section{Specific Aim 3}

The third aim of this body of work was to determine the effect of AM9D on experimental metastasis. To accomplish this goal normal FVB mice were injected with luciferase labeled mammary tumor epithelial cells (luc-MTEC) derived from the MMTV-PyMT transgenic mice used in the experiments described in specific aim 1. Mice received weekly intravenous injections of AM9D, control DNAzyme, or PBS. These mice were sacrificed on day 21 or when they displayed signs of lethargy due to lung tumor burden to assess the role of AM9D on early stage experimental metastasis and overall survival, respectively.

\section{Specific Aim 4}

The fourth aim of this body of work was to determine the mechanism of substrate specificity of MMP-9. As stated above, degradation of basement member components by MMP is one of the first steps in tumor cell invasion and metastasis. Our data indicate that contrary to a general belief that MMP-9 only cleaves types IV and V and XI collagen, MMP-9 generated by tumor and stroma cells is also capable of cleaving type I collagen. Thus, understanding the mechanism behind collagen substrate specificity of MMP-9 sheds light on its role in metastasis, the major cancer-surviving determinant. Specific 
domain(s) and amino acid residues responsible for substrate specificity of the enzyme were identified by deletion and Ala scanning site directed mutagenesis of the MMP-9 molecule. 


\section{CHAPTER 2. TREATMENT OF TUMOR GROWTH WITH AM9D}

\section{INTRODUCTION}

Accumulating evidence suggests that production of matrix metalloproteinase- 9 (MMP-9) by tumor and stroma cells is one of the most important factors for metastatic behavior of tumor cells $[8,23,54]$. MMP-9 is a member of the matrix metalloproteinase family of enzymes, which play an important role in normal physiological responses, including wound healing and bone formation [55]. Some MMPs, including MMP-9, become deregulated during tumorigenesis and are associated with pro-oncogenic events such as neo-angiogenesis, tumor cell proliferation and metastasis [9]. For example, MMP-9 was shown to be upregulated in angiogenic islets of the RIP-Tag2 transgenic mouse model of pancreatic cancer, leading to an increase in the distribution of VEGF, a potent pro-angiogenic factor [30]. Moreover, high levels of MMP-9 expression in breast cancers have been shown to be positively correlated with enhanced tumor cell invasion and metastasis $[28,29]$ and with enhanced progression and poor prognosis [9].

MMP-9 is conserved across several species (human, chimpanzee, dog, cow, mouse, rat, chicken, zebrafish, and A.thaliana). MMP-9 degrades type IV collagen, one of the most abundant collagens in the extracellular matrix (ECM) [56], which may stimulate local invasion, the first step in metastasis. In addition, MMP-9 also cleaves pro-cytokines, chemokines, and growth factors, thereby modifying their biological activity $[10,25,57]$. In addition, tumor cells that stably express MMP-9 cDNA have been shown to have enhanced metastastic ability [37]. Thus, inhibition of MMP-9 expression by our Anti-MMP-9 DNAzymes could be a useful therapeutic modality to decrease the growth and invasive properties of tumor cells.

As described previously, DNAzymes have been used by several investigators to selectively inhibit or modulate different gene expressions in vivo [50]. Khachigian and colleagues have reported that the DNAzymes targeting early growth response factor-1 (Egr-1) mRNA inhibits neointimal formation after balloon injury to the rat carotid artery wall and reduce intimal thickening after stenting pig coronary arteries. DNAzyme targeting c-Jun caused repair of injured rat carotid arteries [51]. Finally, a DNAzyme targeting vascular endothelial growth factor receptor 2 (VEGFR2) significantly inhibited the growth of breast tumors derived from xenografting MDA-MB-435 cells into nude mice [53].

The purpose of the present study was to evaluate the effect of AM9D on breast tumor growth in the MMTV-PyMT mouse model of breast cancer. It is demonstrated for the first time that once weekly intratumoral injection of AM9D, in the absence of any carrier molecule, for four weeks was sufficient to significantly reduce the rate of tumor growth and final tumor load in a dose dependent and statistically significant manner $(\mathrm{p} \leq 0.05)$. Together, the data presented here justify the further development of AM9D for its potential as an anti-tumor agent and as an ideal candidate for breast cancer therapy. 


\section{MATERIALS AND METHODS}

\section{DNAzyme}

All DNA oligonucleotides used in these experiments were synthesised by Integrated DNA Technology (Coralville, IA). The sequence of the DNAzyme targeting mRNA of human and mouse MMP-9 is, 5'-GTGGTGCCAGGCTAGCTACAACGA TTGAGGCG-3'. In the control DNAzyme, 5'-CTAGTCAGCGGCTAGCTACAACG ATAAGCTGCT-3', the catalytic sequence of DNAzyme is flanked by 9 bases randomly chosen and not specific for any MMP coding sequence. DNAzyme used in some of the experiments was labeled with Oregon Green ${ }^{\mathrm{TM}} 488$ C5-maleimide (Invitrogen, Carlsbad, CA). Oregon Green ${ }^{\mathrm{TM}} 488$ C5-maleimide was prepared in dimethyl sulfoxide to a stock concentration of $25 \mathrm{mM}$. The 5'-hydroxyl terminus of the DNAzyme was labeled initially with ATP $\gamma$ S (Sigma, St. Louis, MO; $600 \mu \mathrm{M}$ ) using T4 Polynucleotide kinase (New England Biolabs, Ipswich, MA; 30U) followed by Oregon Green 488 maleimide (1mM) at $37^{\circ} \mathrm{C}$ as suggested by manufacture. The labeled DNAzyme was then purified by ethanol precipitation.

\section{MMTV-PyMT Transgenic Mammary Tumor Model}

The MMTV-PyMT transgenic mice express polyoma middle $\mathrm{T}$ antigen under the control of mouse mammary tumor virus long terminal repeat [58]. The MMTV-PyMT transgenic mouse model is a widely used preclinical model of estrogen and progesterone receptor negative luminal breast cancer with well-defined stages of progression and metastasis to lung $[59,60]$. On a pure $\mathrm{FVB} / \mathrm{Nj}$ strain background, all PyMT-positive females exhibit an average tumor latency of 58 days after birth, independent of pregnancy and will eventually develop mammary tumors in each of the ten mammary glands [61] (Figure 2-1), the time of tumor onset varies among individual glands [60]. More than $90 \%$ of mice develop pulmonary metastasis by 100 days [62]. More importantly, the mammary adenocarcinomas exhibit changes in biomarkers and expression patterns of various MMPs similar to those observed in human breast cancer patients [59, 63-67]. Therefore, this model was chosen to ascertain the role of AM9D as a pharmacologic inhibitor of MMP-9.

All animal experiments were conducted following approval by the University of Tennessee Health Science Center Institutional Animal Care and Use Committee (IACUC). FVB/Nj female mice were obtained from Jackson Laboratory (Bar Harbor, $\mathrm{ME}$ ) and crossed with PyMT positive FVB males. The offspring were genotyped by real-time PCR on a Roche LC 480 LightCycler using the following primers and universal probe library (UPL), probe \#11 (Left primer: 5' AACCCGAGTTCTCCAACAG 3; Right primer: 5' TCAGCAAC ACAAGGATTTC 3') to identify MMTV-PyMT positive females. Female mice were palpated once a week beginning at approximately 4 weeks of

age and palpable tumors were measured in two dimensions (longest diameter and shortest 

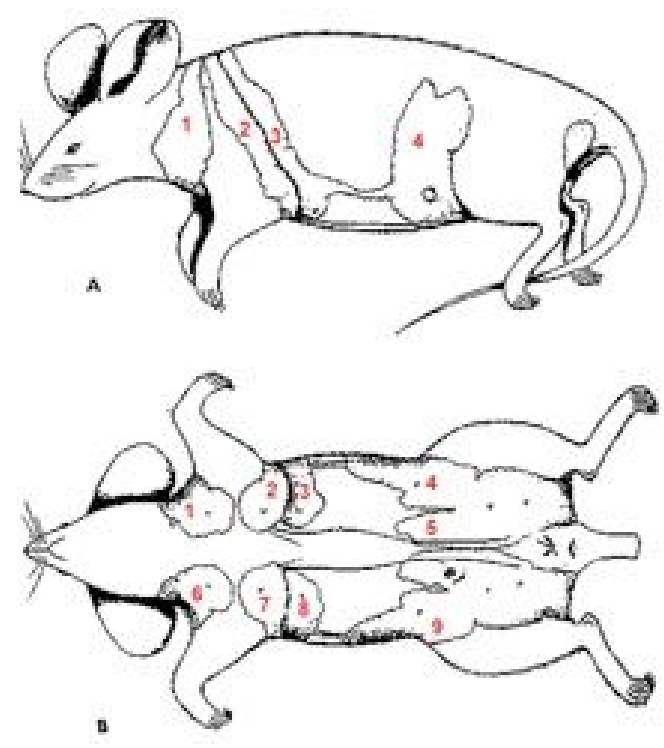

Figure 2-1. Mouse mammary glands.

This is a basic diagram of the 10 mouse mammary glands and possible place of tumor development in the MMTV-PyMT transgenic mouse model. Reprinted with permission from Ward J. The Virtual Mouse Necropsy. Comparative Medicine Branch, NIAID, NIH. Accessed March 25, 2010. http://icg.cpmc.columbia.edu/cattoretti/Protocol/ FilesInPdf/NCIVetp.pdf.

width) with digital calipers. Tumor volume was calculated using the formula, tumor volume $=\left(\right.$ width $^{2} \mathrm{x}$ length $) / 2$. When each transgenic female developed at least three palpable tumors of dimensions of $3 \mathrm{~mm}$ x $5 \mathrm{~mm}$, which typically occurred at 8 weeks of age, each tumor was injected intratumorally with $5 \mu \mathrm{l}$ PBS containing either 10 or $25 \mu \mathrm{g}$ of AM9D or control DNAzyme using a Hamilton syringe mounted with a PT2, 26G needle. Tumors identified at approximately 8 weeks of age were injected once per week for a total of four weeks of therapy, and the site of intratumoral injection was varied to ensure that all areas of the tumor were exposed to the AM9D or control DNAzyme. Palpable mammary tumors that arose after the first intratumoral treatment in other mammary glands of the same mice were left untreated. For each cohort, transgenic females with a combined number of at least 9 tumors of comparable size were utilized (AM9D, $10 \mathrm{ug}, \mathrm{n}=2$ mice, 9 mammary tumors; AM9D, $25 \mu \mathrm{g}, \mathrm{n}=2$ mice for a total of 10 mammary tumors and control DNAzyme, 10 or $25 \mu \mathrm{g}, \mathrm{n}=4$ mice, 12 mammary tumors). The above experiment was repeated using $25 \mu \mathrm{g}$ of either AM9D ( 2 mice; 12 tumors) or control DNAzyme (2 mice; 9 tumors) and the results were included in the calculation of tumor endpoint weight reported.

Tumor growth was monitored weekly by caliper measurement. All animals were euthanized one week after the last DNAzyme treatment (typically at 12 weeks of age). At necropsy, tumors were removed, final tumor dimensions were measured by calipers, and 
the tumor wet weight was determined. Tumors were then either flash frozen in liquid nitrogen, or fixed in $4 \%$ paraformaldehyde overnight, followed by cryoprotection in $25 \%$ sucrose for several days. Cryoprotected tumors were then washed with $0.1 \%$ PBS prior to embedding in OCT compound and preparation of 8 micron frozen sections.

\section{In Situ Hybridization}

The presence of DNAzymes in mammary tumor slices was detected by in situ hybridization using 5' end fluorescently labeled anti-AM9D sense oligonucleotides (5'-CGACCTCAAtcgttgtagctagccTGGcACCAC-3') as a probe. The tumor slices were incubated with $3 \mu \mathrm{g}$ of probe in hybridization buffer consisting of $25 \%$ formamide, $2 \mathrm{X}$ SSC, $0.5 \mathrm{mg} / \mathrm{ml}$ Salmon Sperm DNA, 1X Denhart's solution, $100 \mathrm{mM}$ DTT and 10\% Dextran Sulfate, overnight at $42{ }^{\circ} \mathrm{C}$. The slides were then washed twice with $2 \mathrm{xSSC}$, $0.1 \%$ SDS for 5 min at RT followed by two washes with 2x SSC, 25\% Formamide for 20 min at $45{ }^{\circ} \mathrm{C}$, dried at RT, coverslipped and visualized by fluorescent and confocal microscopy. The nucleus was visualized by addition of DAPI/anti-fade to each slide.

\section{Histology and Immunohistochemistry}

Mammary tumor sections were stained with hematoxylin and Eosin Y (H\&E; Fisher Scientific, Suwanee, GA). To block non-specific staining for immunohistochemistry, sections were treated with $2 \%$ BSA in $1 \mathrm{X}$ PBS/ $0.2 \%$ Triton $\mathrm{X}-100$. Tumor vasculature was then visualized using rat anti-mouse CD31 antibody (1:50) (BD Biosciences, San Jose, California) and Alexa Fluor-594 goat anti-rat IgG $(\mathrm{H}+\mathrm{L})$ secondary antibody (Invitrogen, Carlsbad, CA). Stromal cells (myofibroblasts) were detected by incubating the sections with anti- $\alpha$-smooth muscle actin antibody at 1:250 dilution (Sigma St. Louis, MO) overnight at $4{ }^{\circ} \mathrm{C}$ and Alexa Fluor 488 goat anti-mouse IgG2a (Invitrogen, Carlsbad, CA) secondary antibody at 1:500 dilution, for $1 \mathrm{~h}$ at room temperature. MMP-9 protein was detected using a rabbit anti-mouse MMP-9 antibody at a 1:200 dilution (Santa Cruz) overnight at $4^{\circ} \mathrm{C}$ followed by Alexa Fluor-594 goat anti-rabbit IgG antibody (1:500) at room temperature for 1h. CD31 and caspase-3 stained sections were blindly reviewed and grouped depending on their degree of red (CD31) and green (caspase-3) positive staining. MMP-9 stained slides were quantified by taking z-stack images and using image J. Digital images were captured using a Bio-Rad Confocal Laser Scanning Microscope, using the Lasersharp 2000 software.

\section{Statistical Analysis}

All data are expressed as mean \pm standard deviation or standard error. Data were analyzed with SSPS software (SigmaStat version 2.03) using one-way analysis of variance (ANOVA). Tumor growth over time among three groups was analyzed by two-way ANOVA using Prism software (Graphpad version 4.0b). In all cases, $\mathrm{p}$ values $<0.05$ were considered statistically significant. 


\section{RESULTS}

\section{MMP-9 Is Expressed in Mammary Tumors of MMTV-PyMT Mice}

To confirm the presence of MMP-9 protein in late-stage mammary carcinomas, tumors were harvested from MMTV-PyMT transgenic females, at 12 weeks of age. Tumor sections were stained with antibodies to both $\alpha$-smooth muscle actin (SMA), a marker for stromal myofibroblasts, and MMP-9. Immunohistochemical analysis demonstrated the presence of MMP-9 in stroma and in other areas, which could be tumor epithelium, recruited immune cells, and endothelium (Figure 2-2).

\section{DNAzyme In Vivo Stability}

Prior to testing AM9D for its effect on mammary tumor growth, the in vivo stability and cellular uptake of naked DNAzyme molecules was examined by intratumorally injecting tumor-bearing MMTV-PyMT transgenic female mice with fluorescently labeled AM9D (25 $\mu \mathrm{g})$ suspended in PBS. The animals were then sacrificed at different time intervals post AM9D injection, and mammary tumors were harvested, sectioned, and viewed under fluorescent microscope. Fluorescently labeled oligonucleotides could be easily detected in a diffuse pattern within the tumor for up to 14 days after injection (Figure 2-3). Moreover, the AM9D could also be detected in adjacent, non-injected mammary tumors of the same mouse (Figure 2-3b), indicating a wide distribution pattern than might be expected from intratumoral injection. Therefore, the DNAzymes are stable in vivo and can efficiently distribute within the injected tumor and to a nearby non-injected tumor.

a.

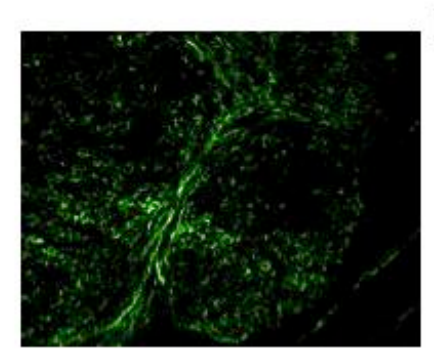

b.

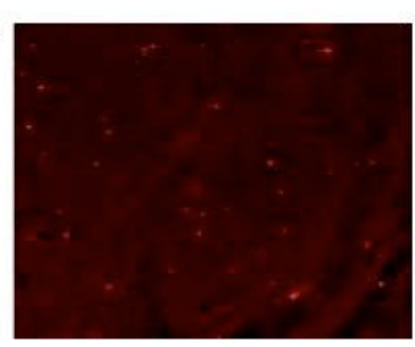

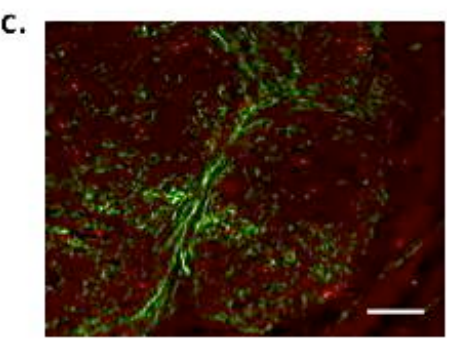

Figure 2-2. MMP-9 in MMTV-PyMT mice mammary tumors.

Immunohistochemical staining for MMP-9 in mammary tumor sections. Tumors were resected from MMTV-PyMT mice and double stained with antibodies to $\alpha$-smooth muscle actin to detect stromal cells (a) and MMP-9 (b). When channels were merged (c), these data show that MMP-9 is present in both stromal cells and in other areas. Magnification 200X. Scale bar in (c) is equivalent to $100 \mu \mathrm{m}$. 
a.

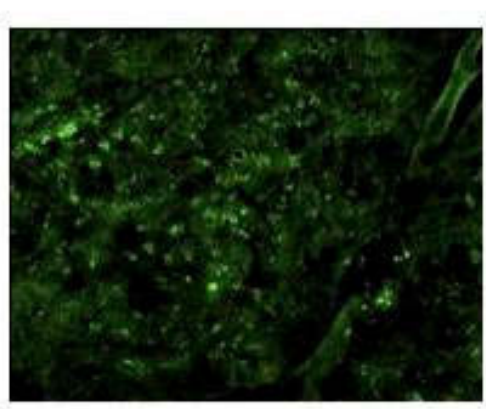

c.

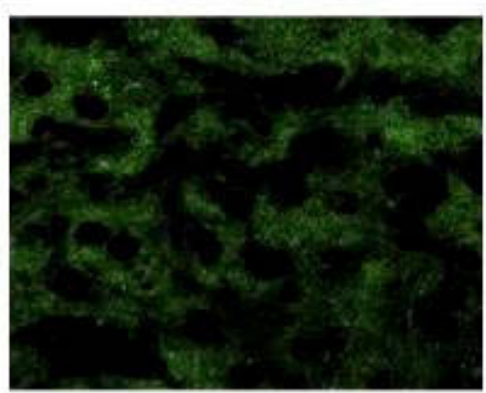

e.

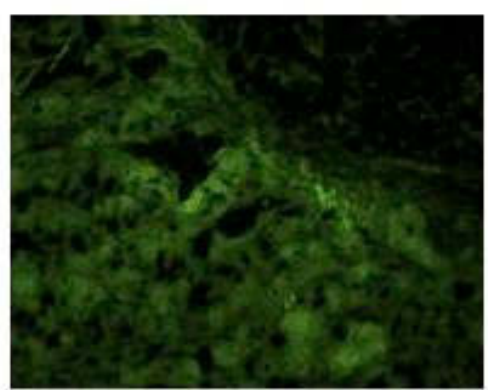

b.

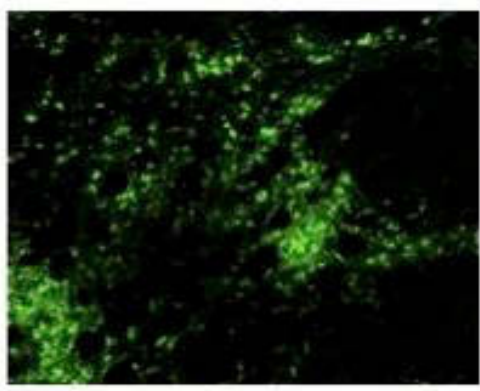

d.

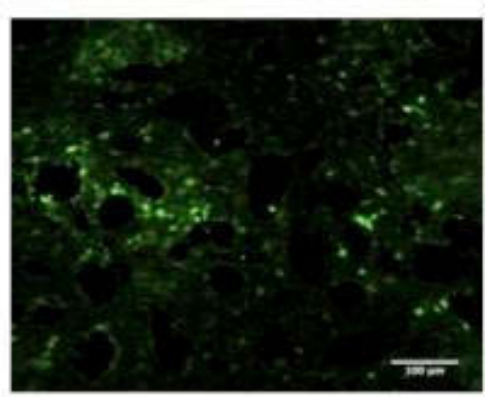

\section{Figure 2-3. Stability of DNAzyme in mammary tumors.}

Mammary tumors were injected as described in the methods with fluorescently labeled AM9D and resected at either (a) 7 days, (b) 10 days, or (c) 14 days post-injection. (e) Mammary tumor injected with unlabeled DNAzyme was used as a negative control. Of note, (d) DNAzyme injected into the $2 \mathrm{R}$ tumor of a mouse was found to be distributed to an adjacent, non-injected mammary tumor, 3R, which had emerged after injections were first initiated. Scale bar in (d) is equivalent to $100 \mu \mathrm{m}$. 


\section{Effect of AM9D Treatment on Final Tumor Load}

The efficacy of AM9D to reduce breast tumor volume in MMTV-PyMT transgenic mice was tested by directly injecting two concentrations (10 $\mu \mathrm{g}$ or $25 \mu \mathrm{g})$ of AM9D or control DNAzyme into mammary tumors of transgenic females bearing at least 3 tumors per mouse, each at an early palpable size $(\sim 3 \mathrm{~mm} \times 5 \mathrm{~mm})$, once a week for 4 weeks. Tumor palpations were performed weekly to determine changes in tumor volume over time. The rate of tumor growth in tumors treated with $25 \mu \mathrm{g}$ of AM9D $(n=12$ tumors) was slower than that of the untreated tumors ( $n=7$ tumors) or DNAzyme control treated ( $\mathrm{n}=9$ tumors) tumors (Figure 2-4a). Although, the observed difference in tumor growth over time in control and AM9D treated groups was not significant at early stage of growth (8-11 weeks of age; 2-way ANOVA, $p>0.05)$, the difference was statistically significant at 12 weeks of age (Figure 2-4), the study endpoint. The p values obtained for AM9D vs. control DNAzyme treated and untreated tumors were $\mathrm{p}<0.001$ and $\mathrm{p}<0.01$, respectively. The final tumor volume of AM9D treated tumors was significantly reduced compared to that of the control DNAzyme treated tumors (Figure 2-4b). In fact, administration of AM9D at $10 \mu \mathrm{g}$ was sufficient to reduce the size of the tumor by $39.5 \%$, which increased to $50.1 \%$ when $25 \mu \mathrm{g}$ of AM9D was utilized $(\mathrm{p}<0.01$ for statistical comparison of control to $10 \mu \mathrm{g}$ and to $25 \mu \mathrm{g}$, one-way ANOVA).

Immunohistochemical analysis of the mammary tumors (Figure 2-5) confirmed that AM9D treatment successfully down-regulated MMP-9 protein expression. As shown in Figure 2-5b, AM9D treatment reduced MMP-9 expression by $66 \pm 11 \%$ in tumor compared to the control DNAzyme treatment (Figure 2-5a). In addition, in situ hybridization of the tumor tissue slices demonstrated the presence of DNAzyme in tumor and the surrounding tissue (Figure 2-6). Taken together, these data show that AM9D efficiently decreases MMP-9 expression in tumors, which is responsible for the observed anti-tumor effects.

\section{Effect of AM9D on Angiogenesis and Apoptosis}

MMP-9 has been shown to play a role in tumor progression through increase of bioavailability of VEGF and other factors that promote angiogenesis [30]. To determine the mechanism of tumor volume reduction by AM9D, the tumor slices were stained for CD-31 and for caspase-3 to assess the effect of AM9D on angiogenesis and apoptosis, respectively. AM9D treatment substantially reduced the number of blood vessels in the tumor as demonstrated by the lack of robust CD-31 immunostaining in the AM9D treated group (Figure 2-7c) versus untreated (Figure 2-7a) or the control DNAzyme treated (Figure 2-7b) groups. These data suggest that anti-angiogenic effect of AM9D delays tumor growth over time and tumor volume at our study endpoint. Moreover, our data also indicate that AM9D induces apoptosis in the tumor. This is based on the observation that only AM9D treated tumors contain a large number of caspase- 3 positive cells

(Figure 2-8). Therefore, AM9D therapy can simultaneously induce tumor cell apoptosis and decrease stromal cell neo-angiogenesis. 
a.

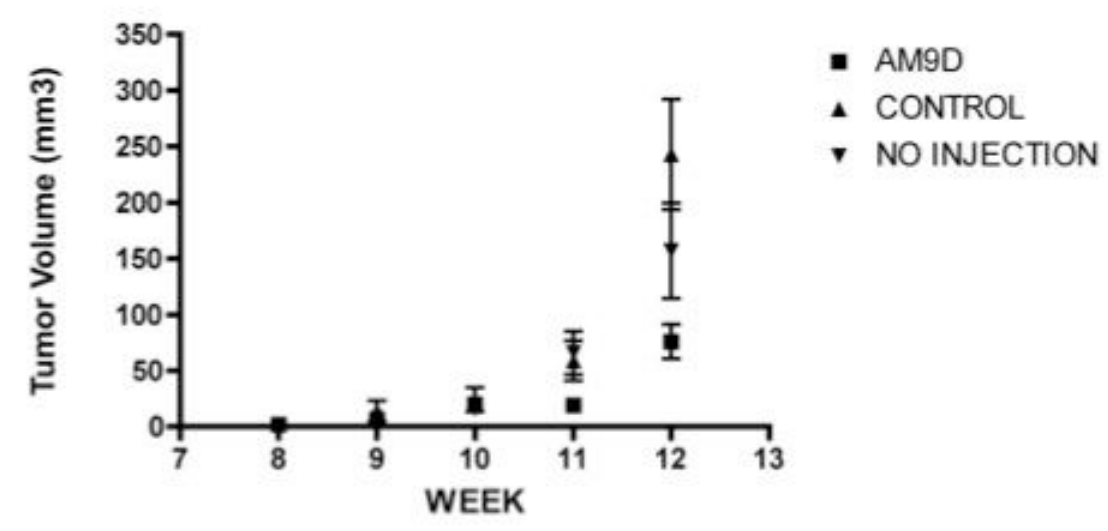

b.

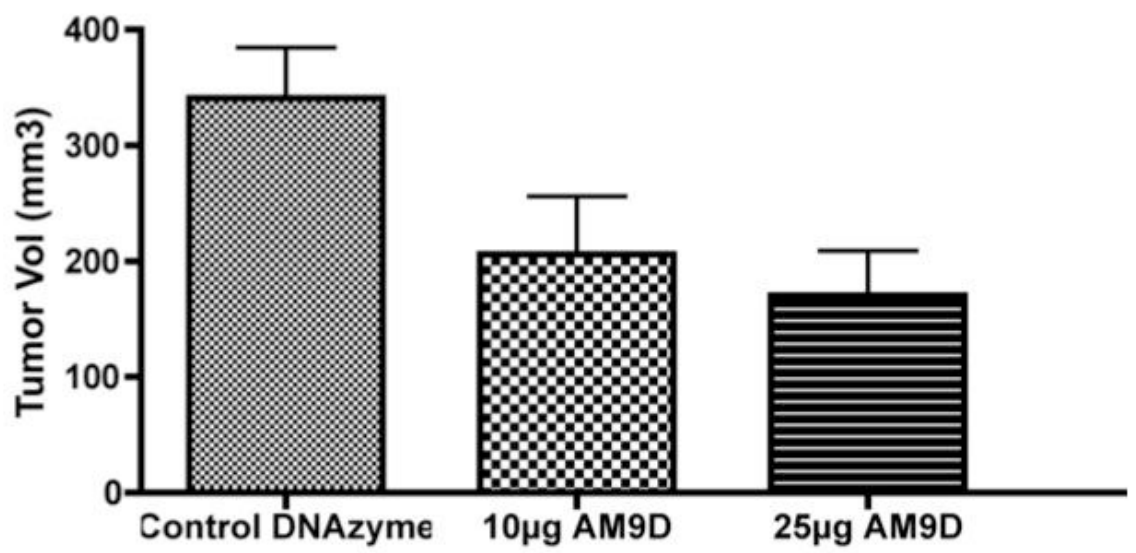

Figure 2-4. Effect of AM9D on the rate of tumor growth and final mean tumor volume.

(a) AM9D-treated tumors ( $\boldsymbol{\square})$ grew at a slower rate than either untreated tumors (no injections, $\boldsymbol{\nabla})$ or tumors treated with control DNAzyme $(\boldsymbol{\bullet})$. The difference between control DNAzyme treated and untreated tumors is not significant at 8-11 weeks of age ( $p>0.05)$, but is statistically significant at 12 weeks of age $(p<0.05)$, the study endpoint. (b) Weekly intratumoral treatment of transgenic mice with $10 \mu \mathrm{g}$ ( $\mathrm{n}=9$ tumors) or $25 \mu \mathrm{g}$ AM9D ( $\mathrm{n}=21$ tumors) per tumor reduced mean tumor burden by $39.5 \%$ or $50.1 \%$, respectively, when compared to tumors treated with control DNAzyme ( $n=24$ tumors) $(\mathrm{p}<0.01$ ANOVA). 
a.

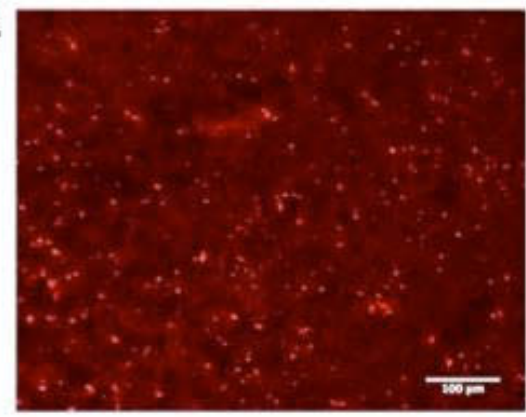

b.

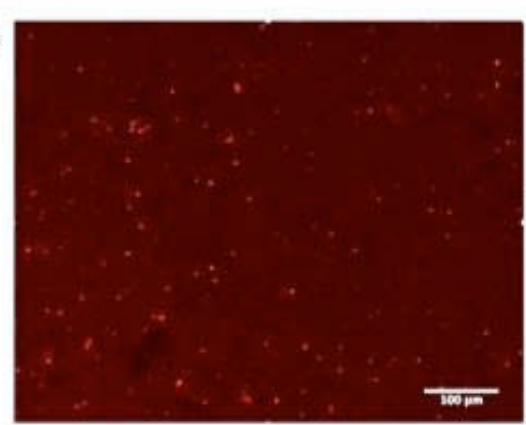

Figure 2-5. Effect of AM9D on MMP-9 protein expression in MMTV-PyMT mammary tumors.

Mammary tumors treated with either $25 \mu \mathrm{g}$ control DNAzyme or AM9D were stained with an anti-MMP-9 antibody. Mammary tumors treated with (b) AM9D for 4 weeks showed lower MMP-9 staining compared to (a) those treated with $25 \mu \mathrm{g}$ control DNAzyme for 4 weeks. Images are shown at 200x magnification; scale bar is equivalent to $100 \mu \mathrm{m}$.
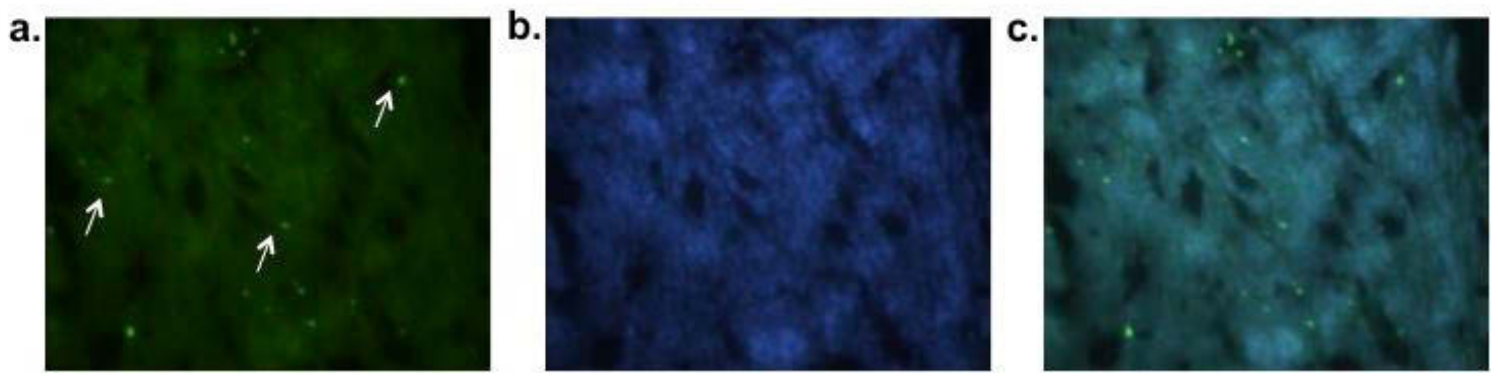

Figure 2-6. Fluorescent in situ hybridization.

In situ hybridization performed on $25 \mu \mathrm{g}$ AM9D-treated mammary tumors at study endpoint. (a) Green signal indicates the presence of AM9D DNAzyme (arrows) and (b) DAPI was used to detect cell nuclei. (c) Images (a) and (b) merged. Magnification 400X. 


\section{a.}

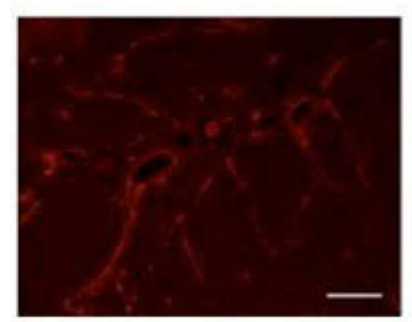

b.

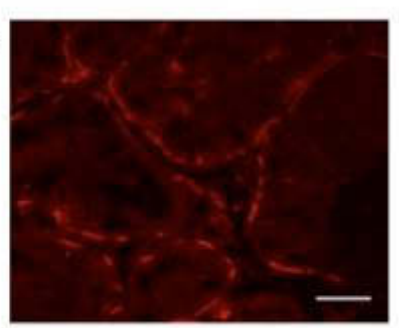

d.

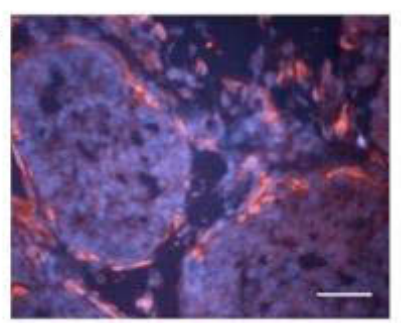

c.

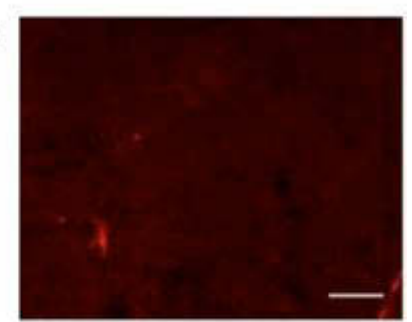

e.

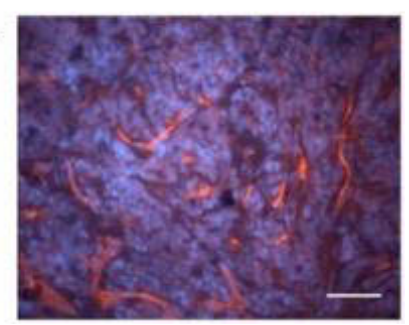

Figure 2-7. AM9D reduces tumor vasculature.

Immunohistochemical staining for CD31 (red) to detect the vasculature in mammary tumors harvested from mice treated with $25 \mu \mathrm{g}$ of AM9D (c and e) or control DNAzyme (b and d). A subset of sections was also counterstained with DAPI ( $d$ and e). Untreated tumors (a) and tumors treated with control DNAzyme (b and d) contained more blood vessels than did tumors treated with AM9D (c and e). Images are shown at 200x (a-c) or $400 \mathrm{x}$ ( $\mathrm{d}$ and e) magnification. Scale bar is equivalent to $100 \mu \mathrm{m}(\mathrm{a}-\mathrm{c})$ and $50 \mu \mathrm{m}(\mathrm{d}$ and e).

a.

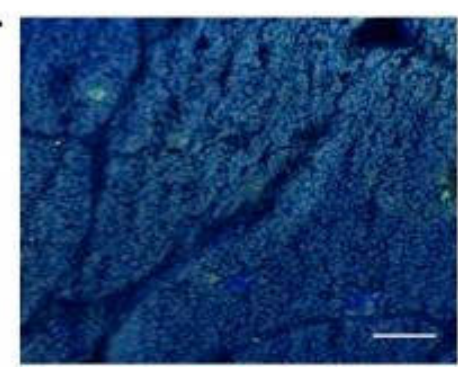

b.

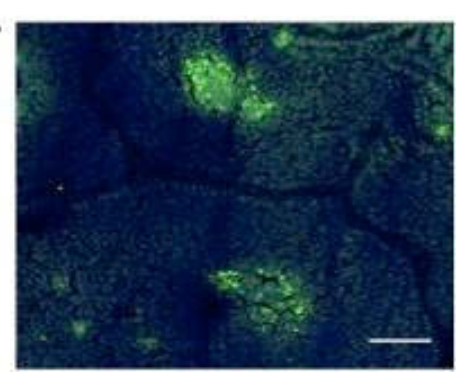

\section{Figure 2-8. AM9D induces apoptosis.}

Immunohistochemical staining of mammary tumors harvested from mice treated for four weeks with $25 \mu \mathrm{g}$ (a) control DNAzyme or (b) AM9D for caspase-3 indicate AM9D treatment (b) induces apoptosis in mammary tumors. Caspase 3 staining is shown in green and nuclei are stained blue with DAPI. Very few caspase-3 positive cells (green) were detected in tumors treated with control DNAzyme (a) compared to AM9D-treated tumors (b), where large regions stained positive for caspase-3. Scale bar is equivalent to $100 \mu \mathrm{m}$. 


\section{DISCUSSION}

In this study, we show for the first time, that the down regulation of MMP-9 in mammary tumors by a novel anti-MMP-9 DNAzyme molecule results in a significant reduction in final tumor volume in the MMTV-PyMT transgenic mouse model of breast cancer. Down regulation of MMP-9 by AM9D was accompanied by a decrease in MMP-9 expression, decreased angiogenesis and increased apoptosis. Moreover, these effects were accomplished by intratumoral injection of naked DNAzyme without the use of any carriers. Together, these data indicate that inhibition of MMP-9 expression by DNAzyme has potential as a novel therapeutic modality to decrease growth and invasion of carcinoma cells in the clinical setting.

It is known that MMP-9 plays a key role in angiogenesis by releasing VEGF [30] and that its down regulation induces apoptosis by stimulating ERK pathway [32]. Martin et al. [68] have demonstrated that spontaneous lung metastases decreased by $80 \%$ in MMTV-PyMT MMP-9 null mice compared to MMTV-PyMT MMP-9 wild type mice. In addition, the lung tumors developed in MMTV-PyMT MMP-9 wild type mice are larger in size and are more highly vascular compared to those tumors that developed in MMTV-PyMT MMP-9 null mice. Thus, the data presented here is consistent with the above studies and demonstrate that down regulation of MMP-9 by AM9D also affects tumor growth via inhibiting angiogenesis and inducing apoptosis (Figures 2-7 and 2-8) as demonstrated by lack of CD31 staining and the enhanced presence of caspase 3 in AM9D treated tumors.

Our results are consistent with those of Almholt, et al. [67] which showed that the broad-spectrum MMP inhibitor Galardin/GM6001, significantly reduced primary mammary tumor growth by $50 \%$ and reduced lung metastasis by more than 100 -fold in the MMTV-PyMT model. However, contrary to broad-spectrum MMP inhibitors, including GM6001, AM9D treatment specifically down regulates MMP-9 without affecting the expression of other members of the MMP family (Figure 1-3b and 1-3c). As demonstrated by the extent of cytoxicity of broad spectrum MMP inhibitors in prior clinical trials [41, 46, 47], total inhibition of MMPs is not practical, since various MMPs can exert both pro-tumorigenic and anti-tumorigenic properties [17]. In addition, MMPs are critical for normal physiological processes, such as bone growth and remodeling, ovulation, and wound healing [19]. Further, in comparison with GM6001 [67], the intratumoral injection of AM9D not only reduced the required frequency of therapy; it was equally efficient in reducing final tumor size. Once weekly, intratumoral injections of $25 \mu \mathrm{g}$ AM9D $(1.25 \mathrm{mg} / \mathrm{kg})$ was sufficient to reduce the size of these spontaneously developed tumors by $50 \%$ as compared to the $51 \%$ tumor reduction observed following daily administration of $100 \mathrm{mg} / \mathrm{kg}$ of GM6001. Thus, the high degree of specificity for targeting MMPs, the lack of in vivo toxicity and the increased efficacy of AM9D as compared to broad spectrum inhibitors should enhance the clinical response of solid tumors, including breast tumors, while evading the serious side effects experienced with systemic therapy based on broad-spectrum MMP inhibitors. 


\section{CHAPTER 3. DISTRIBUTION, CLEARANCE, AND CYTOTOXICITY OF DNAZYME}

\section{INTRODUCTION}

Enzymatic DNA molecules have been used recently in cell based assays and preclinical animal studies to treat various cancers. We have shown that intratumoral injections of anti-MMP-9 DNAzyme (AM9D) reduced mammary tumor burden in MMTV-PyMT transgenic mice by $50 \%$ (Chapter 2). As described previously, DNAzymes designed to specifically target Aurora kinase A inhibited growth of human prostate cancer in vivo [52]. A DNAzyme targeting VEGF2 mRNA led to a $75 \%$ reduction in tumor size compared to saline treated control [53] and treatment of MDA-MB-231 xenograft solid tumor model with an EGR-1 mRNA specific DNAzyme (DzF) resulted in inhibition of tumor growth compared to saline treated control [69]. However, all of these preclinical studies of tumor growth were conducted via intratumoral injections. While intratumoral injections can illustrate the promise of DNAzymes relative to target specificity and therapeutic potential, it is impracticable for clinical trials in humans. Thus, successful systemic application of DNAzymes in pathophysiological and therapeutic studies requires prior demonstration of significant uptake of DNAzyme by the target tissues. Moreover, to optimize DNAzyme regimens, tissue distribution and clearance must also be studied in vivo.

In this body of work, we have shown, for the first time, that naked AM9D is safe when administered systemically to healthy FVB mice and distributes to all organs of healthy mice and the Mouse Mammary Tumor Virus-polyoma middle T antigen (MMTV-PyMT) transgenic mouse model of breast cancer.

\section{MATERIALS AND METHODS}

\section{Synthesis of ${ }^{35}$ S-radiolabeled Oligonucleotides}

The DNAzyme molecules were labeled at the 5 ' end using ATP $\gamma-{ }^{35} \mathrm{~S}$ (Perkin Elmer, Waltham, MA) and T4 polynucleotide kinase (Promega, Madison, WI). The

${ }^{35}$ S-labeled DNAzyme ([ $\left({ }^{35} \mathrm{~S}\right]$-DNAzyme) was then purified using a centri-10 column (Applied Biosystems, Carlsbad, CA). $\left[{ }^{35}\right.$ S]-DNAzyme was dissolved in sterile Phosphate Buffered Saline (PBS). The concentration of the solution was adjusted so that $100 \mu 1$ administered to $20 \mathrm{~g}$ mice resulted in a dose of $10 \mathrm{mg} / \mathrm{kg}$ of body weight (specific activity, $0.275 \mathrm{mci} / \mathrm{kg}$ ). $\left.{ }^{35} \mathrm{~S}\right]-\mathrm{DNAzyme}$ was mixed with unlabeled DNAzyme to obtain the desired concentration. 


\section{Animal Experiments}

All animal studies were done in accordance with the guidelines established by the Animal Care and Use Committee at The University of Tennessee Health Science Center. Twenty-three 8 week-old female FVB mice weighing 20-25 g and 19 MMTV-PyMT transgenic mice (FVB strain) bearing mammary tumors of various sizes and weighing 17-22 $\mathrm{g}$ were used in this study. MMTV-PyMT transgenic mice develop tumors in 6-8 weeks of age. Mice bearing a range of early $\left(<500 \mathrm{~mm}^{3}\right)$ and late stage $\left(>750 \mathrm{~mm}^{3}\right)$ tumors were used.

\section{Systemic Distribution}

Normal Mice. $\left[{ }^{35} \mathrm{~S}\right.$ ]-DNAzyme, $100 \mu \mathrm{l}(10 \mathrm{mg} / \mathrm{kg} ; 0.275 \mathrm{mci} / \mathrm{kg})$ in PBS was administered into 23 healthy anesthetized mice via tail vein injection. Three animals were placed in metabolism cages, immediately following injection, for 7 days $(168 \mathrm{~h})$. The urine and feces were collected daily for total radioactivity determination from each of the three animals. All samples were collected and stored at $-80{ }^{\circ} \mathrm{C}$ until analysis. The remaining 20 mice were divided into 5 groups of 4 animals each and at 2, 6, 24, 48, and $72 \mathrm{~h}$ following intravenous administration of $\left[{ }^{35} \mathrm{~S}\right]$-DNAzyme, one group of animals was sacrificed and liver, heart, lung, kidney, and spleen were removed for determination of total radioactivity. This experiment was repeated using 6 mice divided into 2 groups of 3 mice each. At 2 and $6 \mathrm{~h}$ following intravenous administration of $\left[{ }^{35} \mathrm{~S}\right]$-DNAzyme, one group of animals was sacrificed and liver, heart, lung, kidney, spleen, intestines, brain, pancreas, and stomach were removed for determination of total radioactivity.

Immediately prior to sacrifice, blood samples $(0.5-1 \mathrm{ml})$ were collected from anesthetized mice via the retro-orbital vein.

MMTV-PyMT Mice. DNAzyme was administered as above into 19 tumor bearing mice and these were divided into 5 groups of 3 animals each and one group of 4 animals. At 2, 4, 8, 24, 48, and $72 \mathrm{~h}$ following $\left[{ }^{35} \mathrm{~S}\right]$-DNAzyme administration, one group of animal was sacrificed. Tumor volumes were measured using calipers during the experiments, and after excision, wet weights were recorded. Tumors exceeding $1.37 \mathrm{~g}$ were highly heterogeneous (i.e. necrotic areas and mixture of tumor consistency) and thus were not included in any statistical analysis of mammary tumors. Heart, lung, kidney, liver, spleen, and blood samples were removed for determination of total radioactivity.

\section{Radioactive Sample Analysis}

Organs were solubilized in at least $1 \mathrm{ml}$ SOLVABLE according to manufacturer's instruction (Perkin Elmer) and incubated overnight at $50{ }^{\circ} \mathrm{C}$. Endogenous peroxidase activity was quenched with $10 \mathrm{mM}$ EDTA and $6 \%$ hydrogen peroxide for $1 \mathrm{~h}$ at $50{ }^{\circ} \mathrm{C}$. Blood samples were collected from each mouse and $200 \mu \mathrm{l}$ of each sample was incubated with $1 \mathrm{ml}$ SOLVABLE at $50{ }^{\circ} \mathrm{C}$ for $1 \mathrm{~h}$. The endogenous peroxidase activity in blood was quenched with EDTA and hydrogen peroxide, as above. Approximately $10 \mathrm{ml}$ of 
scintillation cocktail fluid was added to each sample and tissue radioactivity was measured using a Packard Tri-Carb 2900CA liquid scintillation analyzer. Counts per minute obtained from each sample were converted to microgram of DNAzyme equivalents and presented as the total $\mu \mathrm{g}$ DNAzyme per either weight or volume of tissue, blood, urine, or fecal output. Initial and final rates of clearance were calculated based on the slope of the line obtained from plotting $\mu \mathrm{g}$ DNAzyme per gram of tissue (ml blood) as a function of time (initial: 2-6 $\mathrm{h}$ for normal mice and 2-8 $\mathrm{h}$ for MMTV-PyMT mice, final: $24-72 \mathrm{~h}$ ). All data were expressed as mean \pm standard deviation of mean. The quenching effect of tissue on radioactive count was tested by adding appropriate amounts of $\left[{ }^{35} \mathrm{~S}\right]$ - DNAzyme to scintillation vials containing solubilized normal organs. No significant tissue quenching effect was observed.

\section{Cytotoxicity}

Healthy mice were intravenously injected with PBS or various concentrations $(10 \mathrm{mg} / \mathrm{kg}, 32 \mathrm{mg} / \mathrm{kg}$, and $75 \mathrm{mg} / \mathrm{kg}$ of body weight) of either AM9D or Scrambled DNAzyme. Five mice per dosage for a total of 35 mice were used. The mice were sacrificed 7 days after DNAzyme administration. Following dosing, animals were observed daily for signs of toxicity including trouble grooming, lack of food consumption, and any other signs of lethargy; none was observed. At necropsy, liver, heart, lung, kidney, and spleen were collected and fixed in $4 \%$ paraformaldehyde, impregnated with $25 \%$ sucrose that acts as a cryoprotectant, and were processed for histopathological evaluation (standard light microscopic examination of hematoxylin and eosin-stained tissue slides).

\section{RESULTS}

\section{Kinetics of DNAzyme in Normal Mice}

The systemic distribution of DNAzyme in mice and its rate of clearance were determined by injecting naked $\left[{ }^{35} \mathrm{~S}\right]$-AM9D $(10 \mathrm{mg} / \mathrm{kg})$ in PBS via tail vein into healthy FVB mice and the amount of radioactivity present in blood and different organs was measured as a function of time. Figure 3-1a illustrates the tissue/blood distribution time profile of DNAzyme in mice. AM9D injected via tail vein in mice is distributed to all major organs; liver, heart, spleen, kidney, and lungs. Two hours after DNAzyme injection, approximately $10 \%$ of the total DNAzyme was found in major organs (Table 3-1). The order of percentage accumulation was: blood $>$ liver $>$ kidney $>$ lung $>$ spleen $>$ heart. Blood contained a majority of DNAzyme with $6.3 \%$ of the total DNAzyme in the first $2 \mathrm{~h}$ and reduced to $2.1 \%$ after $6 \mathrm{~h}$ (Table 3-1). Studies revealed $1.8 \%, 1.1 \%$ and $0.4 \%$ of total DNAzyme injected was delivered to liver, kidney, and lung, respectively. Finally, spleen and heart contained $0.21 \%$ and $0.2 \%$ of total DNAzyme in 
a

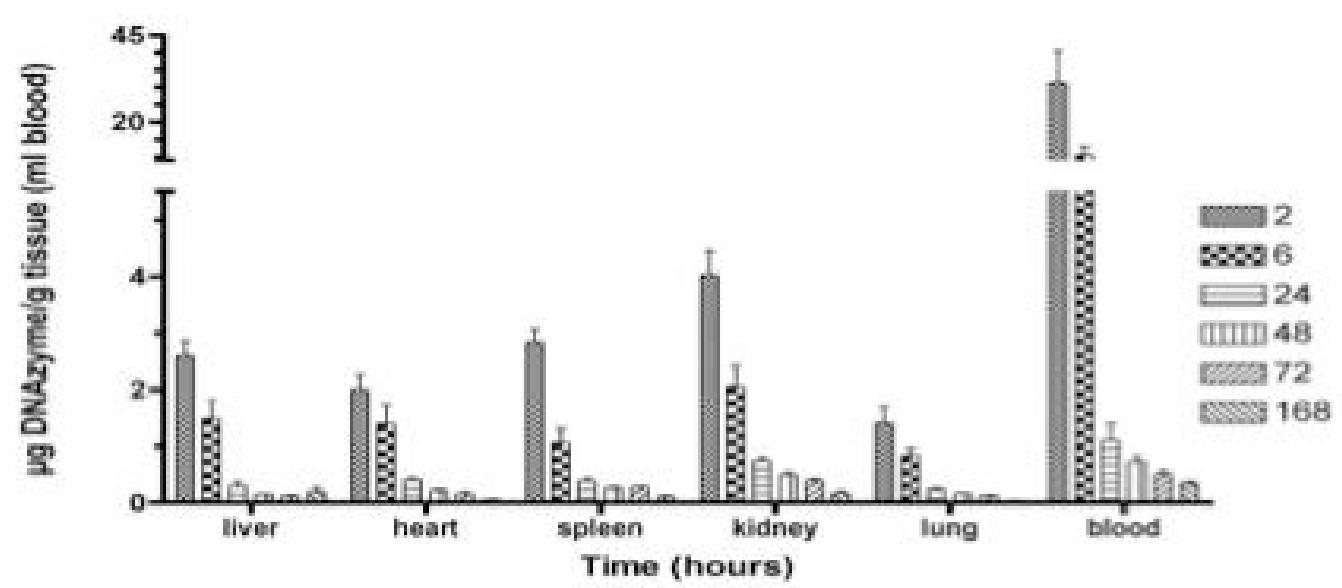

b

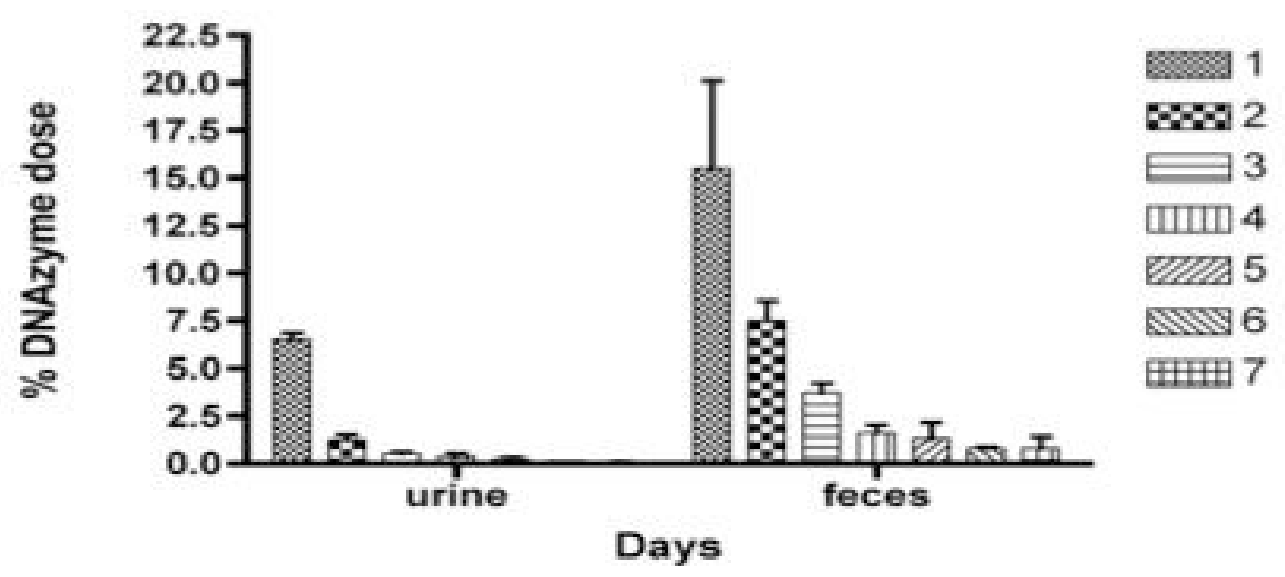

Figure 3-1. Distribution and elimination profile of $\left[{ }^{35} \mathrm{~S}\right]-\mathrm{DNAzyme}$ in normal mice.

(a) Distribution profile for $\left[{ }^{35} \mathrm{~S}\right]$-DNAzyme in tissue and blood. The tissue concentration of $\left[{ }^{35} \mathrm{~S}\right]$-DNAzyme derived radioactivity is based on $\mu \mathrm{g}$ equivalent DNAzyme/g of organ and is the mean $(+/-$ stdev) of 3-4 mice for each tissue. Blood concentrations are the mean values from all samples collected at each time point throughout the experiment. The DNAzyme blood concentration was first corrected for total blood in mouse based on the animal's weight and a mean of blood volume of $79 \mu \mathrm{l} / \mathrm{g}$ body weight. Then, for calculation of $\mu \mathrm{g}$ DNAzyme/g of blood, $1 \mathrm{ml}$ blood was assumed to be equal to $1 \mathrm{~g}$. (b) Elimination profile for $\left[{ }^{35} \mathrm{~S}\right]$-DNAzyme. The urine and fecal concentrations are mean values calculated for the total output from three mice each day for a total of 7 days. 
Table 3-1. Tissue distribution of $\left[{ }^{35} \mathrm{~S}\right]-\mathrm{DNAzyme}$ in normal mice presented in average percentage of total DNAzyme.

\begin{tabular}{lcccccc}
\hline Tissue & $2 \mathrm{~h}$ & $6 \mathrm{~h}$ & $24 \mathrm{~h}$ & $48 \mathrm{~h}$ & $72 \mathrm{~h}$ & 7 days \\
\hline \multirow{2}{*}{ Liver } & 2.198 & 1.375 & 0.281 & 0.141 & 0.108 & 0.185 \\
& $(1.59-2.55)$ & $(.94-2.2)$ & $(.16-.46)$ & $(.12-.16)$ & $(.05-.14)$ & $(.09-.31)$ \\
Heart & 0.205 & 0.144 & 0.042 & 0.022 & 0.016 & 0.005 \\
& $(.15-.26)$ & $(.06-.22)$ & $(.03-.05)$ & $(.01-.02)$ & $(.01-.03)$ & $(.003-.007)$ \\
Spleen & 0.215 & 0.08 & 0.029 & 0.02 & 0.021 & 0.008 \\
& $(.17-.26)$ & $(.05-.14)$ & $(.02-.04)$ & $(.01-.02)$ & $(.017-.023)$ & $(.005-.01)$ \\
Kidney & 1.132 & 0.575 & 0.209 & 0.138 & 0.109 & 0.048 \\
& $(.90-1.5)$ & $(.33-.84)$ & $(.17-.24)$ & $(.11-.16)$ & $(.09-.12)$ & $(.03-.07)$ \\
Lung & 0.366 & 0.216 & 0.061 & 0.043 & 0.033 & 0.01 \\
& $(.28-.51)$ & $(.15-.30)$ & $(.04-.07)$ & $(.04-.05)$ & $(.02-.04)$ & $(.008-.01)$ \\
Blood & 6.264 & 2.103 & 0.305 & 0.143 & 0.102 & 0.068 \\
& $(3.0-11.4)$ & $(.96-3.3)$ & $(.16-.42)$ & $(.08-.17)$ & $(.09-.13)$ & $(.05-.08)$ \\
\hline
\end{tabular}

Numbers in parentheses give the range of data. 
$2 \mathrm{~h}$ post injection, respectively. The majority of the DNAzyme was cleared from these organs within the first $24 \mathrm{~h}$. Thirty-one percent of the delivered dosage of

$\left[{ }^{35} \mathrm{~S}\right]$-DNAzyme was cleared from the system via feces and urine over a period of $72 \mathrm{~h}$.

This experiment was repeated for time points 2 and 6 hours after DNAzyme injections to assess distribution of DNAzyme to the following additional organs: brain, pancreas, stomach, and intestines. Similar to the above experiments, $100 \mu \mathrm{l}$ of $\left[{ }^{35} \mathrm{~S}\right]$-DNAzyme $(10 \mathrm{mg} / \mathrm{kg} ; 0.275 \mathrm{mci} / \mathrm{kg})$ in PBS was administered into 6 healthy anesthetized mice via tail vein injection. The 6 mice were divided into 2 groups of 3 animals each and at 2 and $6 \mathrm{~h}$ following intravenous administration of $\left[{ }^{35} \mathrm{~S}\right]$-DNAzyme, one group of animals was sacrificed and liver, heart, lung, kidney, spleen, intestines, brain, pancreas, and stomach were removed for determination of total radioactivity (Figure 3-2). As shown in Figure 3-2, 2 and $6 \mathrm{~h}$ after injection, in addition to the organs previously described, DNAzyme can be found in brain $(0.312 \mu \mathrm{g}$ and $0.248 \mu \mathrm{g}$ DNAzyme $/ \mathrm{g}$ ), pancreas (1.147 and $1.0 \mu \mathrm{g}$ DNAzyme $/ \mathrm{g}$ ), intestines (11.11 and $11.42 \mu \mathrm{g}$ DNAzyme/g), and stomach (11.92 and $7.41 \mu \mathrm{g}$ DNAzyme/g). This data demonstrates that DNAzyme molecule is capable of passing the blood brain barrier and suggests that it can be used as a therapeutic agent against brain tumors, as well as tumors which affect the pancreas, liver, and stomach (gastrointestinal stromal tumor).

The rate of initial clearance (from 2-6 h) and final clearance (from 24-72 h) of DNAzyme from different organs were calculated based on the amount of DNAzyme remaining in tissues as a function of time (Table 3-2). The rate of initial clearance of DNAzyme from blood was faster than kidney followed by spleen>liver $>$ heart $\geq$ lung

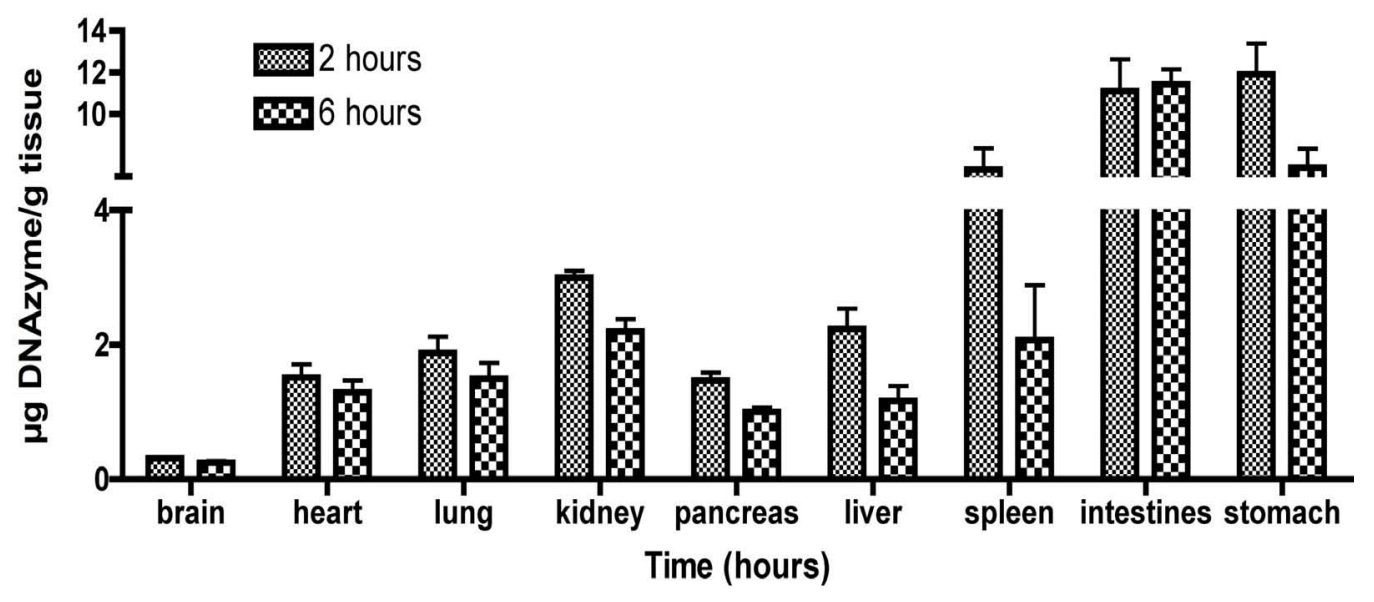

Figure 3-2. Distribution profile of $\left[{ }^{35} \mathrm{~S}\right]$-DNAzyme in additional organs of normal mice.

The tissue concentration of $\left[{ }^{35} \mathrm{~S}\right]$-DNAzyme derived radioactivity is based on $\mu \mathrm{g}$ equivalent DNAzyme/g of organ and is the mean ( $+/$ - stdev) of organs isolated from 3 mice. 
Table 3-2. Rate of $\left[{ }^{35}\right.$ S]-DNAzyme initial and final clearance in normal mice.

\begin{tabular}{|c|c|c|}
\hline Tissue & $\begin{array}{c}\text { Initial clearance }^{\mathrm{a}} \\
\mu \mathrm{g} \text { DNAzyme/g tissue/h }\end{array}$ & $\begin{array}{c}\text { Final clearance }^{\mathrm{b}} \\
\mu \mathrm{g} \text { DNAzyme/g tissue/h }\end{array}$ \\
\hline Liver & 0.281 & 0.0039 \\
\hline Heart & 0.149 & 0.0052 \\
\hline Spleen & 0.442 & 0.0023 \\
\hline Kidney & 0.495 & 0.0074 \\
\hline Lung & 0.143 & 0.0022 \\
\hline Blood & 5.202 & 0.0123 \\
\hline
\end{tabular}

(Table 3-2). The rates of initial and final clearance of DNAzyme from kidney were 0.495 $\mu \mathrm{g}$ DNAzyme/g of tissue/h and $0.0074 \mu \mathrm{g}$ DNAzyme/g of tissue/h, respectively. The rate of initial clearance of AM9D from heart and lung are equivalent, however, DNAzyme is retained in lung longer as its rate of final clearance in lung is approximately 2-fold slower than that of the heart (Table 3-2).

Fecal excretion represented the major pathway of DNAzyme elimination (Figure 3-1b). The amount of DNAzyme excreted in feces (32\%) is 3-fold greater than the amount released from urine (11\%) over the 7-day period. As expected, DNAzyme excretion was time-dependent with the majority being eliminated in the first $72 \mathrm{~h}$.

\section{Kinetics of DNAzyme in Mammary Tumor bearing Mice}

Female MMTV-PyMT transgenic mice bearing early to late stage mammary tumors were used to test the distribution of DNAzyme to mammary tumors. Naked $\left[{ }^{35} \mathrm{~S}\right]$-DNAzyme in PBS was administered to tumor bearing animals via tail vein injections, animals were then sacrificed at different times and the amount of $\left[{ }^{35} \mathrm{~S}\right]$-DNAzyme present in different organs, blood, and mammary tumors were determined as a function of time (Figure 3-3a and $b$ ). The order of percentages of $\left[{ }^{35} \mathrm{~S}\right]$-DNAzyme accumulation in different organs of MMTV-PyMT mice was mammary tumor $>$ liver $\approx$ blood $>$ kidney $>$ spleen $>$ lung $>$ heart. $\left[{ }^{35} \mathrm{~S}\right]$-DNAzyme concentration in the mammary glands was markedly higher than in other tissues. In these mice, $4.1 \%$ of the total injected DNAzyme was accumulated in the mammary tumors in $2 \mathrm{~h}$ (Table 3-3). Mammary tumors of transgenic mice were of varying sizes and the amount 
a

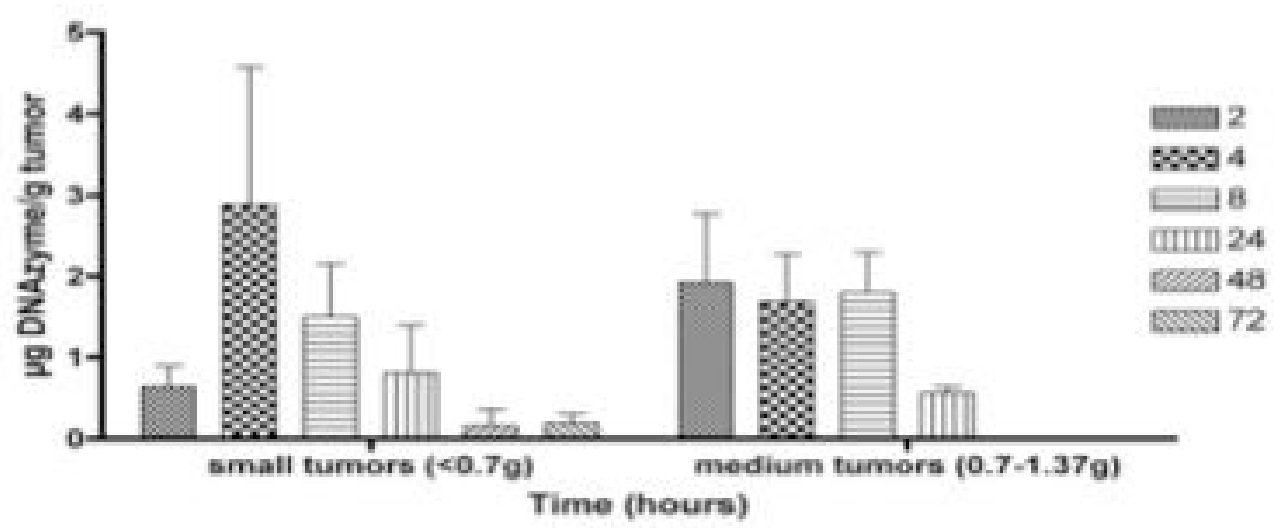

b

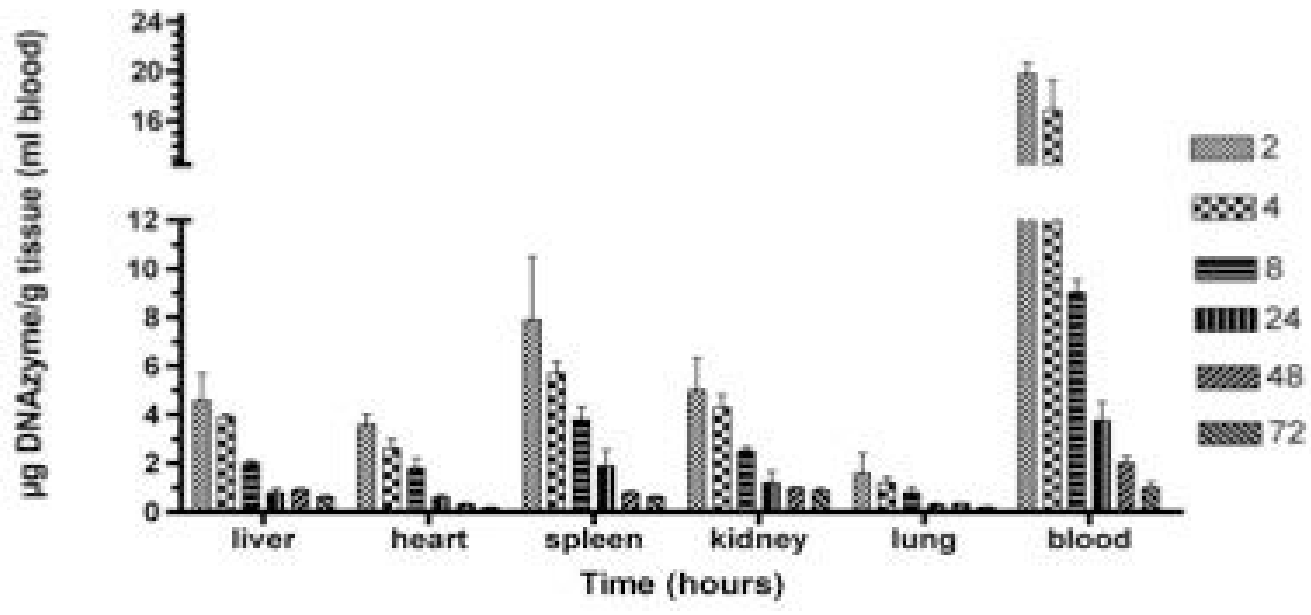

Figure 3-3. Distribution profile of $\left[{ }^{35}\right.$ S]-DNAzyme in MMTV-PyMT mice.

(a) Transgenic mice developed on average 7 mammary tumors per mouse and the mean value of tumor for 3-4 mice were calculated. Small and medium size tumors displayed different accumulation and clearance profiles. For this reason, tumors weighing less than $1.37 \mathrm{~g}$ were divided into two categories, small $(<0.7 \mathrm{~g})$ and medium $(\geq 0.7 \mathrm{~g}, \leq 1.37 \mathrm{~g})$. Tumors exceeding $1.37 \mathrm{~g}$ were excluded. (b) The tissue concentration of $\left[{ }^{35} \mathrm{~S}\right]$-DNAzyme derived radioactivity is based on $\mu \mathrm{g}$ equivalent DNAzyme/g of organ and is the mean of 3-4 mice for each tissue. The blood samples were collected from all mice. The DNAzyme blood concentration was first corrected for total blood in mouse based on the animal's weight and a mean of blood volume of $79 \mu \mathrm{l} / \mathrm{g}$ body weight. Then, for calculation of $\mu \mathrm{g}$ DNAzyme/g of blood, $1 \mathrm{ml}$ blood was assumed to be equal to $1 \mathrm{~g}$. 
Table 3-3. Tissue distribution of $\left[{ }^{35}\right.$ S]-DNAzyme in MMTV-PyMT mice presented in average percentage ${ }^{\mathrm{a}}$ of total DNAzyme.

\begin{tabular}{lcccccc}
\hline Tissue & $2 \mathrm{~h}$ & $4 \mathrm{~h}$ & $8 \mathrm{~h}$ & $24 \mathrm{~h}$ & $48 \mathrm{~h}$ & $72 \mathrm{~h}$ \\
\hline Liver & 3.89 & 3.31 & 1.72 & 0.72 & 0.46 & 0.31 \\
& $(2.7-5.76)$ & $(3.2-3.5)$ & $(1.5-1.9)$ & $(.47-1.0)$ & $(.419-.529)$ & $(.215-.355)$ \\
Heart & 0.33 & 0.24 & 0.17 & 0.05 & 0.018 & 0.009 \\
& $(.27-.41)$ & $(.17-.30)$ & $(.11-.25)$ & $(.03-.07)$ & $(.012-.022)$ & $(.007-.013)$ \\
Spleen & 0.54 & 0.4 & 0.26 & 0.13 & 0.03 & 0.025 \\
& $(.27-.88)$ & $(.35-.46)$ & $(.21-.32)$ & $(.08-.24)$ & $(.029-.038)$ & $(.019-.028)$ \\
Kidney & 1.27 & 1.1 & 0.63 & 0.3 & 0.15 & 0.14 \\
& $(.83-1.9)$ & $(.93-1.3)$ & $(.54-.69)$ & $(.03-.55)$ & $(.13-.16)$ & $(.011-.016)$ \\
Lung & 0.38 & 0.28 & 0.184 & 0.07 & 0.051 & 0.029 \\
& $(.18-.77)$ & $(.18-.39)$ & $(.1-.3)$ & $(.04-.1)$ & $(.046-.055)$ & $(.022-.032)$ \\
Mammary & 4.1 & 5.5 & 5.2 & 1.3 & 0.049 & 0.038 \\
Tumor ${ }^{b}$ & $(.06-9.2)$ & $(.1-8.5)$ & $(3.3-7.2)$ & $(0.5-2.3)$ & $(.011-.105)$ & $(.020-.059)$ \\
Blood & 3.52 & 2.97 & 1.64 & 0.69 & 0.216 & 0.115 \\
& $(3.4-3.8)$ & $(2.4-3.5)$ & $(1.5-1.7)$ & $(.52-.86)$ & $(.168-.274)$ & $(.080-.166)$ \\
& & & & & & \\
\end{tabular}

${ }^{\mathrm{a}}$ Numbers in parentheses give the range of data.

${ }^{\mathrm{b}}$ Tumors larger than $1.37 \mathrm{~g}$ were excluded from calculations. Data range in mammary tumors is attributed to range of tumor sizes. The large range of data in organs, in some cases, is attributed to technical error of injection. 
of DNAzyme accumulated in mammary tumors was proportional to the weight of the tumor burden (Figure 3-4).

Interestingly, the accumulated DNAzyme in the mammary tumor is initially cleared at a slower rate compared to the other organs, with rate of initial clearance (2-8 $\mathrm{h}$ post DNAzyme injection) of $0.068 \mu \mathrm{g}$ DNAzyme/g tissue/h (Table 3-4). The mammary tumors characterized as small tumors $(<0.7 \mathrm{~g})$ continue accumulating DNAzyme $2-4 \mathrm{~h}$ post injection (Figure 3-3a). This corresponds with the initial clearance of DNAzyme from blood 2-4 h post DNAzyme injection (Figure 3-3b). Similar to DNAzyme distribution in normal mice, the percentages of the total DNAzyme accumulated in blood, liver, kidney, lung, spleen, and heart, $2 \mathrm{~h}$ post DNAzyme injection, was 3.5\%, 3.9\%, $1.3 \%, 0.4 \%, 0.5 \%$ and $0.3 \%$, respectively (Table 3-3). However, the rate of initial clearance of DNAzyme from spleen was slower than blood but faster than any other organs tested followed by Liver $\approx$ Kidney $>$ Heart $>$ Lung $>$ Mammary tumors (Table 3-4). The majority of the DNAzyme was eliminated from the organs and blood within the first $24 \mathrm{~h}$ (Figure 3-3b). The rate of initial clearance from liver and kidney was found to be the same $(4.3 \mu \mathrm{g}$ DNAzyme/g tissue/h) during the first $8 \mathrm{~h}$ of administration and slightly increased in kidney between 24-72 h. In heart, the rate of clearance in 2-8 h (initial) and 24-72 $\mathrm{h}$ (final) post administration was 2 and 3.4-folds faster than that in lung, respectively (Table 3-4).

\section{Cytotoxicity of Intravenous Injection of AM9D in Healthy Mice}

Safety of DNAzyme delivered intravenously in healthy FVB mice was determined using single injection of escalating concentrations of AM9D or control DNAzyme $(10 \mathrm{mg} / \mathrm{kg}, 32 \mathrm{mg} / \mathrm{kg}$, and $75 \mathrm{mg} / \mathrm{kg}$ of body weight) in PBS. PBS was used as a control. Seven days post DNAzyme injection, mice were sacrificed and liver, spleen, lung, heart, and kidney were isolated and analyzed for cytotoxicity by H\&E staining (Figure 3-5). All tissues were evaluated (in a blinded manner) for evidence of capillary leakage, acute cellular damage including necrosis or apoptosis, acute inflammation and mitotic activity by a pathologist. No evidence of acute cytotoxicity, mitogenesis, cell death, local or widespread, was observed in the organs examined.

\section{DISCUSSION}

These results indicate that DNAzyme oligonucleotides could be delivered intravenously to all organs without the use of lipids or other carrier molecules, as naked DNAzyme was injected, and that the $\left[{ }^{35} \mathrm{~S}\right]$-AM9D was present in various organs including mammary tumor tissues and organs of high incidence for metastasis (i.e. lung). In addition, mammary tumors can take up the DNAzyme faster and retain it longer than any other organs. Together, these data suggest that DNAzymes can be useful as a therapeutic agent to treat human patients with breast cancer or any other solid tumors. 


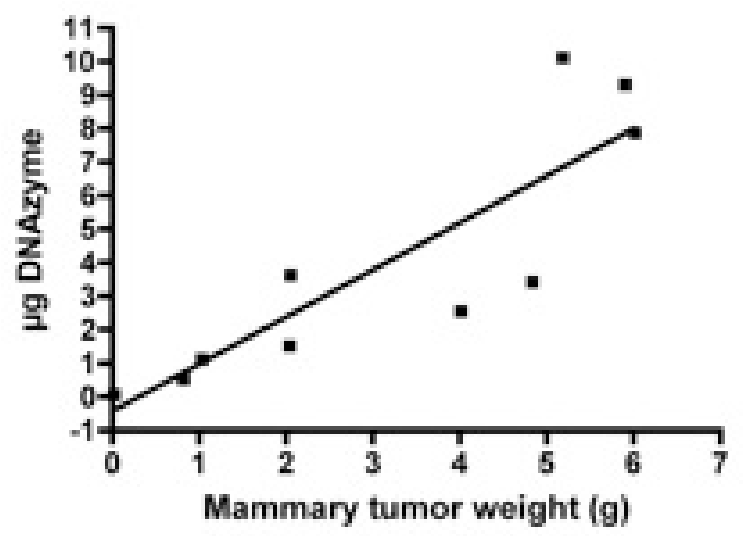

Figure 3-4. Distribution of $\left[{ }^{35}\right.$ S]-DNAzyme in MMTV-PyMT mammary tumors.

Total tumor burden was measured in grams and the total $\mu \mathrm{g}$ DNAzyme found in tumors were calculated. DNAzyme injected into mice bearing tumors of varying sizes show a proportional correlation between tumor size (all tumors combined per mouse) and DNAzyme distribution ( $\left.\mathrm{Y}=1.4045 \mathrm{x}-0.4159, \mathrm{R}^{2}=0.7764\right)$.

Table 3-4. Rate of $\left[{ }^{35}\right.$ S]-DNAzyme initial and final clearance in mice with mammary tumors.

\begin{tabular}{lcc}
\hline Tissue & $\begin{array}{c}\text { Initial clearance }^{\mathrm{a}} \\
\mu \mathrm{g} \text { DNAzyme/g tissue/h }\end{array}$ & $\begin{array}{c}\text { Final clearance }^{\mathrm{b}} \\
\mu \mathrm{g} \text { DNAzyme/g tissue/h }\end{array}$ \\
\hline Liver & 0.434 & 0.0052 \\
Heart & 0.277 & 0.0082 \\
Spleen & 0.653 & 0.0278 \\
Kidney & 0.426 & 0.0063 \\
Lung & 0.134 & 0.0024 \\
Mammary & 0.068 & 0.0128 \\
Tumor & 1.507 & 0.0569 \\
Blood & \\
\hline &
\end{tabular}




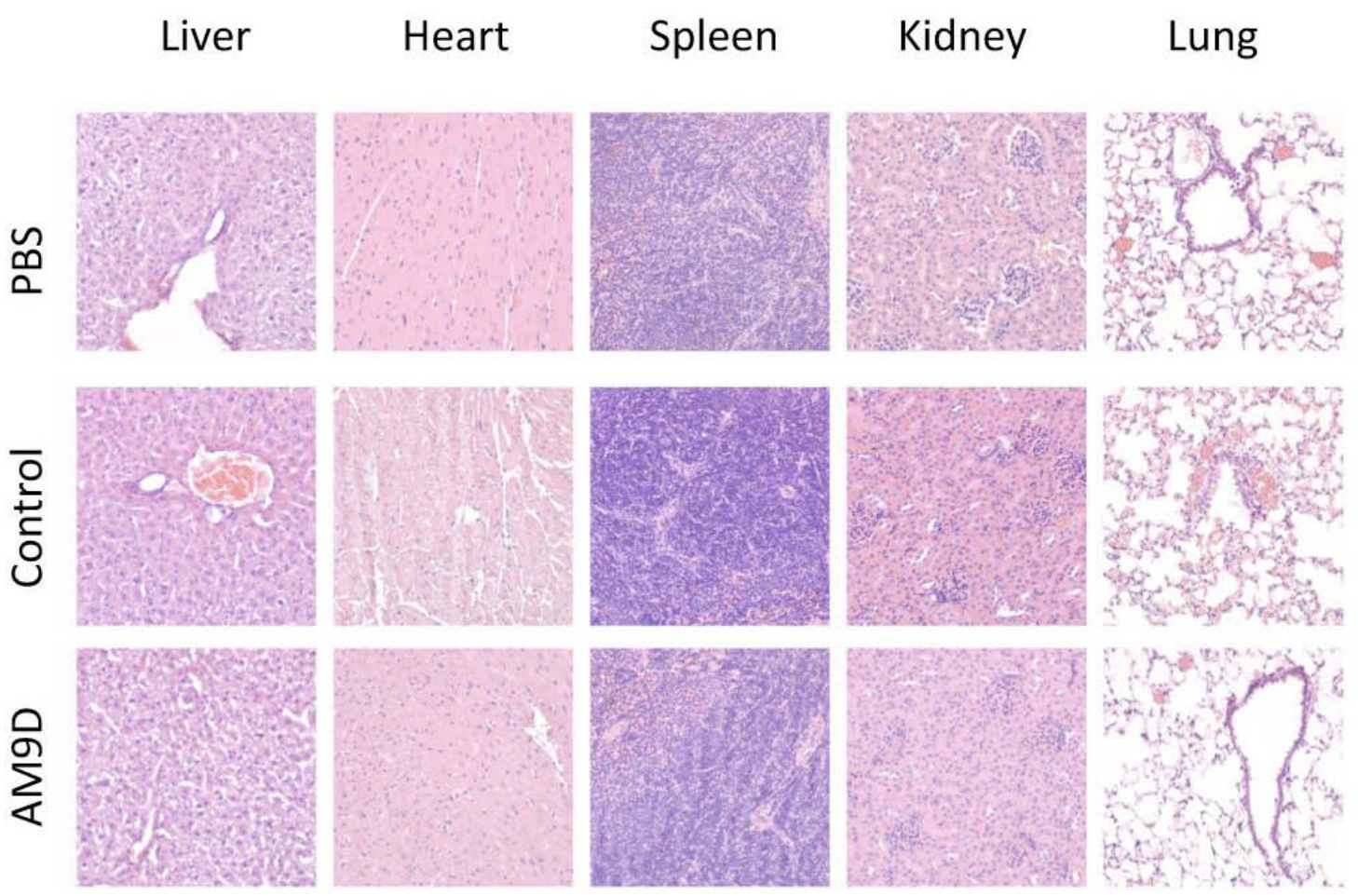

Figure 3-5. Pathology of organs from mice injected with AM9D, control DNAzyme, or PBS.

Mice injected with PBS, or various concentrations of control or AM9D showed no difference in organ pathology. The tissues displayed were extracted from mice that received the highest dose $(75 \mathrm{mg} / \mathrm{kg}$ of AM9D and control DNAzyme; 400x magnification). 
Recently, DNAzymes have emerged as novel, highly selective inhibitors of gene expression. Although they have yet to be used in clinical trials, reports of studies demonstrating the efficacy of DNAzyme based cancer therapies are beginning to emerge [50]. However, thus far, all of the preclinical studies testing the effect of DNAzyme on tumor growth were via intratumoral or subcutaneous injections. In spite of the fact that tumor growth is an important factor in cancer progression, metastasis is ultimately the determining factor for cancer survival for many types of cancer [70-72]. Thus, while intratumoral injections can show promise as to the DNAzymes specificity to its target and future therapeutic capabilities, it is not feasible in humans. To advance the therapeutic potential of DNAzyme toward clinical trial, it is necessary to design an anti-metastatic DNAzyme and demonstrate its anti-metastatic potential based on its systemic distribution, safety and efficacy.

Expression of MMP-9, by tumor and stroma cells has been shown in breast cancer patients [73] and is one of the most important factors for metastatic behavior of tumor cells $[23,54,74]$. MMP-9 degrades type IV collagen, one of the most abundant collagens in the ECM $[11,75]$ and is involved in cell proliferation, angiogenesis, and apoptosis [9, $10,30]$. Increasing evidence suggests that MMPs contribute to the formation of a microenvironment that promotes tumor growth during early stages of tumorigenesis. Our observation that AM9D treatment decreased MMP-9 production (Figure 1-3c and 2-4) and reduced invasive behavior of human MDA-MB-231 cells (Figure 1-3d) suggested that AM9D has a great potential as an anti tumorigenic/metastatic agent. Thus, to utilize anti-MMP-9 DNAzyme (AM9D) as a therapeutic agent in breast cancer preclinical and clinical studies, healthy and MMTV-PyMT transgenic mouse model bearing early to late stage tumors were used to test the distribution of AM9D to different organs and mammary tumors. The order of percentage accumulation of DNAzyme in healthy mice in different organs was: blood $>$ liver $>$ kidney $>$ lung $>$ spleen $>$ heart. In addition to these organs, $\left[{ }^{35} \mathrm{~S}\right]$-DNAzyme was also distributed to brain, intestines, stomach, and pancreas (Figure 3-2). Approximately, 43\% of the delivered dosage of [ $\left.{ }^{35} \mathrm{~S}\right]$-DNAzyme was cleared from the system via feces and urine over a period of $72 \mathrm{~h}$ (Figure 3-1b). This data is consistent with Agrawal et al.'s observation that $40 \%$ of intravenously administered anti-sense phosphorothioate oligonucleotides complementary to HIV RNA

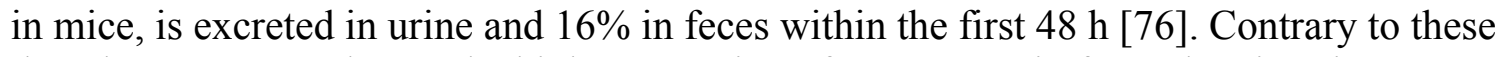
data, however, we observed a higher excretion of DNAzyme in feces than in urine (Figure 3-1b).

Interestingly, when $\left[{ }^{35} \mathrm{~S}\right]-\mathrm{DNAzyme}$ was administered to MMTV-PyMT transgenic mice the amount of DNAzyme accumulated in mammary tumors $2 \mathrm{~h}$ post injection was $0.6 \%$ and $0.2 \%$ higher than in either blood or liver, respectively, and its rate of initial clearance from mammary tissue was slower than the other organs (Tables 3-3 and 3-4). The amount of DNAzyme accumulated in mammary tumors was proportional to the tumor burden (Figure 3-4), suggesting a favorable therapeutic outcome. This is expected considering that mammary tumors can be highly vascularized [77].

DNAzyme administered systemically is safe and at $75 \mathrm{mg} / \mathrm{kg}$ of body weight caused no observable mortality or organ toxicity in mice. Pathological studies did not 
reveal any evidence of acute toxicity, mitogenesis, or cell death, local or widespread in any organs examined (Figure 3-5), contrary to those described for other oligonucleotides [78]. Several investigators have reported hepatocyte toxicity and necrosis $[76,78]$ and renal tubular structural perturbations [76] with oligonucleotide administration as low as $20 \mathrm{mg} / \mathrm{kg}$ [78] and as high as $30 \mathrm{mg} / \mathrm{kg} /$ day over 14 days (total $420 \mathrm{mg} / \mathrm{kg}$ ) [76]. This however, was not observed in this study. It should be noted that the delivered dosage of AM9D for this study $(75 \mathrm{mg} / \mathrm{kg}$ ) was much higher than those used in the other DNAzyme studies [78], however, lower than some studies which showed hepatocyte toxicity [76].

In conclusion, systemic distribution and safety/toxicity studies revealed that the naked AM9D is non-toxic when systemically administered, and has favorable pharmacological properties with respect to intravenous administration and tissue distribution. Most importantly, mammary tumors can take up the naked DNAzyme. The amount of DNAzyme accumulates in the mammary gland is higher and its rate of clearance is slower than any other organs tested. These factors may permit the development of DNAzyme as a cancer therapeutic agent with much improved toxicity profiles as compared with conventional drugs. 


\section{CHAPTER 4. AM9D TREATMENT OF EXPERIMENTAL METASTASIS}

\section{INTRODUCTION}

The role of MMP-9 in cancer metastasis has been widely researched. The treatment of DU145 prostate cancer cells with curcumin, an anti-metastatic derivative from tumeric, has been shown to decrease the levels of MMP-2 and -9 and lead to a decrease in tumor volume [79]. Curcumin treatment has also been shown to alter the invasive and metastatic properties of MCF10A human breast epithelial cells [80] and decrease metastasis to lung in a human breast cancer xenograft model [81] by decreasing the levels of MMP-9 and COX-2. According to Eiseler, et al., highly invasive breast cancer human tissue samples, regardless of stage and progesterone or estrogen dependence, were shown to have reduced Protein Kinase D1 (PKD1) expression in greater than $95 \%$ of the tumor samples compared to normal breast tissue [82]. Furthermore, the invasiveness of MDA-MB-231 cells was reduced by the re-expression of PKD1, which was shown to negatively regulate MMP-9, the mainly expressed MMP in MDA-MB-231 cells. [82]. Thus, PKD1 regulates breast cancer cell invasion through regulation of the expression of MMP-9. Furthermore, Chen et al. provided evidence that the presence of increased levels of MMP-9 in integrin alpha1-null mice enhanced the number of tumors on lung but these tumors were smaller compared to lung tumors in WT counterparts [83]. They also showed that inhibition of MMP-9 by doxycyclin in these alpha1-null mice led to reduced number of lung colonies but bigger tumors were observed. This was because reduced MMP-9 plasma levels led to decreased generation of angiostatin, an anti-angiogenic molecule. Thus, while an MMP-9 inhibitor may be useful in treating tumor cell migration, invasion, and metastasis it may adversely increase growth and vascularization of tumors intravenously introduced to lung.

In previous Chapters of this body of work we have shown that, in accordance with the findings of Eiseler, et al. [82], down-regulation of MMP-9 by AM9D decreases the invasive potential of MDA-MB-231 human breast cancer cells. We have also shown the presence of MMP-9 in MMTV-PyMT mammary tumors (Figure 2-2) and presented evidence that MMP-9 expression is significantly lower in AM9D treated tumors compared to control (Figure 2-5), leading to a reduction in final tumor load (Figure 2-4). Furthermore, AM9D when injected via the tail vein of normal and MMTV-PyMT mice was shown to be distributed to all major organs including lung and was tested to be safe up to $75 \mathrm{mg} / \mathrm{kg}$ of body weight $(1500 \mu \mathrm{g} / 100 \mu \mathrm{l}$ of PBS).

MMP-9 is involved in tumor cell extravasation and colonization [84-87]. Thus, down-regulation of MMP-9 by intravenous administration of AM9D was expected to inhibit the tumor cells from participating in extravasation and seeding of the tumor cells in the lungs. Consequently, the number of lung colonies will be reduced and further lead to increased survival of mice compared to control treated counterparts.

Using an experimental lung metastasis animal model, we have shown that both AM9D and control DNAzyme treatment were equally effective in inhibiting early stage 
experimental metastasis. However, mice treated with these two cohorts did not show statistically significant overall increased survival.

\section{MATERIALS AND METHODS}

\section{Establishing eIF1 alpha-Luciferase2 Mammary Tumor Epithelial Cells (luc-MTECs) ${ }^{1}$}

Several late stage mammary tumors $\left(>500 \mathrm{~mm}^{3}\right)$ were isolated from Hifla DF; PyMT + females. Tumors were chopped with scalpels then with razor blades and the paste digested with type III collagenase $(1 \mathrm{mg} / \mathrm{ml}$, Worthington Biochemical, Lakewood, NJ) in RPMI media containing 5\% FBS ( $5 \mathrm{ml} / \mathrm{g}$ tissue) for 2 hours at $37^{\circ} \mathrm{C}$. Cells were pelleted at $1100 \mathrm{rpm}$ and then washed 4 times with digestion buffer. Cells were plated with F12 medium containing $5 \mu \mathrm{g} / \mathrm{ml}$ insulin, $2 \mu \mathrm{g} / \mathrm{ml}$ hydrocortisone, $5 \mathrm{ng} / \mathrm{ml} \mathrm{EGF}$, $50 \mu \mathrm{g} / \mathrm{ml}$ gentamycin, $100 \mathrm{U}$ penicillin/streptomycin and $10 \% \mathrm{FCS}$, as described by Rijnkels, M., et al. [88]. After 48-72 h, the plating medium was switched to complete mammary cell growth medium (DMEM/F12, 5\% FBS, $5 \mathrm{mg} / \mathrm{ml}$ insulin, $10 \mathrm{ng} / \mathrm{ml}$ EGF). A subset of MTECs was subsequently weaned to reduced growth factor media (DMEM/F12 + 2\% FBS or DMEM/F12 + 0.5\% FBS). For sub-cultivation, cells were rinsed twice with Puck's A saline, then incubated for up to 60 min at $37^{\circ} \mathrm{C}$ in a $3: 1$ solution of dispase II/0.025\% trypsin reconstituted in Puck's A saline. No EDTA was utilized for subcultivating cells, as we found that treating cells with trypsin-EDTA changed tumor cell morphology from an epithelial (cuboidal) to a mesenchymal (spindle) appearance. The luciferase expressing MTEC cells were generated by transducing monolayer cultured WT cells with pEILP (eIF1alpha-Luciferase2-IRES-puromycin, Junming Yue, UTHSC Viral Vector Core) lentivirus particles at 10 m.o.i. For 48 h hours, followed by washing and immediate selection with puromycin to establish pools of stable transfectants. All cells were passaged fewer than 30 times and media was routinely tested for mycoplasma using the MycoAlert kit (Lonza, Basel, Switzerland).

\section{Animals}

All animal studies were performed in accordance with the guidelines established by the Animal Care and Use Committee at The University of Tennessee Health Science Center. Fifty-six 8-week-old female FVB mice were intravenously injected with luc-MTECs $\left(1 \times 10^{6}\right.$ cells) resuspended in $100 \mu$ of sterile PBS containing $0.9 \mathrm{mM} \mathrm{CaCl}_{2}$ and $0.493 \mathrm{mM} \mathrm{MgCl}_{2}$. The injected animals were then divided into two groups. Group I contained 30 mice and group II contained 26 mice.

\footnotetext{
${ }^{1}$ Manuscript in preparation: Schawb, L., Peacock, D., Cushing, R., Majumdar, D., Ingels, J. and Seagroves, T., Hypoxia Inducible Factor-1a Promotes Primary Tumor Growth and Tumor-Initiating Cell Activity in the MMTV-PyMT Model of Breast Cancer.
} 
Group 1. To determine the effect of AM9D treatment on early stage of metastasis, mice in this group were divided into 3 sub-groups of 10 mice each. On day 1-post MTEC injections the mice received weekly injections of PBS (100 $\mu \mathrm{l}$; subgroup 1a), AM9D (1500 $\mu \mathrm{g} / 100 \mu \mathrm{l}$ PBS; subgroup 1b) or control DNAzyme (1500 $\mu \mathrm{g} / 100 \mu \mathrm{l}$ PBS; subgroup 1c). All animals were anesthetized with isoflurane before each injection. Mice received a total of 3 treatments on days 1, 7, and 14 post tumor cells injections and were euthanized one week after the last DNAzyme treatment (Day 21). Mice were weighed weekly and observed for any signs of lethargy (i.e. weight loss, trouble breathing, not grooming) during treatment. Xenogen Bio-imager was used to monitor the development of lung nodules on days 14 and 21 post tumor cell inoculation. The luciferase positive cells were identified in lungs on day 21-post tumor inoculation at which time treatments were stopped and animals were sacrificed. Their lungs were inflated with $4 \%$ paraformaldehyde by cannulation of the trachea, excised, and photographed for any visual macro metastasis. Lungs were then fixed in $4 \%$ paraformaldehyde overnight. Paraffin embedded, 4 micron frozen sections were prepared and analyzed by Dr. Stanley Kosanke (Pathologist, University of Oklahoma). The lung sections were analyzed for the presence of macro and micro lung metastasis. At necropsy, liver, heart, brain, kidney, and spleen were collected and fixed in 4\% paraformaldehyde, impregnated with $25 \%$ sucrose that acts as a cryoprotectant, and were processed for histopathological evaluation (standard light microscopic examination of hematoxylin and eosin-stained tissue slides).

Group 2. To determine the effect of AM9D treatment on survival of the animals with lung nodules, the MTEC inoculated mice were divided into 3 subgroups of 8-9 mice each. The mice in this group received weekly injections of PBS (100 $\mu$; subgroup 2a; $\mathrm{n}=8)$, AM9D (1500 $\mu \mathrm{g} / 100 \mu \mathrm{l}$ PBS; subgroup 2b; $\mathrm{n}=9)$ or control DNAzyme (1500 $\mu \mathrm{g} / 100 \mu \mathrm{l}$ PBS; subgroup 2c; $\mathrm{n}=9$ ) starting from the first day post MTEC injection. Mice were weighed weekly and monitored for any signs of lethargy (i.e. weight loss, trouble breathing, not grooming). The animals were then sacrificed when they lost $\sim 20 \%$ body weight, or if they had trouble breathing, were panting and not grooming. The maximum treatment received by the last surviving animals was 9 injections and these animals were euthanized one week after the last treatment. Lungs were excised, photographed, weighed and fixed in $4 \%$ paraformaldehyde, as stated above.

\section{RESULTS AND DISCUSSION}

\section{Effect of AM9D Treatment on Early Stage Experimental Metastasis}

The efficacy of AM9D treatment in inhibiting and/or reducing early stage experimental metastasis was tested by treating luciferase labeled MTEC (luc-MTEC) inoculated FVB mice with PBS, $1500 \mu \mathrm{g}$ of either AM9D or control DNAzyme, once a week for three weeks. The animals were monitored weekly for the presence of luc-MTEC in lung by Xenogen. At the earliest detection of MTEC in the lung (twenty one days after the initial treatment), animals were sacrificed. Luc-MTEC injected via tail vein of the 
animals were able to metastasize to and colonize in the lungs (Figure 4-1). The average number of gross macro metastases observed in AM9D $(1.1 \pm 1.5)$ and control DNAzyme treated animals $(1.6 \pm 3)$ were, however lower than that of PBS treated groups $(20.25 \pm 31.3$; Figure 4-2). This data suggests that AM9D and control DNAzyme treatment were equally effective in inhibiting metastasis and lung colonization. However, we cannot ignore the large standard deviation in the PBS control cohort due to the variability of 0 to more than 70 surface nodules observed at this stage of experimental metastasis. The analysis of macro metastasis in sectioned lung tissue revealed that AM9D therapy retarded lung metastasis by $56 \%$ compared to PBS, however, control DNAzyme treatment was $72 \%$ and $88 \%$ more effective in reducing lung macro metastasis than both AM9D and PBS treatments, respectively (Figure 4-2b).

The analysis of micro metastasis in sectioned lung tissues also revealed that control DNAzyme therapy retarded lung micro metastasis by $34 \%$ and $24 \%$ compared to AM9D and PBS treatment, respectively (Figure 4-2c). As mentioned above, a few mice in each group did not show any signs of gross macro metastasis (Figure 4-1a). However, analysis of lung tissue slices revealed that majority of the animals developed lung nodules, irrespective of lack of gross lung macro metastasis. The percentages of control DNAzyme, AM9D, and PBS treated animals that did not show any gross macro metastasis were $57 \%, 50 \%$, and $37 \%$, respectively. These data suggest that AM9D and control DNAzyme therapy are equally affective in reducing lung metastasis. These data also suggest that although AM9D down-regulates MMP-9 protein production in vitro and in vivo, both AM9D and control DNAzyme may have a sequence-related off target effect.

Bacterial DNA containing unmethylated $\mathrm{CpG}$ dideoxynucleotide sequence motifs have been shown to stimulate immune cells and this stimulatory effect can be mimicked

a.

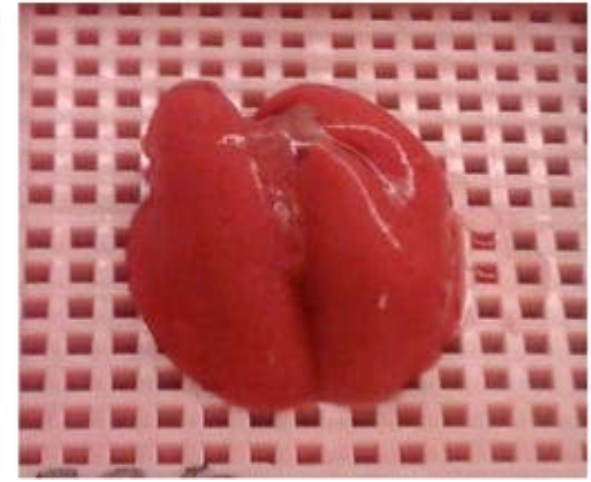

b.

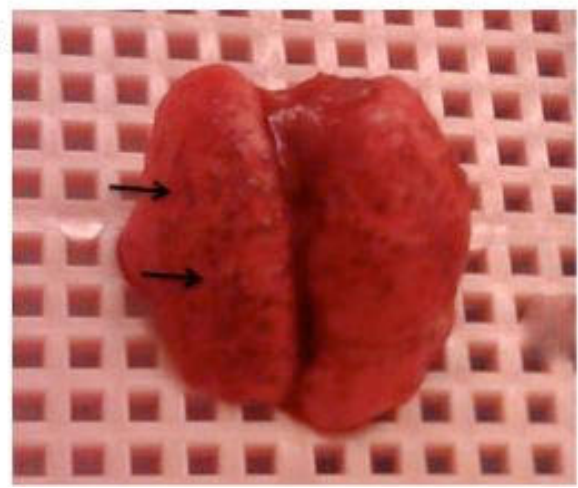

Figure 4-1. Representative lungs images extracted from two mice in the PBS treated group at early stage experimental metastasis.

PBS treated mice had (a) as few as no macromets to (b) greater than 70 macromets as visualized by gross tissue analysis. Arrows in (b) are pointing to macromets. 
a.

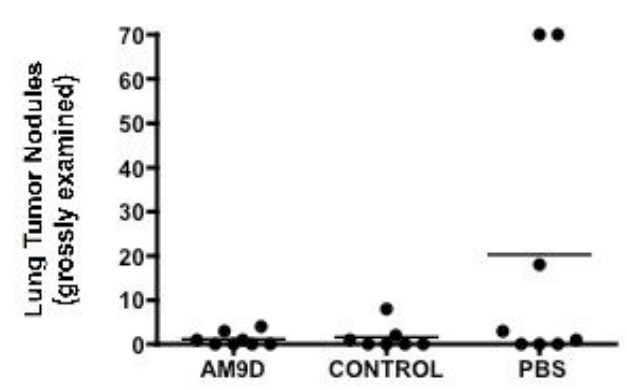

c.

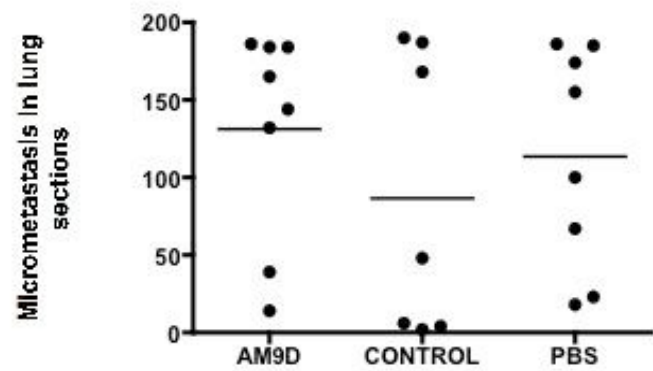

b.

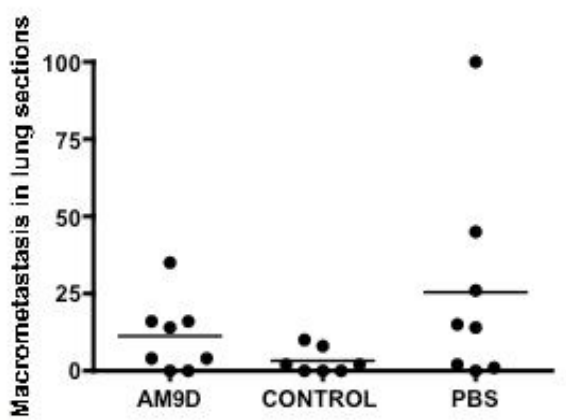

Figure 4-2. Macro and micro metastasis in lungs from early stage experimental metastasis.

Luc-MTEC inoculated Mice were treated weekly with PBS or $1500 \mu \mathrm{g}$ of either AM9D or control DNAzyme for 3 weeks and their lungs were analyzed grossly for (a) macro metastasis $(\mathrm{p}=0.092)$ and a section from each lung were analyzed for (b) macro metastasis $(\mathrm{p}=0.146)$ and (c) micro metastasis $(\mathrm{p}=0.538)$. 
by synthetic $\mathrm{CpG}$ containing oligodeoxynucleotide (CpG-ODN) [89]. CpG motifs have been shown in literature to activate Toll-like receptor 9 (TLR9) and lead to the activation of macrophages, dendritic cells, and B cells [89,90]. This activation is important for the treatment of cancer. $\mathrm{CpG}$ monotherapy is sufficient for inducing T-cell-mediated rejection of established tumors [91]. For these reasons, synthetic CpG-ODNs are currently in human clinical trials for the treatment of cancer [89]. In addition, CpG's that contain a purine two bases ahead of or a pyrimidine two bases after the CG nucleotides have been shown to be more stimulatory compared to CpG-ODNs that do not [90]. The sequences of AM9D and the control DNAzyme each contain two CpG motifs making them possible functional CpG-ODNs (Figure 4-3). The presence of macrophages and dendritic cells in lungs of animals treated with AM9D and control DNAzyme should attest to this hypothesis. Macrophages and dendritic cells were not observed in lungs 7 days after injection, however, lungs should be observed at a shorter time after injection.

AM9D was well tolerated in this early stage experimental metastasis mouse model. Body weights of animals in all groups were similar throughout the 3 weeks of treatment and at sacrifice (Figure 4-4). No obvious adverse effects, including swelling of joints and difficulty in walking, were observed in DNAzyme-treated mice. Furthermore, analysis of organs from mice exposed to weekly injections of AM9D or control DNAzyme for 10 weeks showed no toxic effects (Figure 4-5).

\section{Effect of Long Term AM9D Treatment on Lung Tumor Load in Experimental Metastasis and on Survival}

The efficacy of long term AM9D therapy to reduce lung tumor load and increase survival was tested by intravenously injecting PBS or $1500 \mu \mathrm{g}$ of AM9D or control DNAzyme into 8 week old female FVB mice previously injected with $1 \times 10^{6}$ luc-MTECs, once a week until mice showed signs of lethargy $(\sim 20 \%$ weight loss, trouble breathing/panting, and/or not grooming). The animals were then sacrificed; their lungs were excised, weighed, and photographed. Mice were observed bi-weekly to determine changes in health and weighed weekly (Figure 4-6a). The lungs of all animals sacrificed due illness were completely covered with macro metastasis and no differences between the wet weight of lungs extracted from AM9D and control treated animals was observed (Figure 4-6b). Lungs in the PBS treated cohort showed a slightly elevated lung tumor burden (calculated by dividing lung weight by body weight; Figure 4-6c) compared to control DNAzyme and AM9D treated mice. Mice in the AM9D treated group displayed increased signs of progression-free survival between analysis points 34 to 42 days, however there was no significant extended survival compared to the control treated groups (log rank test, $\mathrm{p}>0.05$; Figure $4-7$ ). This data is consistent with the results obtained from Marimastat clinical trial studies demonstrating that progression-free survival significantly increased in the patients with inoperable gastric cancer using Marimastat, but overall survival did not improve. In subgroups of patients with prior chemotherapy and of patients without distant metastases, overall survival was significantly better in the Marimastat-treated group [45]. These data suggest that AM9D 


\section{AM9D: 5'- GTGGTGCCAGGCTAGCTACAACGATTGAGGTCG -3' \\ Control: 5'- CTAGTCAGCGGCTAGCTACAACGATAAGCTGCT -3'}

\section{Figure 4-3. CpG regions in AM9D and control DNAzyme.}

AM9D and control DNAzyme both contain two CpG regions (red). In each of these sequences one of the $\mathrm{CpG}$ regions has a pyrimidine 2 spaces after (orange). In the AM9D sequence there is a purine 2 spaces before the $\mathrm{CpG}$ region (blue).

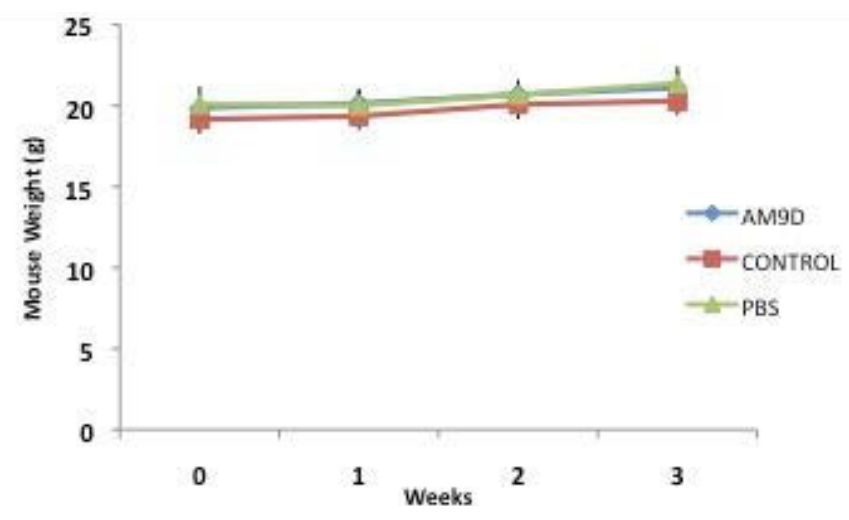

Figure 4-4. Mouse body weights measured during experimental metastasis

The body weights of all the experimental animals were maintained during the course of the treatment (3 weeks) and no difference in body weights was observed between PBS (green), AM9D (blue) or control DNAzyme (red) treatment groups. 


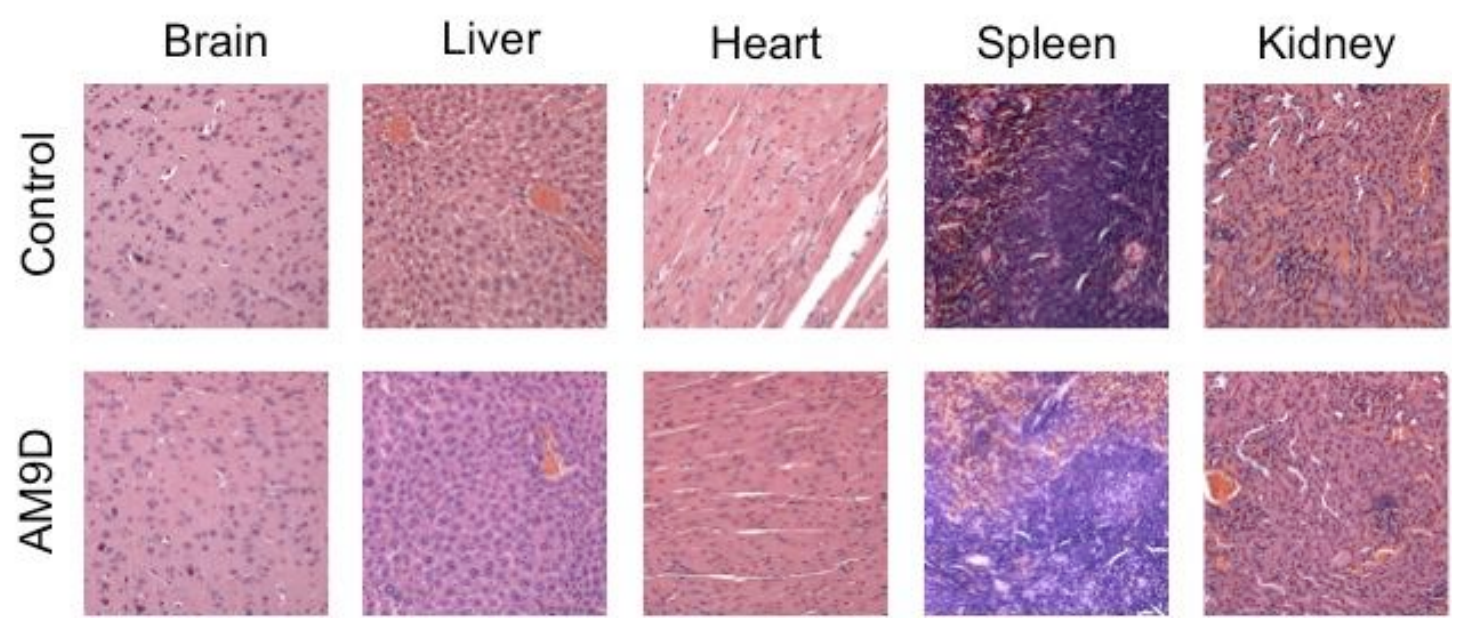

Figure 4-5. Analysis of mice organ pathology.

Mice intravenously injected with luc-MTEC and treated with once weekly injections of $1500 \mu \mathrm{g}$ of either AM9D or control DNAzyme showed no difference in organ pathology. Representative images of various organs of AM9D and control DNAzyme treated mice shown (400x magnification). 
a.

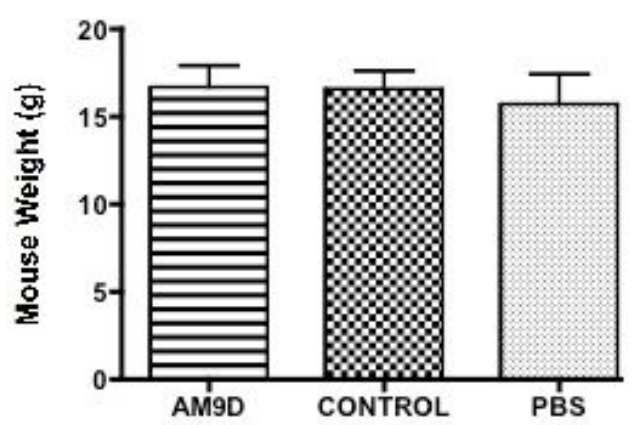

C.

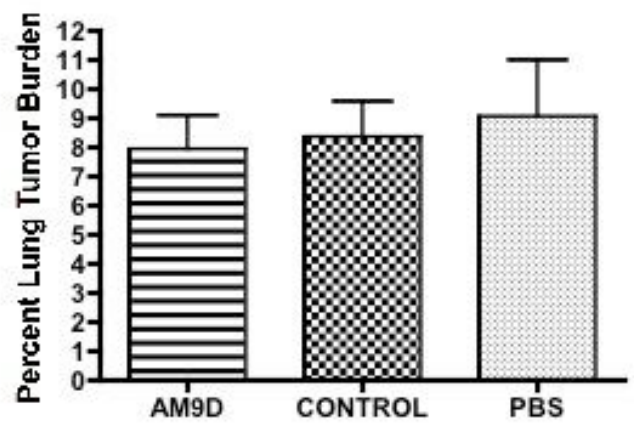

b.

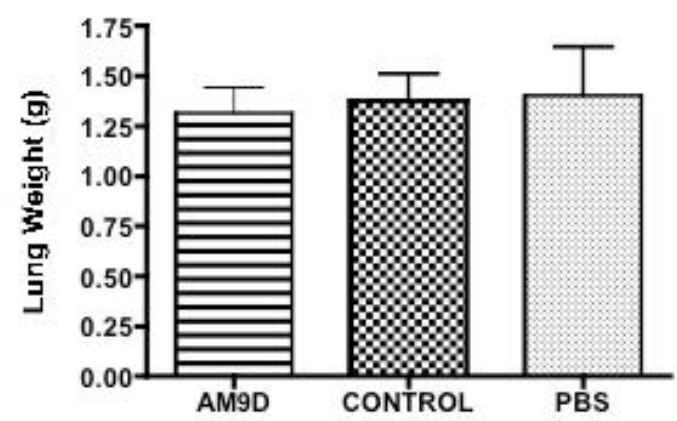

Figure 4-6. Effect of various treatments on mice lung tumor burden.

(a) Mice treated with once weekly injections of PBS or $1500 \mu \mathrm{g}$ of either AM9D or control DNAzyme were weighed on their final day of survival. Mice lungs were weighed upon excision (b) and their total lung tumor burden (c) was calculated. Weights of mice and lungs and calculation of lung tumor burden did not show a significant difference between AM9D, control DNAzyme, and PBS treated groups ( $p>0.05$; error bars show standard deviation). 


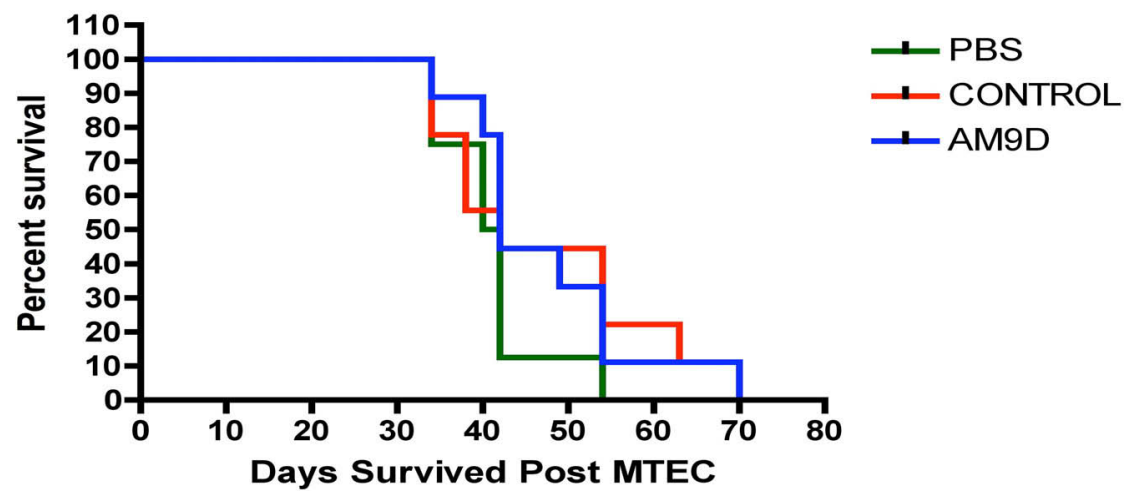

\section{Figure 4-7. Survival curve.}

Survival curve of mice injected with $1 \times 10^{6}$ luc-MTEC and treated with weekly injections of $100 \mu \mathrm{l}$ PBS (green), $1500 \mu \mathrm{g}$ AM9D (blue) or control DNAzyme (red). Log Rank Test $\mathrm{p}=0.5$.

can be used as an adjuvant to primary surgery in order to blunt tumor growth and treat metastasis.

The lack of effect of long term AM9D treatment on tumor growth and overall survival in this experimental metastasis model may be due to time of AM9D delivery, frequency of delivery, mouse strain, pro-tumorigenic effects of MMP-9 downregulation, or a combination of these effects.

Time of delivery and/or frequency of delivery of AM9D may be responsible for the lack of significant decreased tumor burden in AM9D treated mice compared to control cohorts. Shibue, et al., have shown that D2 cells extravasate into lungs between 3-48 $\mathrm{h}$ after tail vein injection [92]. If MMTV-PyMT MTECs mimic this behavior, DNAzyme treatment may have been administered too late to block extravasation and colonization. Chen, et al., showed that treatment of CT26 (colon carcinoma cells) inoculated mice with $40 \mathrm{mg} / \mathrm{kg}$ /day of doxycyclin starting immediately or 2-weeks after tumor cell injections resulted in fewer but larger and more vascularized lung tumors. On the other hand, when therapy started at the time of tumor injections, mice had fewer lung tumors than mice treated 2-weeks after injection of colon carcinoma cells [83]. This suggests that the time and/or the frequency of the treatment have significant effect on development of lung experimental metastasis. In both early stage metastasis and long term AM9D treatment experimental groups, DNAzyme treatment began one day after injection of MTEC tumor cells and continued once weekly. The data presented in Chapter 3 (Distribution, Clearance, and Cytotoxicity of DNAzyme) indicated that DNAzyme administrated intravenously is cleared from the lung within $24 \mathrm{~h}$, but has an extended clearance from mammary tumors. Therefore, while weekly intratumoral injections may have been effective in reducing tumor growth (Figure 2-4), it may not be 
sufficient for treatment of lung metastasis. If the observed lack of significant effect of AM9D therapy on survival of animals with lung metastasis is due to time of initial treatment or frequency of drug delivery, future experiments with DNAzyme treatment should begin in advance to or at the same time as tumor cell inoculations and delivered more frequently. We have observed, however that bi weekly injections (100 $\mu 1 /$ injection), via tail vein results in hardening of the tail and necrosis. Therefore, the use of a different avenue of DNAzyme delivery is a necessity. Jugular vein may be the most efficient route for delivery of AM9D. This would allow for daily administration of $75 \mathrm{mg} / \mathrm{kg}$ AM9D, which would result in a total delivery of $525 \mathrm{mg}$ DNAzyme $/ \mathrm{kg} /$ week.

As mentioned above, Chen, et al., showed that intravenous administration of $40 \mathrm{mg} / \mathrm{kg} /$ day of doxycyclin into animals inoculated with CT26 (colon carcinoma cells) immediately or 2-weeks after tumor cell injections resulted in fewer but larger and more vascularized lung tumors. The increased vascularization was attributed to decreased production of angiostatin by MMP-9 [83]. Thus, MMP-9 inhibitors may have a null or pro-tumorigenic effect when administered intravenously. If anti-MMP-9 DNAzyme (AM9D) therapy leads to (1) decreased MMP-9 protein, (2) decreased anti-angiogenic factors, and (3) subsequent increased vascularization, then it is expected that AM9D treated animals develop larger lung tumors and have a decreased survival rate than the control DNAzyme and PBS treated cohorts. This is contrary to our observation that the AM9D treated mice showed increased signs of progression-free survival between analysis points 34 to 42 days compared to control cohorts (Figure 4-7). Hence, while AM9D did not show extended survival compared to control treated animals, it also did not show detrimental effects such as larger tumors or decreased survival. Thereby, the therapeutic effect of AM9D on experimental metastasis should continue to be evaluated with several adjustments in treatment regimen.

Another possibility for the observed lack of significant outcome of AM9D therapy on lung experimental metastasis may be related to the mouse strain used in these studies. Martin et al. showed that the treatment outcome of a gelatinase inhibitor, SB-3CT, on experimental metastasis is strain dependent [68]. In their experiments, luciferase-labeled 17L3C cells (MTEC from MMTV-PyMT mice) were injected via tail vein into $\mathrm{C} 57 \mathrm{BL} / 6$ and $\mathrm{FVB} / \mathrm{N}$ mice followed by daily injections of $50 \mathrm{mg} / \mathrm{kg}$ of the drug SB-3CT or vehicle for 14 days. They found that SB-3CT therapy resulted in a significant decrease in tumor growth in $\mathrm{C} 57 \mathrm{BL} / 6$ mice, while mice on a $\mathrm{FVB} / \mathrm{N}$ background showed enhanced tumor growth according to luciferase signal upon treatment. The mice utilized in our experimental metastasis model are FVB/N, the same strain that showed enhanced tumor growth when treated with a gelatinase inhibitor in the Martin, et al. publication [68]. These data suggest that the mice with different genetic backgrounds should be used to assess the significance of genetics on efficacy of AM9D in experimental metastasis.

In Chapter 2, I have shown that AM9D is able to reduce tumor growth by up to $50 \%$. In order to determine if AM9D can be used in the treatment of breast cancer metastasis, the determining factor in breast cancer patient survival, the aforementioned experiments (including changes in time and frequency of treatment) must be performed. 


\section{CHAPTER 5. MMP-9 TRESSPASSES ON MMP-1'S TURF}

\section{INTRODUCTION}

High expression levels of a variety of Matrix Metalloproteinases (MMPs), including MMP-1 and MMP-9 have been reported to be associated with progression and poor prognosis of breast cancer [93-95]. MMP-1 and -9 degrade type I and type IV collagen, respectively, two of the most abundant collagens in the ECM [11], making both enzymes important in cancer development, proliferation, and angiogenesis through their involvement in ECM degradation and cytokine release and activation [10,11]. With the use of a transgenic multistage carcinogenic mouse model, MMP-9 has been shown to be up regulated in angiogenic islets, leading to an increase in the bioavailability of VEGF [30]. MMP-1 has been shown to be one of the most highly over expressed genes in bone metastasis [7]. In addition, researchers have shown that the presence of MMP-1 in the stromal-tumor microenvironment plays a role in altering the behavior of tumor cells by binding to and activating PAR1 and facilitating invasion $[5,96]$. We have shown that down regulation of MMP-9 by AM9D inhibits the invasion of MDA-MB-231 cells (Chapter 1, Figure 1-3d). Thus, inhibition of MMP-1 and -9 expression can be used as a therapeutic modality to decrease growth and invasion of tumor cells.

Although MMP-1 and -9 have different substrate specificity, they are both composed of three major domains: $\mathrm{NH}_{2}$-terminal pro-domain, central catalytic domain, and $\mathrm{COOH}$-terminal hemopexin-like domain connected to catalytic domain via a proline-rich hinge region (Figures 1-1 and 5-1). The hinge region of MMP-9 is extended and is similar to Type V collagen. During protein activation, the pro-domain is cleaved [97]. MMP-9 has an additional domain known as the gelatin binding domain composed of 3 homology fibronectin-type II modules of 58 amino acids inserted into the catalytic domain (Figure 5-1b) [98]. We have shown that this domain is responsible for the type V collagen activity of the enzyme [40,99]. The carboxyl-terminal domain of MMP-9 is involved in anchoring the enzyme to CD44 [100-102] and binds to heparin [103]. Although, the role and significance of individual domains in substrate recognition by MMP-9 has been defined, the enzyme reaction mechanism of MMP-9 has yet to be determined.

Latent MMP-9 is a $92 \mathrm{kDa}$ protein that upon activation is converted to an $82 \mathrm{kDa}$ protein that auto-catalytically process to a $68 \mathrm{kDa}$ (fully processed) species [104]. Many cell lines studied contain both $82 \mathrm{kDa}$ and $68 \mathrm{kDa}$ proteins [102, 104]. In an attempt to delineate the complete role of MMP-9 in breast cancer, we isolated and purified the 92 $\mathrm{kDa}$ latent MMP-9 from a highly invasive human breast cancer cell line, MDA-MB-231 and demonstrated that it can be fully processed to a $68 \mathrm{kDa}$ protein upon activation. The amino terminal amino acid analysis of the $68 \mathrm{kDa}$ protein revealed that it has the same $\mathrm{NH}_{3}$-termini, $\mathrm{Met}^{75}$, as the $82 \mathrm{kDa}$ protein, indicating that $68 \mathrm{kDa}$ protein is a carboxyl terminal truncated form of the enzyme. Further characterization of the $68 \mathrm{kDa}$ protein revealed that the enzyme in addition to gelatin and types V and XI collagens, similar to MMP-1, was also able to cleave native triple helical type I collagen. As mentioned 


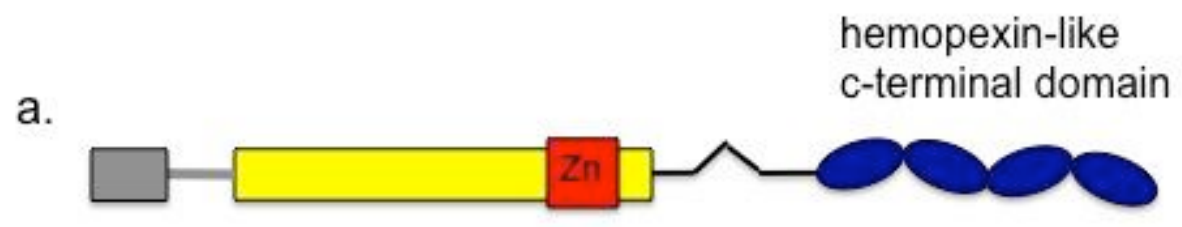

b.

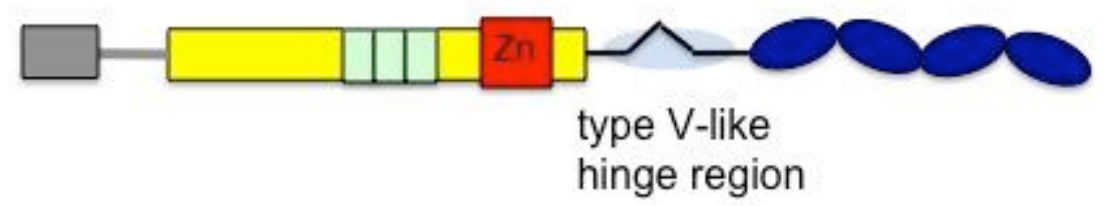

Figure 5-1. Schematic diagram of MMP-1 and -9.

The enzymes share pro-domain (grey), a catalytic domain (yellow and red), a hinge region domain (black jagged line), and a c-terminal hemopexin-like domain (dark blue). The catalytic domain of all MMPs contain a $\mathrm{Zn}$ binding active site (AS) region (red). The hinge region domain is located between the catalytic and c-terminal hemopexin-like domain ( $a$ and $b$ ). MMP-9 contains an extended hinge region, which is often referred to as the type V collagen-like domain (blue oval) due to its Proline rich composition. The catalytic domain of MMP-9 contains 3 homology fibronectin-like repeats, shown in light green (b). 
previously, the $82 \mathrm{kDa}$ protein does not cleave type I collagen as a substrate. These data suggest that MMP-9 plays a dual role in tumor cell invasion; by cleaving type IV collagen, it exposes an HUIV26 cryptic site that is important for angiogenesis and tumor growth [31] and by cleaving type I collagen, the most abundant collagen of the ECM it aids MMP-1 in increasing the proliferation and invasive potential of tumor cells. This dual role that MMP-9 plays in tumorigenesis makes it an even more attractive anti-cancer target. To derive a therapeutic efficient inhibitor specific for MMP-9, it is important to investigate MMP-9 mechanism of substrate specificity.

In this Chapter, the mechanism of type I collagenolysis of $68 \mathrm{kDa}$ MMP-9 was investigated by deletion and alanine scanning site directed mutagenesis techniques.

These studies revealed that presence or the lack of interaction between the side chains of $\mathrm{Glu}^{415}$ in the active site and $\mathrm{Glu}^{447}$ and/or $\mathrm{Arg}^{451}$ located in the hinge region determines specificity of MMP-9 toward type I collagen substrate. The carboxyl-terminal truncated $68 \mathrm{kDa}$ species lacks both $\mathrm{Glu}^{447}$ and $\mathrm{Arg}^{451}$ thus, its active site is flexible and capable of accommodating and consequently cleaving type I collagen. On the other hand, the interaction between $\mathrm{Glu}^{415}$ and $\mathrm{Glu}^{447}$ and/or $\mathrm{Arg}^{451}$ makes the active site of $82 \mathrm{kDa}$ MMP-9 rigid, preventing the enzyme from cleaving type I collagen as a substrate.

\section{MATERIALS AND METHODS}

\section{Mutagenesis}

MMP-9 $\Delta$ 444-502. Type-V like hinge domain (amino acid residues 444-502) was deleted from the full-length MMP-9 cDNA (pETNG) by the polymerase chain reaction (PCR) procedure. The pETNG expression system containing full length MMP-9 cDNA [75] was used as a template for two separate PCR reactions. The 5' primer, 5'-AAG GAG ATA TAC ATA TGC GGG CGA AAC TCC TAG GAA TAG-3' and 3' primer, 5'-GG CAC AGT AGT GGC ACC ATA GAG GTG CCG GAT GCC-3' were used to amplify a $1.55 \mathrm{~kb}$ region of the pETNG corresponding to nucleotides 43 to 1593 and the 5' primer, 5'-GGC ATC CGG CAC CTC TAT GGT / GCC ACT ACT GTG CC-3' and 3' primer, 5'-TCG AGG TCG ACG GTA TCG ATA AGC TTG ATA TCG AAT-3' were used to generate $\mathrm{a} \sim 0.85 \mathrm{~kb}$ PCR product corresponding to nucleotides 1381 to 2400 (1401-1575 looped out) of the MMP-9 sequence. The PCR products were sequenced to verify that the desired deletion mutation is the only mutation generated by PCR. The $1.55 \mathrm{~kb}$ and $0.85 \mathrm{~kb}$ PCR products were used to generate $2.3 \mathrm{~kb}$ MMP-9 cDNA lacking Type-V like hinge domain (nucleotides 1401-1575) by PCR using 5'-AAG GAG ATA TAC ATA TGC GGG CGA AAC TCC TAG GAA TAG-3' and, 5'-TCG AGG TCG ACG GTA TCG ATA AGC TTG ATA TCG AAT-3' as 5' and 3' primers, respectively. The $2.3 \mathrm{~kb}$ PCR product was digested with restriction enzymes $\mathrm{XbaI}$ and SalI and the $2.2 \mathrm{~kb} \mathrm{XbaI} / \mathrm{SalI} \mathrm{cDNA}$ fragment was ligated to NheI/SalI fragment of the expression vector $\mathrm{pET} 12 \mathrm{C}$ for $1 \mathrm{~h}$ at room temperature using T4 DNA Ligase (Promega, Madison, WI) to generate pET $\Delta 444-502$. 
Alanine Scanning Site-Directed Mutations in $\Delta \mathbf{C T}^{(1-456)}$. The following 3' mutagenic primers were used to substitute $\operatorname{Arg}^{445}$ (nucleotides 1405-07), Glu ${ }^{447}$ (nucleotides 1411-13), Glu ${ }^{449}$ (nucleotides 1417-19) or $\mathrm{Arg}^{451}$ (nucleotides 1423-25) with Ala (substituted nucleotide(s) underlined) and generate a stop codon at position 446 (nucleotide 1439) in MMP-9 molecule using pETNG as template: R445A, 5'-GAC TCT AGA CTA TTA GGT GGT GGT TGG AGG CCG TGG CTC AGG TTC AGG GGC AGG ACC ATA-3'; E447A, 5'-CAG GTC GAC TCT AGA CTA TTA GGT GGT GGT TGG AGG CCG TGG CTC AGG TGC AGG GCG AGG-3'; E449A, 5'-CAG GTC GAC TCT AGA CTA TTA GGT GGT GGT TGG AGG CCG TGG CG AGG-3'; R451A, 5'-CAG GTC GAC TCT AGA CTA TTA GGT GGT GGT TGG AGG CGC TGG CTC AGG-3'. All of the above primers were complimentary to nucleotides 1401-1439 in NG and contained a unique XbaI restriction site (TCT AGA) and a STOP codon (TAG) at the 3'end. The 5' primer used in all of the above PCR reactions was 5'-AAG GAG ATA TAC ATA TGC GGG CGA AAC TCC TAG GAA TAG-3'. All the PCR products were sequenced by Dideoxy method [99] and were found to be free of any secondary mutations. The resulting PCR products were digested with XbaI and SalI and ligated to NheI /SalI fragment of pET-12C expression vector.

E415G in $\Delta \mathbf{C T}^{\mathbf{1 - 4 5 6 )}}$. This mutant was generated using two PCR reactions and pETNG as a template. The first PCR used 5' primer, 5'-CAT TCC TCA GTG CCG GGG GCG CTC ATG TAC CC-3' and 3' primer, 5'-CAG GTC GAC TCT AGA CTA TTA GGT GGT GGT TGG AGG-3' to generate a 160 bp PCR fragment containing nucleotides 1300 to 1440 . The above 5' primer contained a unique XbaI restriction site (TCT AGA) and a STOP codon (TAG) at the 3'end. This 160bp fragment was used as a 3 'primer for the second round of PCR using pETNG as a template and 5'-AAG GAG ATA TAC ATA TGC GGG CGA AAC TCC TAG GAA TAG-3' as 5' primer. This generated a $1.4 \mathrm{~kb}$ PCR product (nucleotides 43-1440), which was digested with restriction enzymes NdeI and XbaI and ligated to NdeI-NheI fragment of pET-12c expression vector as described above.

Double Mutant. The $\Delta \mathrm{CT}^{(1-456)}$ E415G/E447A mutant was generated using the previously published Gel. B/E415G mutant in pET-12c as a template [105]. The 5' primer, 5'-AAG GAG ATA TAC ATA TGC GGG CGA AAC TCC TAG GAA TAG-3' and 3' primer, 5'-CAG GTC GAC TCT AGA CTA TTA GGT GGT GGT TGG AGG CCG TGG CTC AGG TGC AGG GCG AGG-3', were used to generate Glu to Ala mutation at position 447 (nucleotides 1341-1343) and a stop codon at position 456 (nucleotide 1439) in MMP-9 E415G mutant protein resulting in $\Delta \mathrm{CT}^{(1-456)}$ truncated mutant with Glu ${ }^{415}$ to Gly and Glu ${ }^{447}$ to Ala substitutions. The PCR product was digested with XbaI and SalI and ligated with NheI and SalI fragment of pET-12c expression vector (Novagen, Rockland, MA).

Enzyme Purification. Plasmids encoding for wild-type and mutant enzymes were introduced into E. coli strain BL21(DE3)(pLysS), the cells bearing the plasmids were induced by IPTG and the latent recombinant proteins were purified on gelatin-agarose affinity columns as described previously [75]. Purified enzymes were dialyzed against 
$50 \mathrm{mM}$ Tris- $\mathrm{HCl}, \mathrm{pH} 7.5,5 \mathrm{mM} \mathrm{CaCl} 2,150 \mathrm{mM} \mathrm{NaCl}$, and $2 \mathrm{mM} \mathrm{ZnCl} 2$ and stored at $-20{ }^{\circ} \mathrm{C}$ until use.

\section{Gelatin Zymography}

The activity of the purified enzymes toward gelatin was assessed by running proteins on a non-reducing SDS/Polyacrylamide gel (8\%) containing $1 \mathrm{mg} / \mathrm{ml}$ gelatin. Protein samples were mixed with the SDS/PAGE sample buffer without reducing agents and were loaded without being boiled. After electrophoresis, the gels were washed twice with $50 \mathrm{mM}$ Tris- $\mathrm{HCl}, 5 \mathrm{mM} \mathrm{CaCl} 2,1 \mathrm{mM} \mathrm{ZnCl} 2,1 \%$ Triton X-100, and $0.02 \% \mathrm{NaN} 3$ at $25{ }^{\circ} \mathrm{C}$ and incubated in the same buffer for $16 \mathrm{~h}$ at $37^{\circ} \mathrm{C}$. The gels were stained with Coomassie Brilliant Blue. Gelatin zymography depicts MMPs as negatively stained bands of gelatinolytic activity.

\section{Determination of Kcat/Km Values for the Fluorogenic Peptide Substrate Mca-PLGL(Dpa)AR-NH2.}

The latent enzymes were activated by $1 \mathrm{mM}$ APMA at $37^{\circ} \mathrm{C}$ for $14-16 \mathrm{~h}$. The concentrations of the active enzymes, $[\mathrm{E}]_{\mathrm{T}}$, were determined by active-site titration with the MMP inhibitor GM6001 as described previously [106]. The Kcat/Km values for the fluorogenic peptide substrate were then obtained by assaying the enzymes at $23^{\circ} \mathrm{C}$ using $1.5 \mu \mathrm{M}$ peptide substrate as previously described [99]. Assays were conducted under the condition where $\mathrm{K}_{m}>>$ [S], and $K_{\text {cat }} / K_{m}$ values were calculated from the following equation: $K_{\text {cat }} / K_{m}=\mathrm{v}_{\mathrm{o}} /[\mathrm{E}]_{\mathrm{T}}[\mathrm{S}]$.

\section{Kinetic Analysis of Type I Collagenolytic Activity}

To determine the Kcat/Km values of the MMP-9 mutant enzymes for type I collagen, enzymes $(0.02 \mu \mathrm{M})$ were mixed with various concentrations of bovine type I collagen $(1.1,1.65,2.2$, and $2.75 \mu \mathrm{M})$ in assay buffer that was composed of $50 \mathrm{mM}$ Tris, $\mathrm{pH} 7.5,5 \mathrm{mM} \mathrm{CaCl} 2,150 \mathrm{mM} \mathrm{NaCl}$, and $2 \mu \mathrm{M} \mathrm{ZnCl}_{2}$. Reactions were allowed to proceed at $27{ }^{\circ} \mathrm{C}$ for $6 \mathrm{~h}$ before being quenched by the presence of $10 \mathrm{mM}$ EDTA. Reaction mixtures were boiled for $5 \mathrm{~min}$ and electrophoresed on $8 \%$ SDS-PAGE. Proteins bands were visualized by Coomassie Brilliant Blue staining. The integrated intensities of the $\alpha 1$ (I) and $\alpha 2$ (I) collagen bands were determined by using an Alpha Imager 2000 documentation and analysis system (Alpha Innotech Corp., San Leandro, $\mathrm{CA}$ ). The difference between the integrated intensities of the $\alpha 1$ (I) collagen band in the presence and in the absence of the enzyme was used to calculate the catalytic activity of the enzyme as described previously [107]. 


\section{Analysis of Gelatinolytic Activity of the Enzymes}

The gelatinolytic activity of enzymes was determined using ${ }^{14} \mathrm{C}$-labeled gelatin as described previously $[40,108,109]$. Specific activity was calculated by dividing the amount of gelatin degraded per hour by the nanomoles of enzyme present in the assay. The assays were performed in triplicates and the results were averaged.

\section{RESULTS}

\section{Expression, Purification, and Activation of Deletion Mutant Enzymes}

The major aim of this study was to identify the structural elements that are sufficient to endow MMP-9 with type I collagenolytic activity. Since the fully processed carboxyl-terminal truncated MMP-9 (68 kDa protein) was shown to be able to cleave type I collagen, a series of MMP-9 deletion mutant enzymes (Figure 5-2) were designed to address the role and significance of the hemopexin domain and hinge region in type I collagen substrate specificity of MMP-9. The first deletion mutant, $\Delta \mathrm{CT}^{(1-456)}$ consisted of complete deletion of the hemopexin domain (amino acid 503-706) and partial deletion of the hinge region (amino acid 457-502). $\Delta \mathrm{CT}^{(1-443)}$ consisted of complete deletion of both the hemopexin domain and the hinge region (amino acids 444-706). The $\Delta 444-502$ mutant is comprised of MMP-9 molecule lacking only the hinge region, amino acid residues 444-502. All mutant enzymes were expressed in E. coli as latent enzymes and purified on gelatin agarose affinity column as described previously [75].

\section{Characterization of Deletion Mutants MMP-9}

To assess whether deletion mutants were correctly folded and retained general proteolytic activity, they were activated with APMA and the catalytic efficiencies of MMP-9, $\Delta \mathrm{CT}^{(1-456)}, \Delta \mathrm{CT}^{(1-443)}$ and MMP-9 $\Delta 444-502$ enzymes toward gelatin and a general MMP fluorogenic peptide substrate, Mca-PLGL(Dpa)AR-NH2, were determined. As demonstrated in Figure 5-3 and Table 5-1, all activated mutant enzymes were able to cleave gelatin. However, only the $\Delta 444-502$ mutant enzyme with intact hemopexin domain had similar gelatinolytic activity as the wild type MMP-9. All other deletion mutations resulted in a decreased catalytic efficiency of the enzyme toward gelatin substrate. $\Delta \mathrm{CT}^{(1-456)}$ and $\Delta \mathrm{CT}^{(1-443)}$ mutants had 3.2-fold and 3.6-fold lower activity toward gelatin compared to WT MMP-9, respectively (Table 5-1). This is consistent with Roeb, et al., finding that MMP-9 hemopexin domain has a high affinity for gelatin [103]. Therefore it is not surprising that $\Delta \mathrm{CT}^{(1-443)}$ and $\Delta \mathrm{CT}^{(1-456)}$, both lacking the hemopexin domain, had lower activity toward gelatin substrate while, specific activity of MMP-9 hinge region deleted mutant $(\Delta 444-502)$ for gelatin was similar to that of the wild type enzyme. 
MMP-9

(706aa)

MMP-9 $\Delta 444-502$

$\Delta \mathrm{CT}(1-456)$

$\Delta \mathrm{CT}(1-443)$
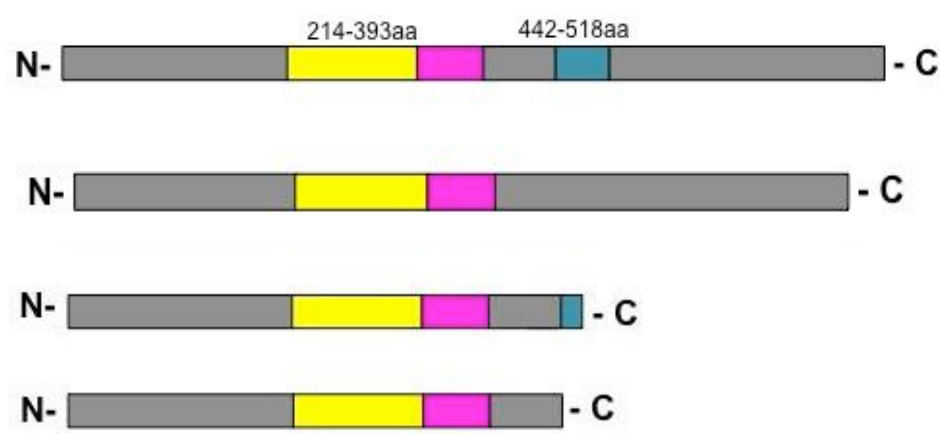

Fibronectin-like gelatin binding domain

Zinc binding domain (Active Site)

Type $\mathrm{V}$ collagen-like domain (hinge)

\section{Figure 5-2. MMP-9 recombinant deletion mutants.}

Full-length MMP-9 is comprised of 706 amino acids and does not use type I collagen as a substrate. $\Delta 444-502$ mutant is comprised of MMP-9 molecule lacking hinge region, amino acid residues 444-502. $\Delta \mathrm{CT}^{(1-456)}$ recombinant mutant lacks amino acid residues 457-706 corresponding to the hemopexin domain and partial hinge region. In $\Delta \mathrm{CT}^{(1-443)}$ recombinant mutant both hemopexin domain and hinge region were deleted (amino acid residues 444-706). 


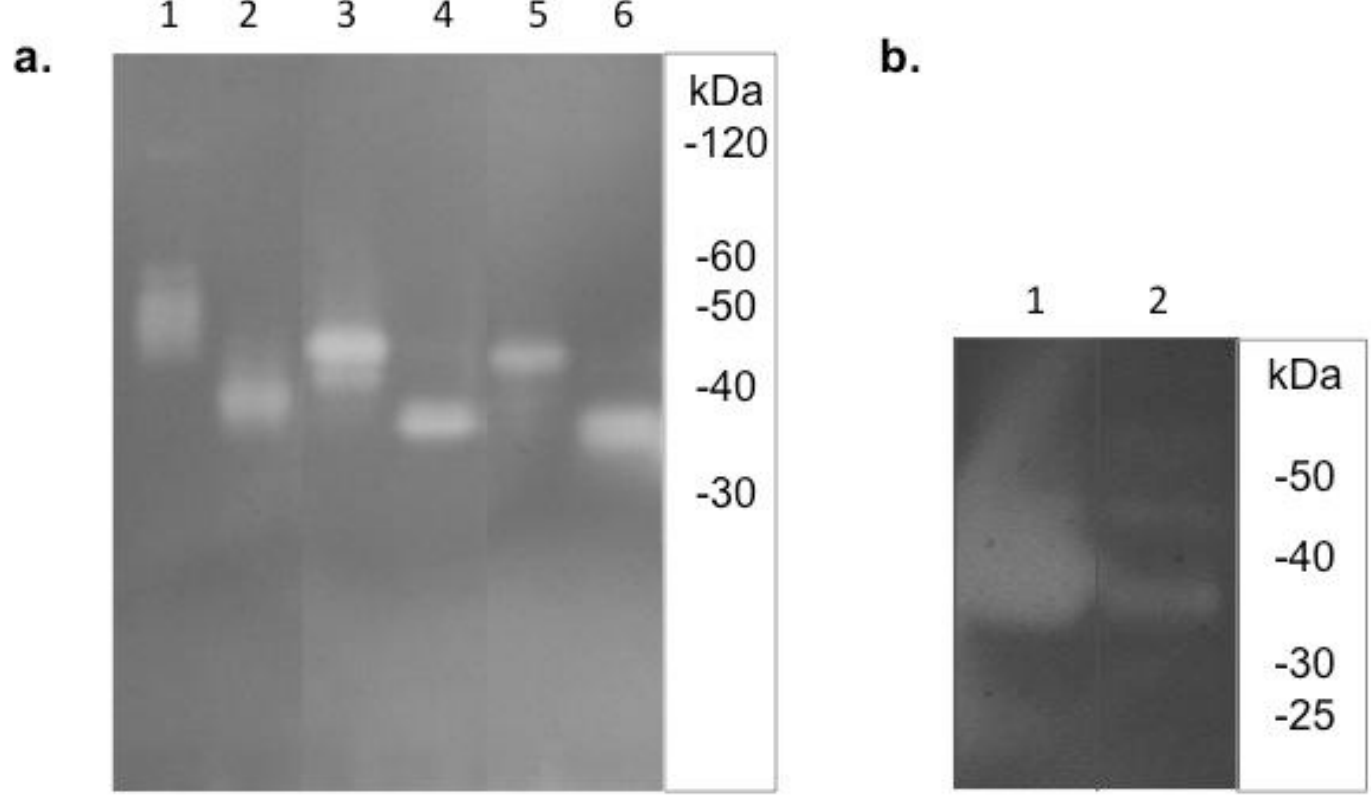

Figure 5-3. Gelatin- gel zymography of purified mutant enzymes.

(a) Lanes 1, 3, and 5 show the latent form of WT MMP-9, $\Delta \mathrm{CT}^{(1-456)}$ and $\Delta \mathrm{CT}^{(1-443)}$, respectively. Lanes 2, 4, and 6 shows the active form of WT MMP-9, $\Delta C \mathrm{~T}^{(1-456)}$ and $\Delta \mathrm{CT}^{(1-443)}$, respectively. (b) Lanes 1 and 2 show the latent and active forms of $\Delta 444-502$, respectively.

Table 5-1. Proteolytic activity of deletion mutant enzymes

\begin{tabular}{|c|c|c|c|c|c|}
\hline $\begin{array}{l}\text { Enzyme } \\
\mu \mathrm{M}^{-1}\end{array}$ & $\begin{array}{l}\text { Kcat/Km } \\
\text { (McaPLGLDpaAR) } \\
\mathrm{mM}^{-1} \mathrm{~S}^{-1}\end{array}$ & $\begin{array}{l}\text { Specific Activity } \\
\text { for Gelatin } \\
\mu \mathrm{g} / \mathrm{h} / \mathrm{nmol}\end{array}$ & $\begin{array}{l}\text { Kcat } \\
\text { Type I } \\
\text { collagen } \\
\mathrm{h}^{-1}\end{array}$ & $\begin{array}{l}\mathrm{Km} \\
\text { Type I } \\
\text { collagen } \\
\mu \mathrm{M}^{-1}\end{array}$ & $\begin{array}{l}\mathrm{Kcat} / \mathrm{Km} \\
\text { Type I } \\
\text { collagen } \\
\mathrm{h}^{-1} \mu \mathrm{M}^{-1}\end{array}$ \\
\hline MMP-1 & $14.17 \pm 0.5$ & $272 \pm 9$ & 146 & 5.36 & 27.23 \\
\hline MMP-9 & $585 \pm 30.9$ & $187,669 \pm 11,921$ & ND & ND & ND \\
\hline$\Delta 444-502$ & $145.33 \pm 2.58$ & $187,157 \pm 224$ & 33.03 & 8.9 & 3.71 \\
\hline$\Delta \mathrm{CT}^{(1-456)}$ & $128.9 \pm 14.1$ & $58,959 \pm 359$ & ND & ND & ND \\
\hline$\Delta \mathrm{CT}^{(1-443)}$ & $613 \pm 2.1$ & $52,272 \pm 5149$ & 3.7 & 2.1 & 1.8 \\
\hline
\end{tabular}

$\mathrm{ND}=$ Not Determined 
As shown in Table 5-1, the catalytic efficiency (Kcat/Km) of both $\Delta \mathrm{CT}^{(1-456)}$ and $\Delta 444-502$ toward the Mca-PLGL(Dpa)AR-NH2 were 4.5 and 4 times lower than that of the wild type enzyme, respectively. The $\Delta \mathrm{CT}^{(1-443)}$ mutant, however, had similar Kcat $/ \mathrm{Km}$ for the peptide substrate to wild type MMP-9 $\left(585 \pm 30.9 \mathrm{mM}^{-1} \mathrm{~S}^{-1}\right)$. These findings suggest that presence of amino acid residues 444-456 in the hinge region plays a role in general proteolytic activity of the enzyme.

As mentioned previously, contrary to $82 \mathrm{kDa}$ MMP-9, the $68 \mathrm{kDa}$ active MMP-9 cleaves type I collagen, suggesting a role for carboxyl terminal domain and hinge region in type I collagenolytic activity of the enzyme. Therefore, the ability of deletion mutants to cleave type I collagen was assessed. As demonstrated in Table 5-1, only deletion mutants lacking the entire hinge region with $(\Delta 444-502)$ or without $\left(\Delta \mathrm{CT}^{(1-443)}\right)$ the carboxyl terminal domain were able to cleave type I collagen. $\Delta \mathrm{CT}^{(1-443)}$, in addition to gelatin and type $\mathrm{V}$ collagen (data not shown), was able to use triple helical type I collagen as a substrate (Table 5-1) with Kcat/Km value of $1.8 \mathrm{~h}^{-1} \mu \mathrm{M}^{-1}$. This value is 15.1 times lower than the value obtained for MMP-1 $\left(27.23 \mathrm{~h}^{-1} \mu \mathrm{M}^{-1}\right)$. Interestingly, contrary to this enzyme, $\Delta \mathrm{CT}^{(1-456)}$ does not cleave type I collagen, suggesting that presence of amino acids 444-456 in the $\Delta \mathrm{CT}^{(1-456)}$ molecule hinders the enzyme from utilizing type I collagen as a substrate. This hypothesis was confirmed by the observation that complete deletion of the hinge region from the full length MMP-9 $(\Delta 444-502)$ endowed the enzyme with type I collagenolytic activity. The catalytic efficiency of the $\Delta 444-502$ mutant toward type I collagen substrate was $3.71 \mathrm{~h}^{-1} \mu \mathrm{M}^{-1}$ (Table 5-1). This values is 2 times higher than the value obtained for $\Delta \mathrm{CT}^{(1-443)}$. This may be due to the hemopexin domain binding to and helping to present type I collagen to the AS in $\Delta 444-502$ molecule.

\section{$\mathrm{Glu}^{447}$ and $\mathrm{Arg}^{451}$ Residues in the Hinge Region Play a Role in Type I Collagenolytic Activity of MMP-9}

Analysis of activity of $\Delta \mathrm{CT}^{(1-456)}$ and $\Delta \mathrm{CT}^{(1-443)}$ enzymes toward type I collagen substrate suggested that the 13 amino acid residues, ${ }^{444}$ PRPEPEPRPPTTT ${ }^{456}$ in the hinge region of MMP-9 determines the substrate specificity of the enzyme (Figure 5-4, Table 5-2). The role of specific amino acid residues in this region of the MMP-9 molecule in its type I collagenolytic activity was evaluated by alanine scanning site directed mutagenesis. The charged amino acid residues, $\mathrm{Arg}^{445}, \mathrm{Glu}^{447}, \mathrm{Glu}^{449}$ and $\mathrm{Arg}^{451}$ in $\Delta \mathrm{CT}^{(1-456)}$ (Figure 5-4) were individually substituted with Ala and the effect of each mutation on substrate specificity of the enzyme was evaluated. All site directed mutant enzymes were expressed in $E$. coli, purified, and their enzymatic activities were determined following activation by APMA.

Gelatin gel zymography showed that upon activation with APMA, the $45 \mathrm{kDa}$ unglycosylated latent R445A, E447A, E449A, and R451A $\Delta \mathrm{CT}^{(1-456)}$ mutant enzymes were converted to $37 \mathrm{kDa}$ active species (Figure 5-5) as expected. 
$\Delta \mathrm{CT}(1-456)$

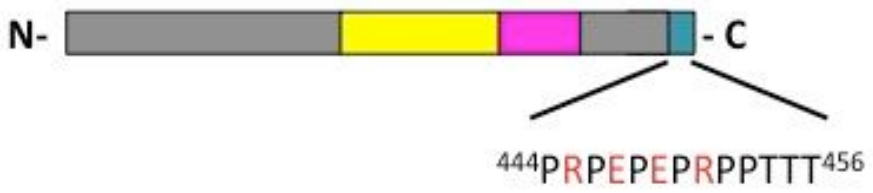

Figure 5-4. Alanine mutations in $\Delta \mathbf{C T}^{(1-456)}$.

Schematic diagram of $\Delta \mathrm{CT}^{(1-456)}$, showing the amino acid residues in the hinge region involved in type I collagenolytic activity of the enzyme. The amino acids in red signify the amino acids individually mutated to Ala.

Table 5-2. Proteolytic activity of the Ala mutants

\begin{tabular}{llllll}
\hline $\begin{array}{l}\text { Enzyme } \\
\mu \mathrm{M}^{-1}\end{array}$ & $\begin{array}{l}\text { Kcat/Km } \\
(\mathrm{McaPLGLDpaAR}) \\
\mathrm{mM}^{-1} \mathrm{~S}^{-1}\end{array}$ & $\begin{array}{l}\text { Specific Activity } \\
\text { for Gelatin } \\
\mu \mathrm{g} / \mathrm{h} / \mathrm{nmol}\end{array}$ & $\begin{array}{l}\text { Kcat } \\
\text { Type I } \\
\text { collagen } \\
\mathrm{h}^{-1}\end{array}$ & $\begin{array}{l}\mathrm{Km} \\
\text { Type I } \\
\text { collagen } \\
\mu \mathrm{M}^{-1}\end{array}$ & $\begin{array}{l}\text { Kcat/Km } \\
\text { Type I } \\
\text { collagen } \\
\mathrm{h}^{-1} \mu \mathrm{M}^{-1}\end{array}$ \\
\hline MMP-1 & $14.17 \pm 0.5$ & $272 \pm 9$ & 146 & 5.36 & 27.23 \\
$\Delta \mathrm{CT}^{(1-456)}$ & $128.9 \pm 14.1$ & $58,959 \pm 359$ & $\mathrm{ND}$ & $\mathrm{ND}$ & $\mathrm{ND}$ \\
$\mathrm{R} 445 \mathrm{~A}$ & $328.1 \pm 11.9$ & $71,154 \pm 174$ & $\mathrm{ND}$ & $\mathrm{ND}$ & $\mathrm{ND}$ \\
$\mathrm{E} 447 \mathrm{~A}$ & $85.95 \pm 1.5$ & $10,239 \pm 130$ & 0.418 & 0.157 & 2.66 \\
E449A & $275.37 \pm 16.8$ & $149,680 \pm 19,758$ & $\mathrm{ND}$ & $\mathrm{ND}$ & $\mathrm{ND}$ \\
$\mathrm{R} 451 \mathrm{~A}$ & $135.1 \pm 10.26$ & $248,706 \pm 13,896$ & 0.641 & 0.236 & 2.71 \\
\hline
\end{tabular}

$\mathrm{ND}=$ Not Determined 


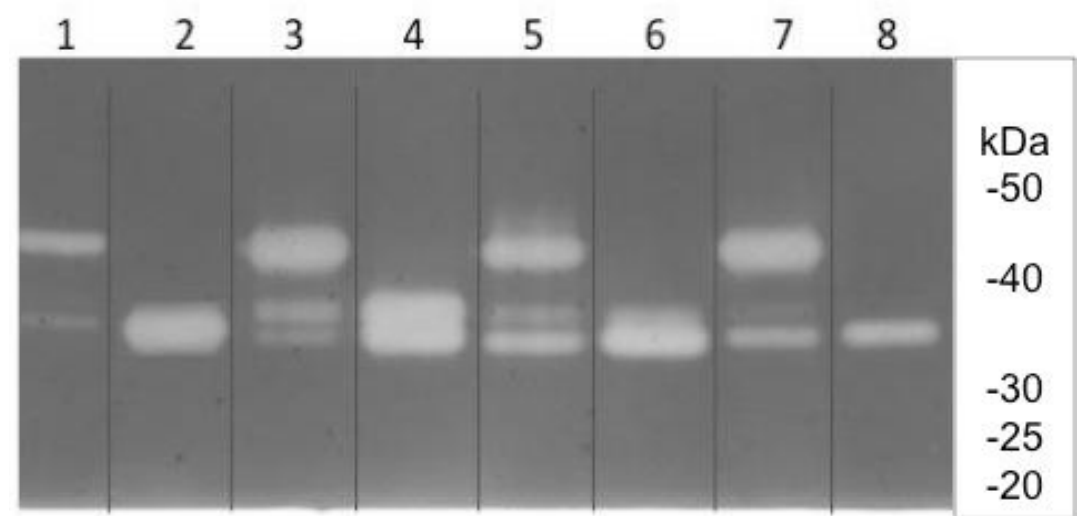

Figure 5-5. Gelatin- gel zymography of purified site directed mutant enzymes.

Lanes 1, 3, 5 and 7 correspond to the latent forms and lanes 2, 4, 6 and 8 correspond to the active forms of $\Delta \mathrm{CT}^{(1-456)}$ mutant enzymes R445A, E447A, E449A, and R451A, respectively.

The catalytic efficiencies of all of the mutant enzymes toward the peptide substrate Mca-PLGL(Dpa)AR-NH2 and gelatin were then determined at $23{ }^{\circ} \mathrm{C}$ and $37^{\circ} \mathrm{C}$, respectively. As shown in Table 5-2, all of the Ala substitutions changed catalytic efficiency and specific activity of the $\Delta \mathrm{CT}^{(1-456)}$ enzyme for peptide substrate and gelatin, respectively. While, R451A substitution did not have a significant effect on $\mathrm{Kcat} / \mathrm{Km}$ value of the $\Delta \mathrm{CT}^{(1-456)}$ for the synthetic substrate, the catalytic efficiency of R445A and E449A for the substrate were found to be 2.6 and 2.3 times higher than that of $\Delta \mathrm{CT}^{(1-456)}$, respectively. The observed differences between catalytic efficiency of $\Delta \mathrm{CT}^{(1-456)}$ and the Ala mutant enzymes for synthetic substrate could be due to higher catalytic activity (Kcat) and/or higher affinity of the mutant enzymes for the synthetic substrate. The E447A mutant had 1.5 times lower $\mathrm{Kcat} / \mathrm{Km}$ value for the synthetic substrate than $\Delta \mathrm{CT}^{(1-456)}$.

All of the alanine mutations also changed specific activity of $\Delta \mathrm{CT}^{(1-456)}$ enzyme for gelatin substrate. While the specific activities of R445A, E449A, and R451A mutants for gelatin substrate were 1.2, 2.5, and 4.2-fold higher than that of $\Delta \mathrm{CT}^{(1-456)}$, respectively, introduction of Ala mutation at position 447 in $\Delta \mathrm{CT}^{(1-456)}$ reduced gelatinolytic activity of the enzyme by 5.7-fold (Table 5-2). These data suggest that amino acid residues at positions 447,449 , and 451 are involved in general proteolytic activity of MMP-9.

The effect of Ala mutations in type I collagenolytic activity of $\Delta \mathrm{CT}^{(1-456)}$ was assessed using soluble type I collagen as a substrate. As shown in Table 5-2, substitution of $\mathrm{Glu}^{447}$ and $\mathrm{Arg}^{451}$ with Ala endowed $\Delta \mathrm{CT}^{(1-456)}$ with type I collagenolytic activity. E447A and R451A (Table 5-2) were able to cleave type I collagen less efficiently than $\Delta 444-502$ mutant enzyme $\left(3.71 \mathrm{~h}^{-1} \mu \mathrm{M}^{-1}\right.$; Table $\left.5-1\right)$. The Kcat/Km of E447A and R451A 
mutants were 2.66 and $2.71 \mathrm{~h}^{-1} \mu \mathrm{M}^{-1}$, respectively (Table 5-2). These data indicate that the presence of $\mathrm{Glu}^{447}$ and $\mathrm{Arg}^{451}$ residues in MMP-9 hinders the enzymes from cleaving type I collagen. We have previously shown that presence of $\mathrm{Glu}^{415}$ in the active site of MMP-9 also prevents the enzyme from using type I collagen as a substrate [105]. This was based on the observation that substituting $\mathrm{Glu}^{415}$ in the active site of MMP-9 with Gly, an amino acid counter part in MMP-1, provided the enzyme with type I collagenolytic activity [105]. These data together suggests that interaction between the side chain of Glu ${ }^{447}$ and/or $\mathrm{Arg}^{451}$ with Glu ${ }^{415}$ make the active site of MMP-9 rigid and capable of accommodating specific substrates, i.e. gelatin and type $\mathrm{V}$ collagen. Removal of the side chain of either of these amino acid residues or a complete deletion of the hinge region as in $\Delta 444-502$ and $\Delta C T^{(1-443)}$ mutant enzymes makes the structure of the active site more flexible and capable of cleaving both types I and V collagen.

\section{Interaction Between Glu ${ }^{415}$ and Glu ${ }^{447}$ and/or Arg $^{451}$ Dictates Substrate Specificity of MMP-9}

To test the above hypothesis we introduced $\mathrm{Glu}^{415}$ to Gly mutation into $\Delta \mathrm{CT}^{(1-456)}$ and $\mathrm{E} 447 \mathrm{~A} / \Delta \mathrm{CT}^{(1-456)}$ enzymes (Figure 5-6) and studied the effect of mutations on type I collagenolytic activity of the enzymes. If interaction between the side chains of $\mathrm{Glu}^{415}$ and $\mathrm{Glu}^{447}$ dictates substrate specificity of MMP-9, then removal of the side chain of either amino acids from $\Delta \mathrm{CT}^{(1-456)}$ should result in an enzyme capable of cleaving type I collagen in addition to gelatin and synthetic substrate. Moreover, introduction of E415G mutation in $\mathrm{E} 447 \mathrm{~A} / \Delta \mathrm{CT}^{(1-456)}$ should, in principal, increase the activity of the enzyme toward type I collagen.

As shown in Figure 5-6 and Table 5-3, the latent E415G/ $\Delta \mathrm{CT}^{(1-456)}(\mathrm{E} 415 \mathrm{G})$ and $\mathrm{E} 415 \mathrm{G} / \mathrm{E} 447 \mathrm{~A} / \Delta \mathrm{CT}^{(1-456)}(\mathrm{DM})$ are $47 \mathrm{kDa}$ proteins that after activation by APMA are
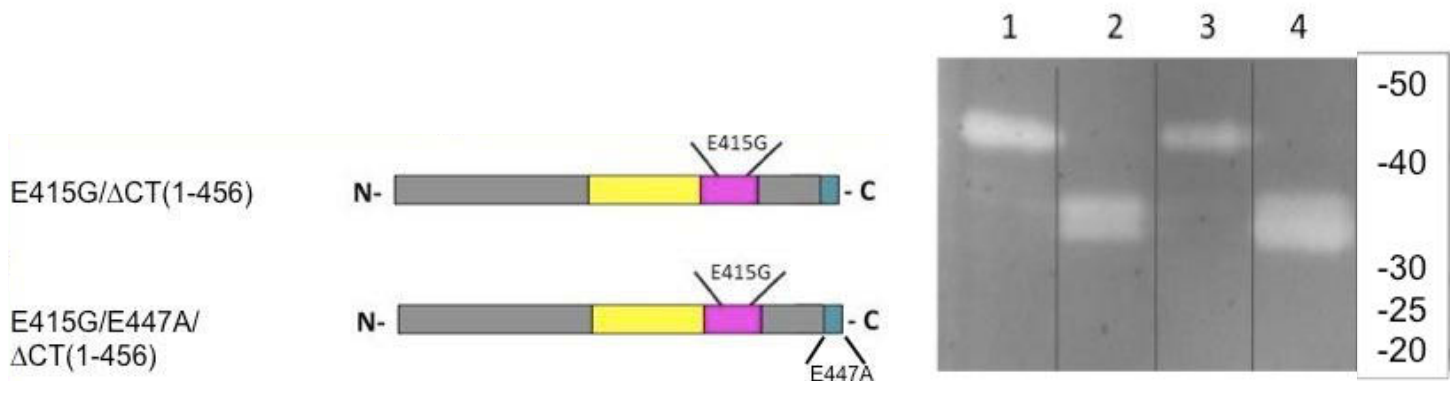

Figure 5-6. Schematic diagram and gelatinolytic activities of E415G and DM.

The figure to the left is schematic diagrams of $\Delta \mathrm{CT}^{(1-456)}$ showing the position of $\mathrm{Glu}^{415}$ and $\mathrm{Glu}^{447}$ in the protein molecule. To the right is a gelatin gel zymography depicting molecular weights of latent (lanes 1 and 3) and active (lanes 2 and 4) forms of $\mathrm{E} 415 \mathrm{G} / \Delta \mathrm{CT}^{(1-456)}$ and $\mathrm{E} 415 \mathrm{G} / \mathrm{E} 447 \mathrm{~A} / \Delta \mathrm{CT}^{(1-456)}(\mathrm{DM})$ mutant enzymes, respectively. 
Table 5-3. E415G and DM proteolytic activity.

\begin{tabular}{llllll}
\hline $\begin{array}{l}\text { Enzyme } \\
\mu \mathrm{M}^{-1}\end{array}$ & $\begin{array}{l}\text { Kcat/Km } \\
(\text { McaPLGLDpaAR) } \\
\mathrm{mM}^{-1} \mathrm{~S}^{-1}\end{array}$ & $\begin{array}{l}\text { Specific } \\
\text { Activity for } \\
\text { Gelatin } \\
\mu \mathrm{g} / \mathrm{h} / \mathrm{nmol}\end{array}$ & $\begin{array}{l}\text { Kcat } \\
\text { Type I } \\
\text { collagen } \\
\mathrm{h}^{-1}\end{array}$ & $\begin{array}{l}\mathrm{Km} \\
\text { Type I } \\
\text { collagen } \\
\mu \mathrm{M}^{-1}\end{array}$ & $\begin{array}{l}\text { Kcat/Km } \\
\text { Type I } \\
\text { collagen } \\
\mathrm{h}^{-1} \mu \mathrm{M}^{-1}\end{array}$ \\
\hline $\mathrm{MMP}-1$ & $14.17 \pm 0.5$ & $272 \pm 9$ & 146 & 5.36 & 27.23 \\
$\Delta \mathrm{CT}^{(1-456)}$ & $128.9 \pm 14.1$ & $58,959 \pm 359$ & $\mathrm{ND}$ & $\mathrm{ND}$ & $\mathrm{ND}$ \\
$\mathrm{E} 415 \mathrm{G}$ & $130.63 \pm 0.53$ & $56,779 \pm 2,956$ & 8.041 & 2.3 & 3.5 \\
$\mathrm{DM}$ & $29.52 \pm 0.6$ & $39,864 \pm 984$ & 11.89 & 1.94 & 6.1 \\
\hline
\end{tabular}

$\mathrm{ND}=$ Not Determined

converted to $37 \mathrm{kDa}$ proteins capable of cleaving gelatin and using

Mca-PLGL(Dpa)AR-NH2 as a substrate. The catalytic efficiency and specific activity of $\mathrm{E} 415 \mathrm{G}$ for the synthetic substrate and gelatin were equal to those of $\Delta \mathrm{CT}^{(1-456)}$, respectively (Table 5-3). Contrary to E415G, the catalytic efficiency of DM mutant enzyme for the synthetic substrate and its specific activity for gelatin were 4.4 and 1.4-fold lower than those of $\Delta \mathrm{CT}^{(1-456)}$ (Table 5-3). This data confirms the previous observation that amino acid residue at position 447 is involved in general proteolytic activity of MMP-9.

The catalytic efficiency (Kcat/Km) of E415G and DM enzymes for type I collagen was determined at $27^{\circ} \mathrm{C}$ (Table $5-3$ ). We found that similar to previously described Gel.B/E415G mutant [105], mutation of Glu ${ }^{415}$ to Gly in $\Delta \mathrm{CT}^{(1-456)}$ confers the enzyme with type I collagenolytic activity at an efficiency of $3.5 \mathrm{~h}^{-1} \mu \mathrm{M}^{-1}$ (Table 5-3). The double mutant had a catalytic efficiency of $6.1 \mathrm{~h}^{-1} \mu \mathrm{M}^{-1}$, which is 1.7 - and 2.3-fold higher compared to individual E415G and E447A mutants, respectively (Table 5-2) and is equal to the efficiency of single mutants combined. This additive effect of double mutations on the rate of cleavage of type I collagen by $\Delta \mathrm{CT}^{(1-456)}$ proves our hypothesis that the interaction between $\mathrm{Glu}^{415}$ and $\mathrm{Glu}^{447}$ is the major determinant in collagen substrate specificity. The interaction(s) between the side chains of $\mathrm{Glu}^{447}$ and $\mathrm{Glu}^{415}$ makes the active site rigid, preventing the active site from accommodating type I collagen molecule. Breaking this interaction by either replacing, $\mathrm{Glu}^{447}$ or $\mathrm{Arg}^{451}$ to Ala makes the active site flexible and capable of cleaving type I collagen.

\section{DISCUSSION}

In this report we demonstrate, for the first time, that the ability of $68 \mathrm{kDa}$ MMP-9 to cleave type I collagen comes from its active site ability to adopt a conformation that mediates collagen binding and catalysis and this process is dependent on the lack of interaction between a Glu residue at position 415 located in the AS region of the enzyme and $\mathrm{Glu}^{477}$ residue located in the hinge region. The removal of amino acid side chain at 
positions 415 and/or 447 provides flexibility necessary for the enzyme active site to change conformation upon binding collagen, leading to catalysis. This is based on the observation that only MMP-9 mutants lacking $\mathrm{Glu}^{415}$ (as in E415G), Glu ${ }^{447}$ (as in E447A, $\Delta \mathrm{CT}^{(1-443)}$, and $\Delta 444-502$ mutants), or their combination (as in $\mathrm{E} 447 \mathrm{~A} / \mathrm{E} 415 \mathrm{G} / \Delta \mathrm{CT}^{(1-456)}$ ) were able to use type I collagen as a substrate. The carboxyl terminal deletion mutant $\left(\Delta \mathrm{CT}^{(1-456)}\right)$ and full length MMP-9 although had high activity toward the peptide substrate and gelatin, were not able to cleave type I collagen. $\Delta C \mathrm{CT}^{(1-456)}$ was by all indications stable, properly folded, and able to be processed by APMA to a $37 \mathrm{kDa}$ active species. An amino acid sequence alignment revealed that the amino acid residues 444-456 $\left({ }^{444}\right.$ PRPEPEPRPPTTT $\left.{ }^{456}\right)$ is responsible for the observed difference in the type I collagenolytic activity of $\Delta \mathrm{CT}^{(1-456)}$ and $\Delta \mathrm{CT}^{(1-443)}$ mutant enzymes (Figure 5-2 and 5-4).

We have previously demonstrated that MMP-9 mutant (Gel.B/E415G), in which $\mathrm{Glu}^{415}$ located in its active site is substituted by Gly, its corresponding residue in all type I collagen cleaving MMPs, is able to cleave native triple helical type I collagen [105]. These data together suggested that the interaction between $\mathrm{Glu}^{415}$ and an amino acid residue(s) in the sequence ${ }^{444}$ PRPEPEPRPPTTT ${ }^{456}$ make the active site of MMP-9 rigid, preventing the enzyme from binding to and cleaving type I collagen.

This was confirmed by the observation that the replacement of $\mathrm{Glu}^{447}$ and $\mathrm{Arg}^{451}$ in $\Delta \mathrm{CT}^{(1-456)}$ with Ala (E447A and R451A) endowed the enzyme with type I collagenolytic activity (Table 5-2). These mutants retained peptide substrate and gelatinolytic activity, indicating that the general proteolytic activity of $\Delta \mathrm{CT}^{(1-456)}$ was not compromised by these substitutions. The effect of E447A and R451A mutation on kinetic parameters of $\Delta \mathrm{CT}^{(1-456)}$ for type I collagen was similar to the replacement of $\mathrm{Glu}^{415}$ with Gly in $\Delta \mathrm{CT}^{(1-456)}$ (Table 5-3) and removal of the entire hinge region of MMP-9 $(\Delta 444-502$; Table 5-1). As shown in the diagram below (Figure 5-7), presence of the 13 amino acids in full-length MMP-9 and $\Delta \mathrm{CT}^{(1-456)}$ makes the AS of these enzymes rigid and blocks type I collagen from entering the AS. Further processing of $82 \mathrm{kDa}$ by $\mathrm{COOH}$-terminal truncation, to $68 \mathrm{kDa}$ enzyme and deletion of the remaining hinge region in $\Delta \mathrm{CT}^{(1-443)}$ removed the $\mathrm{Glu}^{415}$ and $\mathrm{Glu}^{447}$ interaction and made the AS less rigid. This allowed type I collagen to enter the AS of $\Delta \mathrm{CT}^{(1-443)}$ and be cleaved with a Kcat/Km of $1.8 \mathrm{~h}^{-1} \mu \mathrm{M}^{-1}$ (Figure 5-7; bottom left). Substitution of $\mathrm{Glu}^{415}$ with Gly (Figure 5-7; top right), Glu ${ }^{447}$ (Figure 5-7; bottom right) or $\mathrm{Arg}^{451}$ with Ala also affected the interaction of the hinge region with AS Glu ${ }^{415}$ by breaking the side chain ionic interactions. This made the active site less rigid and capable of cleaving type I collagen with a $\mathrm{Kcat} / \mathrm{Km}$ of 3.5 , 2.66 and $2.71 \mathrm{~h}^{-1} \mu \mathrm{M}^{-1}$, respectively. These data indicated that the interaction of $\mathrm{Glu}^{415}$ and $\mathrm{Glu}^{477}$ in MMP-9 dictates substrate specificity of the enzyme.

This was substantiated by substituting the $\mathrm{Glu}^{415}$ residue with Gly and Glu ${ }^{477}$ with Ala in $\Delta \mathrm{CT}^{(1-456)}$. The catalytic activity (Kcat) of the double mutant $\mathrm{E} 415 \mathrm{G} / \mathrm{E} 477 \mathrm{~A} / \Delta \mathrm{CT}^{(1-456)}$ toward type I collagen was 1.5 and 28.4 folds higher than that of E415G and E477A mutants, respectively (Table 5-2 and 5-3). The affinity of the double mutant for type I collagen $(\mathrm{Km})$, however, was similar to that for E415G mutant. Generation of the E415G/E447A/ $\Delta \mathrm{CT}^{(1-456)}(\mathrm{DM})$ lead to an additive effect on type I collagen catalytic efficiency. The Kcat $/ \mathrm{Km}$ of $6.1 \mathrm{~h}^{-1} \mu \mathrm{M}^{-1}$ was approximately 2 times 


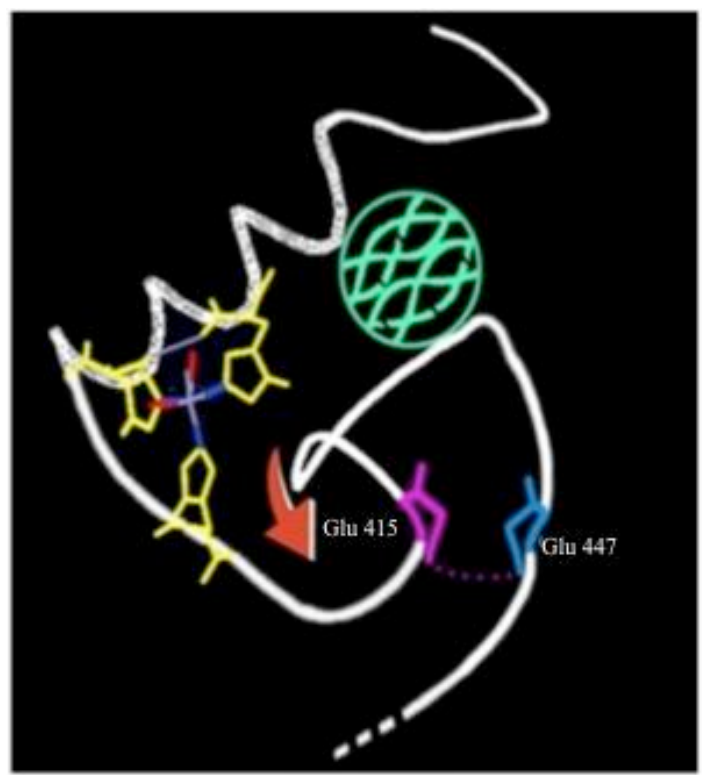

MMP-9

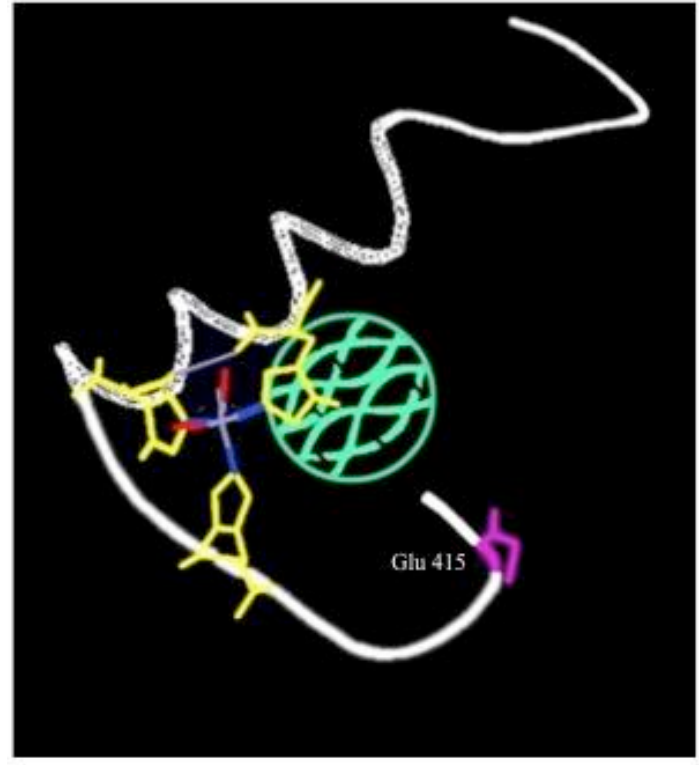

$\Delta$ CT 1-443

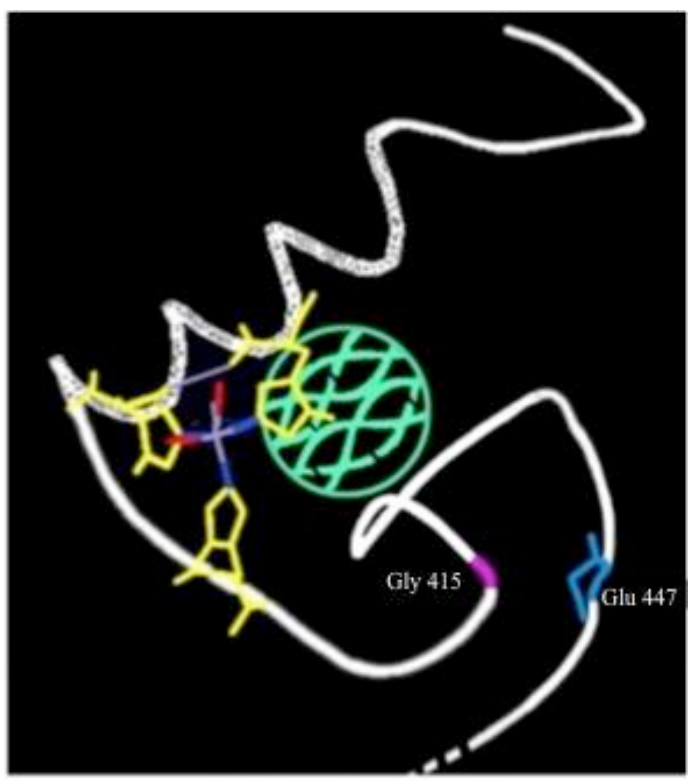

MMP-9 E415G

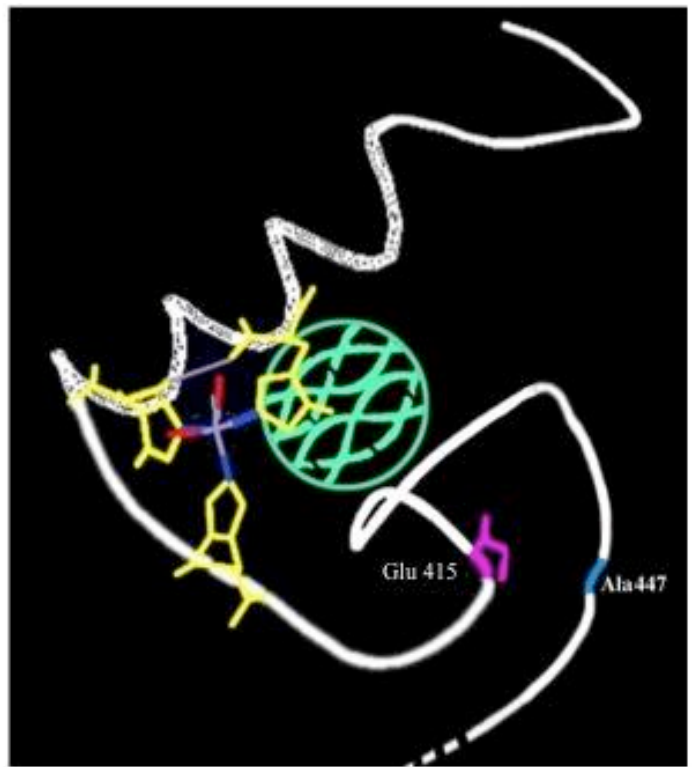

MMP-9 E447A

Figure 5-7. Schematic diagram of MMP-9 mutants with type I collagenolytic activity.

This diagram shows full length MMP-9 without any mutations (upper left) and the rigidity of the AS caused by the interaction between $\mathrm{Glu}^{415}$ and $\mathrm{Glu}^{447}$, which inhibits type I collagen (green ball) from entering the AS. When Glu ${ }^{415}$ is mutated to Gly (upper right), the hinge region is completely deleted (lower left), or Glu ${ }^{447}$ is mutated to Ala (lower right) the interaction between $\mathrm{Glu}^{415}$ and $\mathrm{Glu}^{447}$ is broken and the enzyme gains type I activity. 
higher compared to E415G, E447A, and R451A single mutations in $\Delta \mathrm{CT}^{(1-456)}$.

According to the X-ray crystal structures of MMP-9 catalytic domain [105] and full length MMP-1 [110], Glu ${ }^{415}$ is located in a turn at the bottom of the AS where the polypeptide chain turns back towards the center of the enzyme and $\mathrm{Glu}^{447}$ and $\mathrm{Arg}^{451}$ are located at the beginning of the hinge region (Figure 5-7). Considering that $\mathrm{Glu}^{415}$ is not positioned along the enzyme/substrate interface, it is unlikely that it or a substituting residue would directly interact with the collagen substrate. The significance of this residue in type I collagenolysis is probably related to its direct/indirect interaction with $\mathrm{Glu}^{447} / \mathrm{Arg}^{451}$ affecting the conformation and flexibility of the AS of the enzyme. Thus, it is conceivable that any substitution at these positions have a general effect on the mobility of the AS. The observation that the $\Delta \mathrm{CT}^{(1-443)}, \mathrm{E} 415 \mathrm{G}, \mathrm{E} 477 \mathrm{~A}$ R451A and $\Delta 444-502$ mutant enzymes are capable of cleaving type I collagen supports this notion and suggests that the flexibility provided by the lack of $\mathrm{Glu}^{415}-\mathrm{Glu}^{447}$ interaction is essential for type I collagenolytic activity. Consistent with this hypothesis is also the fact that full length MMP-9 and $\Delta \mathrm{CT}^{(1-456)}$ mutant enzymes cannot cleave native type I collagen substrate (Table 5-1). Thus, it is reasonable to conclude that the interaction of $\mathrm{Glu}^{415}$ with the hinge region makes the active site rigid, preventing MMP-9 from cleaving type I collagen. Disruption of this interaction, on the other hand, provides the flexibility necessary for enzyme active site to change conformation and be able to bind and cleave collagen substrate.

These data indicate that therapeutic studies which target only MMP-1 may not be very effective due to the cleavage of type I collagen by the fully processed MMP-9. Thus, this novel role identified for the type V collagen-like hinge region of MMP-9 in cleavage of type I collagen aids in understanding the relationship between the structure and function of MMPs and the involvement of different exocites in the substrate specificity. This can lead to discovery of novel and targeted therapeutic agents. 


\section{CHAPTER 6. SUMMARY}

Increasing evidence suggests that MMPs contribute to the formation of a microenvironment that promotes tumor growth during early stages of tumorigenesis. MMP-9 is one of the most important factors for metastatic behavior of tumor cells [23, 54, 74]. MMP-9 expression has been shown to be upregulated in breast tumors isolated from cancer patients [73]. MMP-9 degrades type IV collagen, one of the most abundant collagens in the ECM $[11,75]$ and is involved in cell proliferation, angiogenesis, and apoptosis $[9,10,30]$. Our observation that AM9D specifically decreased MMP-9 mRNA and protein production (Figure 1-3b and $\mathrm{c}$ ) and reduced invasive behavior of human MDA-MB-231 cells (Figure 1-3d) suggested that AM9D has potential as an anti tumorigenic/metastatic agent.

MMTV-PyMT transgenic mice were used to test the effect of AM9D on tumor growth in vivo. This model was chosen because of its similarity to human breast cancer and its metastatic potential. AM9D treatment of $10 \mu \mathrm{g}$ and $25 \mu \mathrm{g} / \mathrm{tumor} /$ week for a total of four weeks showed a 39.5 and $50 \%$ reduction in final tumor load.

Immunohistochemical analysis of tumor tissues showed that AM9D treatment reduced MMP-9 production in tumor cells by $66 \%$ compared to control DNAzyme treatment. In addition, AM9D treatment decreased vasculature and induced apoptosis in mammary tumors as demonstrated by CD31 and Caspase-3 immunostaining, respectively. These results showed promise as to the use of AM9D to treat tumor growth in vivo. However, there were several limitations in this study. First, the tumors of the MMTV-PyMT model developed at different time points and only the earlier developed tumors being treated with AM9D or control DNAzyme. This led to termination of treatment after 4 injections. Second, due to the development of the large size mammary tumors during the course of the treatment, the mice were sacrificed prematurely, inhibiting our ability to fully assess the effect of AM9D on spontaneous lung metastasis. Thus, experimental metastasis was utilized to determine the effect of AM9D on metastasis.

To utilize AM9D as a therapeutic treatment in experimental metastasis, AM9D needed to first be evaluated for its distribution, clearance and safety in normal and MMTV-PyMT mice. Healthy FVB and MMTV-PyMT mice were injected with naked $\left[{ }^{35} \mathrm{~S}\right]$-AM9D $(10 \mathrm{mg} / \mathrm{kg})$ in PBS via tail vein. $\left[{ }^{35} \mathrm{~S}\right]$-DNAzyme was distributed to all major organs in mice, including liver, kidney, lung, spleen, heart, pancreas, intestines, stomach, and brain (Figure 3-2). In normal mice the order of percentage accumulation was: blood $>$ liver $>$ kidney $>$ lung $>$ spleen $>$ heart. Studies revealed $1.8 \%, 1.1 \%$ and $0.4 \%$ of total DNAzyme injected was delivered to liver, kidney, and lung, respectively (Table 3-1). In MMTV-PyMT mice bearing small to large mammary tumors, the order of percentages of $\left[{ }^{35} \mathrm{~S}\right]$-DNAzyme accumulation in different organs was mammary tumor $>$ liver $\approx$ blood $>$ kidney $>$ spleen $>$ lung $>$ heart. In these mice, $4.1 \%$ of the total injected DNAzyme was accumulated in the mammary tumors in $2 \mathrm{~h}$ (Table 3-3) and the amount of DNAzyme accumulated in mammary tumors was proportional to the total weight of tumor burden (Figure 3-4). Interestingly, the accumulated DNAzyme in the mammary tumor is initially cleared at a slower rate compared to the other organs. The 
percentages of total DNAzyme accumulated in various organs in MMTV-PyMT mice were similar to normal mice (Table 3-1 and 3-3). In normal and MMTV-PyMT mice the majority of the DNAzyme was cleared from these organs within the first $24 \mathrm{~h}$. Thirty-one percent of the delivered dosage of $\left[{ }^{35} \mathrm{~S}\right]$-DNAzyme was cleared from the system of normal mice via feces and urine over a period of $72 \mathrm{~h}$ (Figure 3-1b). The safety of DNAzyme was tested by a single injection or AM9D or control DNAzyme in various concentrations $(10 \mathrm{mg} / \mathrm{kg}, 32 \mathrm{mg} / \mathrm{kg}$, and $75 \mathrm{mg} / \mathrm{kg}$ of body weight) and $100 \mu \mathrm{l} \mathrm{PBS}$ into normal FVB mice. Systemic distribution and safety/toxicity studies revealed that the naked AM9D is non-toxic when systemically administered, and has favorable pharmacological properties with respect to intravenous administration and tissue distribution. Most importantly, mammary tumors can take up the naked DNAzyme. The amount of DNAzyme accumulates in the mammary gland is higher and its rate of clearance is slower than any other organs tested. Taken together, these data show the potential of DNAzymes to be distributed to organs susceptible to tumors (brain, pancreas, stomach, etc.), taken up by tumors, and display extended half-life in tumors.

AM9D and control DNAzyme both showed evidence of a possible sequence related affect on metastasis when used as therapy for early stage experimental metastases. This may be due to AM9D and control DNAzyme containing $\mathrm{CpG}$ regions. $\mathrm{CpG}$ monotherapy has been shown to induce T-cell-mediated rejection of established tumors [91]. Assessment of long term lung tumor burden and survival suggests that AM9D treated mice have an advantage of progression-free survival over mice treated with control DNAzyme or PBS between days 32-42, however, all cohorts were eventually overcome by an equal volume of lung tumor burden (Figure 4-4) and there was no advantage of overall survival in either groups. This lack of effect maybe due to time of AM9D delivery, frequency of delivery, mouse strain, pro-tumorigenic effects of MMP-9 downregulation, or a combination of these effects. These are all concerns that must be investigated to confirm the anti-metastatic effect of AM9D.

Finally, in this body of work we showed that MMP-9, through its cleavage of type I collagen, might play a more important role in tumorigenesis than once believed. We have demonstrated that $68 \mathrm{kDa}$ truncated fully processed MMP-9 in addition to type IV collagen, is capable of cleaving type I collagen. Kinetic analysis of truncated MMP-9 demonstrated that amino acid sequence 444-456 in the hinge region of MMP-9 is responsible for substrate specificity of the enzyme. The absence of this region in $\Delta \mathrm{CT}^{(1-443)}$ and $\Delta 444-502$ garnered these enzymes with type I collagenolytic activity. Further analysis of amino acid sequence 444-456 identified the two amino acids Glu ${ }^{447}$ and $\mathrm{Arg}^{451}$ as being directly involved in substrate recognition by the enzyme. Substitution of Glu ${ }^{415}$ with Gly and/or replacement of $\mathrm{Glu}^{447}$ and $\mathrm{Arg}^{451}$ with Ala in $\Delta \mathrm{CT}^{(1-456)}$ made the enzyme capable of using type I collagen as a substrate. The catalytic efficiency of the double mutant $\left(\mathrm{E} 415 \mathrm{G} / \mathrm{E} 447 \mathrm{~A} / \Delta \mathrm{CT}^{(1-456)}\right)$ toward type I collagen was 2-fold higher than either E415G or E447A mutant, indicating that interaction of $\mathrm{Glu}^{415}$ with $\mathrm{Glu}^{447}$ dictates substrate specificity of the enzyme. Lack of this interaction makes the active site flexible, allowing the enzyme to cleave both type IV and I collagen, the two most important components of the ECM. This observation is important because it further illuminates the role of MMP-9 in tumorigenesis and metastases. 


\section{CHAPTER 7. AM9D: FROM PRECLINIC TO CLINIC}

\section{AM9D FOR BREAST CANCER PATIENTS}

There are several lines of evidence that suggest MMP-9 levels in serum and tissue could be a sensitive biomarker for tumor aggressiveness and metastasis in breast cancer patients [111-115]. Moses, et al. first described that the analysis of urinary MMP-9 may be a useful determinant for disease status in a variety of human cancers, including breast cancer [113]. In this study, urine specimens were obtained from patients prior to surgical or other therapeutic intervention and all breast cancer urine specimens were obtained from patients with metastatic disease. One hundred percent of these specimens were positive for MMP-9 compared to only $24 \%$ of normal control breast tissue [113]. Pellikainen, et al. evaluated the expression of MMP-9 in estrogen receptor positive (ER+/HER2) breast cancer patients and discovered positive stromal MMP-9 expression predicted decreased progression-free survival and decreased overall survival [116]. Furthermore, $\mathrm{Wu}$, et al. measured serum and tissue levels of MMP-9 in breast cancer patients, benign breast disease patients, and healthy controls and correlated the levels with patients' clinicopathologic characteristics [112]. Sixty-three and 77\% of the breast cancer patients displayed high MMP-9 serum levels and tissue staining, respectively, that positively correlated with lymph node metastasis [112].

As described earlier (Chapter 1), breast cancer is divided into 3 subtypes: luminal $\mathrm{A}\left(\mathrm{ER}\right.$ or $\left.\mathrm{PR}^{+} / \mathrm{HER} 2^{-}\right)$, luminal $\mathrm{B}\left(\mathrm{ER}\right.$ or $\left.\mathrm{PR}^{+} / \mathrm{HER}^{+}\right)$, and triple negative (ER $\left.{ }^{-} / \mathrm{PR}^{-} / \mathrm{HER}^{-}\right)$. Interestingly, MMP-9 serum levels were equally increased in HER2 ${ }^{+}$ and HER2 ${ }^{-}$patients, as well as, $\mathrm{ER}^{+}$and $\mathrm{ER}^{-}$breast cancer patients [112]. Triple negative breast cancer accounts for approximately $15 \%$ of breast cancer cases and is marked with high relapse rates, metastasis, and early death [117]. In a comparison of breast cancer patients with triple-negative or HER2 overexpression, the triple-negative patients experienced more lymph node metastasis compared to those with overexpressed HER2 [118]. MMP-9 expression was positively correlated with lymph node metastasis in breast cancer patients [112]. Additionally, the 5 year disease-free survival in patients with triple-negative was much shorter than HER2-expressing patients [118]. The lack of standard therapy and poor prognosis are causes of the high mortality [117]. Targeting MMP-9 that has been shown to be expressed in hormone positive and negative breast cancer patients, could play an important role in tumor treatment and reduce metastasis to lymph nodes and other metastatic sites of breast cancer patients. We have shown the distribution of MMP-9 DNAzyme (AM9D) to all major organs, including lung, brain and liver (Chapter 3, Figure 3-2). To this end, AM9D will be a useful therapeutic treatment for hormone positive and negative breast cancer patients at the early stages of tumor growth and metastasis. 


\section{AM9D AS AN ADJUVANT TO SURGERY}

MMPs play a role in the normal physiology and pathology of wound healing. When tissue suffers injury cell proliferation increases, inflammatory cells infiltrate the wounded area and release MMPs, including MMP-9, while the tissue regenerates [119]. A first line treatment for breast tumor is surgical excision. Zhao, et al., demonstrated that surgical excision of an implanted MDA-MB-245 mammary tumor in mice led to increased serum expression of MMP- 9 on days 1, 3, 19, 26, 33, and 40 after surgical site wounding compared to non-surgical tumor bearing control cohorts [115]. This increased MMP-9 expression was positively correlated with the increased tumor volume in the surgery group between weeks 4-6 compared to the control group. Furthermore, elevated host serum MMP-9 levels, as a result of surgery wound, was positively correlated to metastatic lung tumor burden at the study endpoint [115]. To my knowledge, no studies have been performed on breast cancer patients to determine the levels of MMP-9 serum expression post surgical incision. However, if MMP-9 serum expressions in patients mimic those of preclinical studies, AM9D would play an important therapeutic role as an adjuvant to breast tumor surgery to abate tumor metastasis and surgery-stimulated growth at the site of excision.

\section{FUTURE AM9D PRECLINICAL STUDIES}

MMPs are considered promising targets for breast cancer therapy because of their major involvement in malignant pathologies and metastasis to distant organs [120]. The preclinical studies outlined in this body of work further display the therapeutic potential of downregulating MMP-9 expression by an MMP-9 specific catalytic DNA molecule. While we show the efficacy of AM9D on reducing tumor growth (Chapter 2), its efficiency on inhibition of metastasis needs to be further explored. We displayed that a majority of DNAzyme is cleared from major organs, including lung, in the first $24 \mathrm{~h}$ (Chapter 3, Figures 3-1 and 3-3). The chronic cytotoxicity experiments for DNAzyme were performed with weekly injections of DNAzyme for 9 weeks (Chapter 4, Figure 4-5). To further explore AM9D efficacy on the treatment of metastasis, a therapeutically efficient regimen must be determined. To accomplish this goal DNAzyme injections could be increased from weekly to daily injections over a period of 3 weeks for survival analysis upon early stage metastasis and until mice are overcome by tumor burden. Performing daily injections of $75 \mathrm{mg} / \mathrm{kg}$ AM9D for a period of 3 weeks would expose animals to a total of $1,575 \mathrm{mg} / \mathrm{kg}$ DNAzyme, which would require re-evaluation of mice for cytotoxicity. This would be a 7-fold increase from the original $225 \mathrm{mg} / \mathrm{kg}$ injected in previous experiments and should escalate DNAzyme accumulation in major organs.

If multiple injections prove to be too cumbersome, DNAzyme can be packaged into nanoparticles as an alternate delivery approach. Designing nanoparticles has the added effect of targeting two metastatic sites, such as lung and liver, simultaneously [121]. Targeted delivery is a promising method for the development of efficient and safe therapeutic molecules for oncology [122]. Rapid vasculature development in tumor results in larger than normal pore size within vessel walls, which allows nanoparticles to 
more easily extravasate into tumor tissue than normal tissue [123]. Tumor tissues also contain a deficiently developed lymphatic system that limits drainage of nanoparticles. Therefore, nanoparticles can improve the accumulation of DNAzyme within the tumor through their enhanced permeability and retention capabilities [123]. Similar to our observations of DNAzyme clearance (Chapter 3), Bellocq, et al. showed the majority of systemically administered DNAzyme cleared from organs after $24 \mathrm{~h}$ in mice. However, they found that injecting DNAzyme packaged with transferrin-modified polyplexes nanoparticle resulted in slower clearance of DNAzyme compared to DNAzyme packaged with non-modified polyplexes [121]. Transferrin receptor (Tf-R) is often upregulated in rapidly growing cells; furthermore, lung and liver both have high Tf-R expression [121]. Packaging our AM9D with transferrin-modified polyplexes would require additional functional and pharmacokinetic studies; however, this could decrease non-specific distribution throughout the body, decrease the observed rapid excretion, and increase accumulation thereby eliminating the need for daily injections of AM9D.

In lieu of the emerging organ toxicities and side effects of broad spectrum inhibitors, including tyrosine kinase inhibitors [124], we cannot ignore the possibility of AM9D side effects surfacing. While we showed no evidence of organ toxicity in mice injected with DNAzyme (Chapter 3), we negated to observe normal mammary tissue for the presence of toxicity in these studies. MMP-9 has been shown to be present in normal breast tissue [125]. To my knowledge, there are no studies outlining a clear role of MMP-9 in normal breast tissue. Therefore, the down regulation of MMP-9 in normal breast tissue by AM9D may lead to potential side effects. Any possible toxicities may be found through the investigation of MMP-9 in normal breast tissue in the absence and presence of AM9D.

AM9D opens the door to the development of effective anti-MMP therapies. AM9D could be used as a therapy for hormone positive and negative breast cancer patients as an adjuvant to surgery and in combination with other chemotherapeutic modalities. Overall, AM9D shows promise as a therapeutic modality for breast cancer treatment and warrants further investigation. 


\section{LIST OF REFERENCES}

1. Society AC (2009). Breast Cancer Facts and Figures 2009-2010, American Cancer Society, Inc. : Atlanta, GA.

2. $\mathrm{Hu} \mathrm{X}$, et al. (2009). Genetic alterations and oncogenic pathways associated with breast cancer subtypes. Mol Cancer Res 7: 511-522.

3. Boyce BF, Yoneda T, Guise TA (1999). Factors regulating the growth of metastatic cancer in bone. Endocr Relat Cancer 6: 333-347.

4. Mundy GR (2002). Metastasis to bone: causes, consequences and therapeutic opportunities. Nat Rev Cancer 2: 584-593.

5. Duffy MJ, McGowan PM, Gallagher WM (2008). Cancer invasion and metastasis: changing views. J Pathol 214: 283-293.

6. Minn AJ, et al. (2005). Distinct organ-specific metastatic potential of individual breast cancer cells and primary tumors. J Clin Invest 115: 44-55.

7. Kang Y, et al. (2003). A multigenic program mediating breast cancer metastasis to bone. Cancer Cell 3: 537-549.

8. Lochter A, Galosy S, Muschler J, Freedman N, Werb Z, Bissell MJ (1997). Matrix metalloproteinase stromelysin-1 triggers a cascade of molecular alterations that leads to stable epithelial-to-mesenchymal conversion and a premalignant phenotype in mammary epithelial cells. J Cell Biol 139: 1861-1872.

9. Egeblad M, Werb Z (2002). New functions for the matrix metalloproteinases in cancer progression. Nat Rev Cancer 2: 161-174.

10. Rao JS (2003). Molecular mechanisms of glioma invasiveness: the role of proteases. Nat Rev Cancer 3: 489-501.

11. Birkedal-Hansen H, et al. (1993). Matrix metalloproteinases: a review. Crit Rev Oral Biol Med 4: 197-250.

12. Nenan S, Boichot E, Lagente V, Bertrand CP (2005). Macrophage elastase (MMP-12): a pro-inflammatory mediator? Mem Inst Oswaldo Cruz 100 Suppl 1: 167-172.

13. Billinghurst RC, et al. (1997). Enhanced cleavage of type II collagen by collagenases in osteoarthritic articular cartilage. J Clin Invest 99: 1534-1545.

14. Nap AW, Dunselman GA, de Goeij AF, Evers JL, Groothuis PG (2004). Inhibiting MMP activity prevents the development of endometriosis in the chicken chorioallantoic membrane model. Hum Reprod 19: 2180-2187. 
15. Aimes RT, Quigley JP (1995). Matrix metalloproteinase-2 is an interstitial collagenase. Inhibitor-free enzyme catalyzes the cleavage of collagen fibrils and soluble native type I collagen generating the specific 3/4- and 1/4-length fragments. J Biol Chem 270: 5872-5876.

16. Okada Y, et al. (1992). Matrix metalloproteinase 9 (92-kDa gelatinase/type IV collagenase) from HT 1080 human fibrosarcoma cells. Purification and activation of the precursor and enzymic properties. J Biol Chem 267: 21712-21719.

17. Martin MD, Matrisian LM (2007). The other side of MMPs: protective roles in tumor progression. Cancer Metastasis Rev 26: 717-724.

18. Overall CM (2002). Molecular determinants of metalloproteinase substrate specificity: matrix metalloproteinase substrate binding domains, modules, and exosites. Mol Biotechnol 22: 51-86.

19. Coussens LM, Fingleton B, Matrisian LM (2002). Matrix metalloproteinase inhibitors and cancer: trials and tribulations. Science 295: 2387-2392.

20. Wolf K, Sandner P, Kurtz A, Moll W (1996). Messenger ribonucleic acid levels of collagenase (MMP-13) and matrilysin (MMP-7) in virgin, pregnant, and postpartum uterus and cervix of rat. Endocrinology 137: 5429-5434.

21. Woessner JF, Jr., Gunja-Smith Z (1991). Role of metalloproteinases in human osteoarthritis. J Rheumatol Suppl 27: 99-101.

22. Nagase H, Visse R, Murphy G (2006). Structure and function of matrix metalloproteinases and TIMPs. Cardiovasc Res 69: 562-573.

23. Gavrilovic J, Moens G, Thiery JP, Jouanneau J (1990). Expression of transfected transforming growth factor alpha induces a motile fibroblast-like phenotype with extracellular matrix-degrading potential in a rat bladder carcinoma cell line. Cell Regul 1: 1003-1014.

24. Martorana AM, Zheng G, Crowe TC, O'Grady RL, Lyons JG (1998). Epithelial cells up-regulate matrix metalloproteinases in cells within the same mammary carcinoma that have undergone an epithelial-mesenchymal transition. Cancer Res 58: $4970-4979$.

25. Hojilla CV, Mohammed FF, Khokha R (2003). Matrix metalloproteinases and their tissue inhibitors direct cell fate during cancer development. Br J Cancer 89: $1817-1821$.

26. Shima I, et al. (1993). Production of matrix metalloproteinase 9 (92-kDa gelatinase) by human oesophageal squamous cell carcinoma in response to epidermal growth factor. Br J Cancer 67: 721-727. 
27. Overall CM, Kleifeld O (2006). Tumour microenvironment - opinion: validating matrix metalloproteinases as drug targets and anti-targets for cancer therapy. Nat Rev Cancer 6: 227-239.

28. Watanabe H, Nakanishi I, Yamashita K, Hayakawa T, Okada Y (1993). Matrix metalloproteinase-9 (92 kDa gelatinase/type IV collagenase) from U937 monoblastoid cells: correlation with cellular invasion. J Cell Sci 104 ( Pt 4): 991 999.

29. Cha HJ, et al. (1996). Anti-invasive activity of ursolic acid correlates with the reduced expression of matrix metalloproteinase-9 (MMP-9) in HT1080 human fibrosarcoma cells. Cancer Res 56: 2281-2284.

30. Bergers G, et al. (2000). Matrix metalloproteinase-9 triggers the angiogenic switch during carcinogenesis. Nat Cell Biol 2: 737-744.

31. Xu J, et al. (2001). Proteolytic exposure of a cryptic site within collagen type IV is required for angiogenesis and tumor growth in vivo. J Cell Biol 154: 10691079.

32. Bhoopathi P, Chetty C, Kunigal S, Vanamala SK, Rao JS, Lakka SS (2008). Blockade of tumor growth due to matrix metalloproteinase-9 inhibition is mediated by sequential activation of betal-integrin, ERK, and NF-kappaB. J Biol Chem 283: 1545-1552.

33. Matrisian LM, et al. (1986). The mRNA coding for the secreted protease transin is expressed more abundantly in malignant than in benign tumors. Proc Natl Acad Sci U S A 83: 9413-9417.

34. Liotta LA, Rao CN, Wewer UM (1986). Biochemical interactions of tumor cells with the basement membrane. Annu Rev Biochem 55: 1037-1057.

35. Chintala SK, Tonn JC, Rao JS (1999). Matrix metalloproteinases and their biological function in human gliomas. Int J Dev Neurosci 17: 495-502.

36. Morini M, et al. (2000). The alpha 3 beta 1 integrin is associated with mammary carcinoma cell metastasis, invasion, and gelatinase B (MMP-9) activity. Int $J$ Cancer 87: 336-342.

37. Bernhard EJ, Gruber SB, Muschel RJ (1994). Direct evidence linking expression of matrix metalloproteinase 9 (92-kDa gelatinase/collagenase) to the metastatic phenotype in transformed rat embryo cells. Proc Natl Acad Sci U S A 91: 42934297.

38. Yodkeeree S, Ampasavate C, Sung B, Aggarwal BB, Limtrakul P (2010). Demethoxycurcumin suppresses migration and invasion of MDA-MB-231 human breast cancer cell line. Eur J Pharmacol 627: 8-15. 
39. Overall CM, Lopez-Otin C (2002). Strategies for MMP inhibition in cancer: innovations for the post-trial era. Nat Rev Cancer 2: 657-672.

40. O'Farrell TJ, Pourmotabbed T (1998). The fibronectin-like domain is required for the type V and XI collagenolytic activity of gelatinase B. Arch Biochem Biophys 354: 24-30.

41. Smyth E (2003). The Trouble with Inhibitors. In Horizon Symposia Signalling Scissors: New Perspectives on Proteases, pp. 1-4.

42. Haq M, Shafii A, Zervos EE, Rosemurgy AS (2000). Addition of matrix metalloproteinase inhibition to conventional cytotoxic therapy reduces tumor implantation and prolongs survival in a murine model of human pancreatic cancer. Cancer Res 60: 3207-3211.

43. Zervos EE, Shafii AE, Rosemurgy AS (1999). Matrix metalloproteinase (MMP) inhibition selectively decreases type II MMP activity in a murine model of pancreatic cancer. J Surg Res 81: 65-68.

44. Bloomston M, Zervos EE, Rosemurgy AS, 2nd (2002). Matrix metalloproteinases and their role in pancreatic cancer: a review of preclinical studies and clinical trials. Ann Surg Oncol 9: 668-674.

45. Bramhall SR, et al. (2002). Marimastat as maintenance therapy for patients with advanced gastric cancer: a randomised trial. Br J Cancer 86: 1864-1870.

46. Wojtowicz-Praga SM, Dickson RB, Hawkins MJ (1997). Matrix metalloproteinase inhibitors. Invest New Drugs 15: 61-75.

47. Rasmussen HS, McCann PP (1997). Matrix metalloproteinase inhibition as a novel anticancer strategy: a review with special focus on batimastat and marimastat. Pharmacol Ther 75: 69-75.

48. Khachigian LM (2000). Catalytic DNAs as potential therapeutic agents and sequence-specific molecular tools to dissect biological function. J Clin Invest 106: 1189-1195.

49. Santoro SW, Joyce GF (1998). Mechanism and utility of an RNA-cleaving DNA enzyme. Biochemistry 37: 13330-13342.

50. Dass CR, Choong PF, Khachigian LM (2008). DNAzyme technology and cancer therapy: cleave and let die. Mol Cancer Ther 7: 243-251.

51. Khachigian LM, Fahmy RG, Zhang G, Bobryshev YV, Kaniaros A (2002). c-Jun regulates vascular smooth muscle cell growth and neointima formation after arterial injury. Inhibition by a novel DNA enzyme targeting c-Jun. J Biol Chem 277: 22985-22991. 
52. Qu Y, et al. (2008). Effects of DNAzymes targeting Aurora kinase A on the growth of human prostate cancer. Cancer Gene Ther 15: 517-525.

53. Zhang L, Gasper WJ, Stass SA, Ioffe OB, Davis MA, Mixson AJ (2002). Angiogenic inhibition mediated by a DNAzyme that targets vascular endothelial growth factor receptor 2. Cancer Res 62: 5463-5469.

54. Noel A, Jost M, Maquoi E (2008). Matrix metalloproteinases at cancer tumor-host interface. Semin Cell Dev Biol 19: 52-60.

55. Stuelten CH, DaCosta Byfield S, Arany PR, Karpova TS, Stetler-Stevenson WG, Roberts AB (2005). Breast cancer cells induce stromal fibroblasts to express MMP-9 via secretion of TNF-alpha and TGF-beta. J Cell Sci 118: 2143-2153.

56. Fenhalls G, Geyp M, Dent DM, Parker MI (1999). Breast tumour cell-induced down-regulation of type I collagen mRNA in fibroblasts. Br J Cancer 81: 11421149.

57. Coussens LM, Werb Z (1996). Matrix metalloproteinases and the development of cancer. Chem Biol 3: 895-904.

58. Qiu TH, Chandramouli GV, Hunter KW, Alkharouf NW, Green JE, Liu ET (2004). Global expression profiling identifies signatures of tumor virulence in MMTV-PyMT-transgenic mice: correlation to human disease. Cancer Res 64: 5973-5981.

59. Lin EY, et al. (2003). Progression to malignancy in the polyoma middle T oncoprotein mouse breast cancer model provides a reliable model for human diseases. Am J Pathol 163: 2113-2126.

60. Fantozzi A, Christofori G (2006). Mouse models of breast cancer metastasis. Breast Cancer Res 8: 212.

61. Ward J. The Virtual Mouse Necropsy. Comparative Medicine Branch, NIAID, NIH. Accessed March 25, 2010. http://icg.cpmc.columbia.edu/cattoretti/Protocol/ FilesInPdf/NCIVetp.pdf.

62. Lifsted T, et al. (1998). Identification of inbred mouse strains harboring genetic modifiers of mammary tumor age of onset and metastatic progression. Int J Cancer 77: 640-644.

63. Herschkowitz JI, et al. (2007). Identification of conserved gene expression features between murine mammary carcinoma models and human breast tumors. Genome Biol 8: R76.

64. Pedersen TX, et al. (2005). Extracellular protease mRNAs are predominantly expressed in the stromal areas of microdissected mouse breast carcinomas. Carcinogenesis 26: 1233-1240. 
65. Szabova L, Yamada SS, Birkedal-Hansen H, Holmbeck K (2005). Expression pattern of four membrane-type matrix metalloproteinases in the normal and diseased mouse mammary gland. J Cell Physiol 205: 123-132.

66. Almholt K, Green KA, Juncker-Jensen A, Nielsen BS, Lund LR, Romer J (2007). Extracellular proteolysis in transgenic mouse models of breast cancer. $J$ Mammary Gland Biol Neoplasia 12: 83-97.

67. Almholt K, et al. (2008). Metastasis is strongly reduced by the matrix metalloproteinase inhibitor Galardin in the MMTV-PymT transgenic breast cancer model. Mol Cancer Ther 7: 2758-2767.

68. Martin MD, et al. (2008). Effect of ablation or inhibition of stromal matrix metalloproteinase-9 on lung metastasis in a breast cancer model is dependent on genetic background. Cancer Res 68: 6251-6259.

69. Mitchell A, Dass CR, Sun LQ, Khachigian LM (2004). Inhibition of human breast carcinoma proliferation, migration, chemoinvasion and solid tumour growth by DNAzymes targeting the zinc finger transcription factor EGR-1. Nucleic Acids Res 32: 3065-3069.

70. Berger AC, et al. (2005). Colon cancer survival is associated with decreasing ratio of metastatic to examined lymph nodes. J Clin Oncol 23: 8706-8712.

71. Phadke PA, Vaidya KS, Nash KT, Hurst DR, Welch DR (2008). BRMS1 suppresses breast cancer experimental metastasis to multiple organs by inhibiting several steps of the metastatic process. Am J Pathol 172: 809-817.

72. Vasselli JR, et al. (2003). Predicting survival in patients with metastatic kidney cancer by gene-expression profiling in the primary tumor. Proc Natl Acad Sci US A 100: 6958-6963.

73. Jones JL, Glynn P, Walker RA (1999). Expression of MMP-2 and MMP-9, their inhibitors, and the activator MT1-MMP in primary breast carcinomas. $J$ Pathol 189: 161-168.

74. Duffy MJ, Maguire TM, Hill A, McDermott E, O'Higgins N (2000). Metalloproteinases: role in breast carcinogenesis, invasion and metastasis. Breast Cancer Res 2: 252-257.

75. Pourmotabbed T, Solomon TL, Hasty KA, Mainardi CL (1994). Characteristics of $92 \mathrm{kDa}$ type IV collagenase/gelatinase produced by granulocytic leukemia cells: structure, expression of cDNA in E. coli and enzymic properties. Biochim Biophys Acta 1204: 97-107.

76. Agrawal S, Temsamani J, Tang JY (1991). Pharmacokinetics, biodistribution, and stability of oligodeoxynucleotide phosphorothioates in mice. Proc Natl Acad Sci U S A 88: 7595-7599. 
77. Lau DH, Xue L, Young LJ, Burke PA, Cheung AT (1999). Paclitaxel (Taxol): an inhibitor of angiogenesis in a highly vascularized transgenic breast cancer.

Cancer Biother Radiopharm 14: 31-36.

78. Dass CR, Choong PF (2010). Sequence-related off-target effect of Dz13 against human tumor cells and safety in adult and fetal mice following systemic administration. Oligonucleotides 20: 51-60.

79. Hong JH, Ahn KS, Bae E, Jeon SS, Choi HY (2006). The effects of curcumin on the invasiveness of prostate cancer in vitro and in vivo. Prostate Cancer Prostatic Dis 9: 147-152.

80. Lee KW, Kim JH, Lee HJ, Surh YJ (2005). Curcumin inhibits phorbol esterinduced up-regulation of cyclooxygenase-2 and matrix metalloproteinase- 9 by blocking ERK1/2 phosphorylation and NF-kappaB transcriptional activity in MCF10A human breast epithelial cells. Antioxid Redox Signal 7: 1612-1620.

81. Aggarwal BB, et al. (2005). Curcumin suppresses the paclitaxel-induced nuclear factor-kappaB pathway in breast cancer cells and inhibits lung metastasis of human breast cancer in nude mice. Clin Cancer Res 11: 7490-7498.

82. Eiseler T, Doppler H, Yan IK, Goodison S, Storz P (2009). Protein kinase D1 regulates matrix metalloproteinase expression and inhibits breast cancer cell invasion. Breast Cancer Res 11: R13.

83. Chen X, et al. (2005). Increased plasma MMP9 in integrin alpha1-null mice enhances lung metastasis of colon carcinoma cells. Int J Cancer 116: 52-61.

84. Itoh T, et al. (1999). Experimental metastasis is suppressed in MMP-9-deficient mice. Clin Exp Metastasis 17: 177-181.

85. Gerg M, et al. (2008). Distinct functionality of tumor cell-derived gelatinases during formation of liver metastases. Mol Cancer Res 6: 341-351.

86. Rao VH, et al. (1995). Expression of $72 \mathrm{kDa}$ and $92 \mathrm{kDa}$ type IV collagenases from human giant-cell tumor of bone. Clin Exp Metastasis 13: 420-426.

87. Lewis CE, Pollard JW (2006). Distinct role of macrophages in different tumor microenvironments. Cancer Res 66: 605-612.

88. Rijnkels M, Rosen JM (2001). Adenovirus-Cre-mediated recombination in mammary epithelial early progenitor cells. J Cell Sci 114: 3147-3153.

89. Krieg AM (2006). Therapeutic potential of Toll-like receptor 9 activation. Nat Rev Drug Discov 5: 471-484.

90. Chuang TH, Lee J, Kline L, Mathison JC, Ulevitch RJ (2002). Toll-like receptor 9 mediates CpG-DNA signaling. J Leukoc Biol 71: 538-544. 
91. Krieg AM (2004). Antitumor applications of stimulating toll-like receptor 9 with CpG oligodeoxynucleotides. Curr Oncol Rep 6: 88-95.

92. Shibue T, Weinberg RA (2009). Integrin beta1-focal adhesion kinase signaling directs the proliferation of metastatic cancer cells disseminated in the lungs. Proc Natl Acad Sci U S A 106: 10290-10295.

93. Wyatt CA, Geoghegan JC, Brinckerhoff CE (2005). Short hairpin RNA-mediated inhibition of matrix metalloproteinase-1 in MDA-231 cells: effects on matrix destruction and tumor growth. Cancer Res 65: 11101-11108.

94. Hughes S, et al. (2007). Matrix metalloproteinase single-nucleotide polymorphisms and haplotypes predict breast cancer progression. Clin Cancer Res 13: 6673-6680.

95. Provatopoulou X, et al. (2009). Circulating levels of matrix metalloproteinase-9 (MMP-9), neutrophil gelatinase-associated lipocalin (NGAL) and their complex MMP-9/NGAL in breast cancer disease. BMC Cancer 9: 390.

96. Boire A, Covic L, Agarwal A, Jacques S, Sherifi S, Kuliopulos A (2005). PAR1 is a matrix metalloprotease-1 receptor that promotes invasion and tumorigenesis of breast cancer cells. Cell 120: 303-313.

97. Bu CH, Pourmotabbed T (1995). Mechanism of activation of human neutrophil gelatinase B. Discriminating between the role of $\mathrm{Ca} 2+$ in activation and catalysis. J Biol Chem 270: 18563-18569.

98. Allan JA, Docherty AJ, Barker PJ, Huskisson NS, Reynolds JJ, Murphy G (1995). Binding of gelatinases A and B to type-I collagen and other matrix components. Biochem J 309 ( Pt 1): 299-306.

99. O'Farrell TJ, Pourmotabbed T (2000). Identification of structural elements important for matrix metalloproteinase type $\mathrm{V}$ collagenolytic activity as revealed by chimeric enzymes. Role of fibronectin-like domain and active site of gelatinase B. J Biol Chem 275: 27964-27972.

100. Abecassis I, Olofsson B, Schmid M, Zalcman G, Karniguian A (2003). RhoA induces MMP-9 expression at CD44 lamellipodial focal complexes and promotes HMEC-1 cell invasion. Exp Cell Res 291: 363-376.

101. Dufour A, Zucker S, Sampson NS, Kuscu C, Cao J (2010). Role of matrix metalloproteinase-9 dimers in cell migration: design of inhibitory peptides. J Biol Chem 285: 35944-35956.

102. Behzadian MA, Wang XL, Windsor LJ, Ghaly N, Caldwell RB (2001). TGF-beta increases retinal endothelial cell permeability by increasing MMP-9: possible role of glial cells in endothelial barrier function. Invest Ophthalmol Vis Sci 42: 853859. 
103. Roeb E, et al. (2002). The matrix metalloproteinase 9 (mmp-9) hemopexin domain is a novel gelatin binding domain and acts as an antagonist. $J$ Biol Chem 277: 50326-50332.

104. Morodomi T, Ogata Y, Sasaguri Y, Morimatsu M, Nagase H (1992). Purification and characterization of matrix metalloproteinase 9 from U937 monocytic leukaemia and HT1080 fibrosarcoma cells. Biochem J 285 ( Pt 2): 603-611.

105. O'Farrell TJ, Guo R, Hasegawa H, Pourmotabbed T (2006). Matrix metalloproteinase- 1 takes advantage of the induced fit mechanism to cleave the triple-helical type I collagen molecule. Biochemistry 45: 15411-15418.

106. Pourmotabbed T, Aelion JA, Tyrrell D, Hasty KA, Bu CH, Mainardi CL (1995). Role of the conserved histidine and aspartic acid residues in activity and stabilization of human gelatinase B: an example of matrix metalloproteinases. $J$ Protein Chem 14: 527-535.

107. Tsukada H, Pourmotabbed T (2002). Unexpected crucial role of residue 272 in substrate specificity of fibroblast collagenase. J Biol Chem 277: 27378-27384.

108. Harris ED, Jr., Krane SM (1972). An endopeptidase from rheumatoid synovial tissue culture. Biochim Biophys Acta 258: 566-576.

109. Bu CH, Pourmotabbed T (1996). Mechanism of Ca2+-dependent activity of human neutrophil gelatinase B. J Biol Chem 271: 14308-14315.

110. Rowsell S, et al. (2002). Crystal structure of human MMP9 in complex with a reverse hydroxamate inhibitor. J Mol Biol 319: 173-181.

111. Zucker S, Lysik RM, Zarrabi MH, Moll U (1993). M(r) 92,000 type IV collagenase is increased in plasma of patients with colon cancer and breast cancer. Cancer Res 53: 140-146.

112. Wu ZS, et al. (2008). Prognostic significance of MMP-9 and TIMP-1 serum and tissue expression in breast cancer. Int J Cancer 122: 2050-2056.

113. Moses MA, Wiederschain D, Loughlin KR, Zurakowski D, Lamb CC, Freeman MR (1998). Increased incidence of matrix metalloproteinases in urine of cancer patients. Cancer Res 58: 1395-1399.

114. Hemati S, Sadeghi, M., Motovali-Bashi, M., Sahebi, A., Vaise Malekshahi, Z. (2010). Higher plasma MMP-9 level in breast cancer patients with MMP-9 promoter T allele. J Biol Res - Thessalon 13: 113-118.

115. Zhao T, Xia WH, Zheng MQ, Lu CQ, Han X, Sun YJ (2008). Surgical excision promotes tumor growth and metastasis by promoting expression of MMP-9 and VEGF in a breast cancer model. Exp Oncol 30: 60-64. 
116. Pellikainen JM, Ropponen KM, Kataja VV, Kellokoski JK, Eskelinen MJ, Kosma VM (2004). Expression of matrix metalloproteinase (MMP)-2 and MMP-9 in breast cancer with a special reference to activator protein-2, HER2, and prognosis. Clin Cancer Res 10: 7621-7628.

117. Oakman C, Viale G, Di Leo A (2010). Management of triple negative breast cancer. Breast 19: 312-321.

118. Wang YJ, Wang N, Wang B, Qin WX, Xue CY (2009). [Comparison of clinicopathologic characteristics and prognosis of triple-negative with Her-2overexpressing breast cancer]. Zhonghua Zhong Liu Za Zhi 31: 346-350.

119. Coussens LM, Werb Z (2002). Inflammation and cancer. Nature 420: 860-867.

120. Mannello F (2006). Natural bio-drugs as matrix metalloproteinase inhibitors: new perspectives on the horizon? Recent Pat Anticancer Drug Discov 1: 91-103.

121. Bellocq NC, Pun SH, Jensen GS, Davis ME (2003). Transferrin-containing, cyclodextrin polymer-based particles for tumor-targeted gene delivery. Bioconjug Chem 14: 1122-1132.

122. Bartlett DW, Su H, Hildebrandt IJ, Weber WA, Davis ME (2007). Impact of tumor-specific targeting on the biodistribution and efficacy of siRNA nanoparticles measured by multimodality in vivo imaging. Proc Natl Acad Sci $U$ $S$ A 104: 15549-15554.

123. MacEwan SR, Callahan DJ, Chilkoti A (2010). Stimulus-responsive macromolecules and nanoparticles for cancer drug delivery. Nanomedicine (Lond) 5: 793-806.

124. Lodish MB, Stratakis CA (2010). Endocrine side effects of broad-acting kinase inhibitors. Endocr Relat Cancer 17: R233-244.

125. Kohrmann A, Kammerer U, Kapp M, Dietl J, Anacker J (2009). Expression of matrix metalloproteinases (MMPs) in primary human breast cancer and breast cancer cell lines: New findings and review of the literature. BMC Cancer 9: 188.

126. Santoro SW, Joyce GF (1997). A general purpose RNA-cleaving DNA enzyme. Proc Natl Acad Sci U S A 94: 4262-4266. 


\section{APPENDIX. DEVELOPMENT OF AM9D MATERIALS AND METHODS}

DNAZYME

Several DNAzyme molecules were synthesized by Integrated DNA Technology (Coralville, IA). All the DNAzymes consisted of nine oligonucleotides on each arms complementary to different regions of MMP-9 mRNA flanking the nucleotide 10-23 catalytic core [49, 126]. Sequences of DNAzymes targeting mRNA of MMP-9 were, AM9D-1: 5'-AGCCCAGCAggctagctacaacgaCAGGAGCAC-3'; AM9D-2: 5'-AAGGGTGGAggctagctacaacgaTGGCGCTGT-3'; AM9D-3 5'-ATAGCGGTAggctagctacaacgaAGGTATTCC-3'; AM9D-4: 5'-CCCCAGAGAggctagctacaacgaTTCGACTCT-3'; AM9D-5: 5'-GTGGTGCCAggctagctacaacgaTTGAGGTCG-3'. Scrambled DNAzyme (CTAGTCAGCggctagctacaacgaTAAGCTGCT), where the arms flanking the 10-23 catalytic core were composed of random sequence and sense control DNAzymes containing sense oligonucleotide sequences corresponding to each DNAzyme in both arms were used as negative controls. Nucleotides in lower case represent the 10-23 catalytic domain and the corresponding MMP-9 sequences are in capital. Where indicated, DNAzymes were fluorescently labeled at 5' end with Oregon Green ${ }^{\mathrm{TM}} 488$ maleimide as suggested by the manufacture (Molecular Probes, Eugene, OR). The labeled oligonucleotides were purified with the MERmaid Kit (BIO 101, La Jolla, CA).

\section{IN VITRO TRANSCRIPTION AND CLEAVAGE ANALYSIS OF MMP-9 RNA BY DNAZYMES}

The 764-nucleotide MMP-9 RNA transcript was prepared by in vitro transcription (T3 polymerase) of pBSNG4.1 [75] digested with Bsm1 restriction enzyme. DNAzymes $(12.5 \mu \mathrm{M})$ were incubated with the RNA substrate $(0.48 \mu \mathrm{M})$ in $50 \mathrm{mM}$ Tris- $\mathrm{HCl}, \mathrm{pH} 7.5$, containing $10 \mathrm{mM} \mathrm{MgCl} 2$ at $37{ }^{\circ} \mathrm{C}$ for $2 \mathrm{~h}$. The reactions were stopped with $90 \%$ formamide in TBE and the reaction products were separated on a $4 \%$ polyacrylamide-urea gel. The RNA products were stained with Ethidium Bromide and their intensities were determined using an Alpha Imager 2000 documentation and analysis system (Alpha Innotech Corp., San Leandro, CA).

\section{CELL TRANSFECTION}

The COS-7 and MDA-MB-231 cell lines were obtained from American Type Culture Collection (ATTC, Manassas, VA). COS-7 cells were grown in Dulbecco's modified Eagles medium (DMEM), $\mathrm{pH} 7.4$, containing 10\% fetal bovine serum (FBS), $100 \mathrm{i} . \mathrm{u} . / \mathrm{ml}$ penicillin, and $100 \mu \mathrm{g} / \mathrm{ml}$ streptomycin at $37^{\circ} \mathrm{C}$ in a humidified atmosphere of $10 \%$ CO2. The COS-7 NG was generated by stably transfecting COS-7 cells with pcDNA3-MMP-9. Sub-confluent COS-7 NG cells (60-70\%) were incubated in serum free medium and transiently transfected with Oregon Green ${ }^{\mathrm{TM}} 488$ maleimide labeled 
DNAzyme (AM9D-5; $24 \mu \mathrm{g}$ ) using DOTAP transfection reagent according to the manufacturer's instruction (Roche, Mannheim, Germany). After $24 \mathrm{~h}$ incubation at $37^{\circ} \mathrm{C}$ in serum free medium, cells were collected, sorted, and the transfected cells were isolated for further analysis. MDA-MB-231 human breast cancer cells (ATCC; Manassas, VA) were plated onto $10 \mathrm{~cm}$ dishes in DMEM media supplemented with $10 \%$ fetal bovine serum (FBS) and allowed to grow to $80-90 \%$ confluence at $37{ }^{\circ} \mathrm{C}$ with $5 \%$ $\mathrm{CO}_{2}$. The cells were then serum-starved for 4 hours prior to transient transfection with

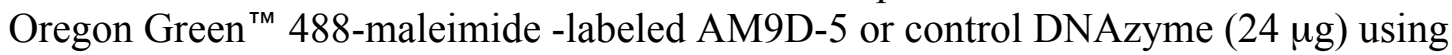
Lipofectamine 2000 (Invitrogen, Carlsbad, CA). After a $18 \mathrm{~h}$ incubation at $37^{\circ} \mathrm{C}$ in serum free medium, transfected cells were sorted for the presence of Oregon Green on a BD Biosciences Aria cytometer and positive cells were collected for further analysis.

\section{ANALYSIS OF MMP-9 MRNA AND PROTEIN PRODUCTION IN AM9D TRANSFECTED CELLS}

The amount of MMP-9 mRNA and its enzyme activity in the DNAzyme transfected COS-7 NG cells were measured by reverse transcription-polymerase chain reaction (RT-PCR) and gelatin gel zymography [75], respectively. Total RNA from the transfected COS-7 NG cells was isolated by Trizol reagent (Invitrogen, Carlsbad, CA) and reverse transcribed with random hexamer primers (Promega, Madison, WI) using MMLV-RT enzyme (Invitrogen, Carlsbad, CA). The amount of MMP-9 mRNA present in the RNA samples was quantified by PCR using specific MMP-9 primers (forward; 5'-GCAGGAATGCGGCTCTGG-3' and reverse primer; 5'-CCCGTCGAAGGGATACC-3'). $\beta$-actin mRNA was also amplified as an internal control, with forward; 5'-CAAGAGATGGCCACGGCGGCT-3' and reverse; 5'-TCCTTCTGCATCCTGTCAGCA-3' Primers. The PCR products were subjected to $1 \%$ agarose gel and visualized by Ethidium Bromide staining. MMP-9 expression was quantified by an alpha imager 2000 documentation and analysis system (Alpha Innotech corporation San Leandro, CA).

\section{CELL INVASION ASSAY}

MDA-MB-231 cells were transfected with fluorescently labeled AM9D-5 or control DNAzyme for $18 \mathrm{~h}$ in serum free DMEM medium as above. The fluorescent positive cells was identified by flow cytometry, isolated and seeded in ECMatrix ${ }^{\mathrm{TM}}$ invasion chambers (Millipore, Billerica, MA). After $24 \mathrm{~h}$ incubation at $37^{\circ} \mathrm{C}$ with $5 \%$ $\mathrm{CO} 2$, the number of cells that migrated though the ECM layer and attached to the polycarbonate membrane was quantified spectrophotometerically at $560 \mathrm{~nm}$ according to the manufacturer's protocol. All assays were conducted in triplicate and the values were averaged. 


\section{VITA}

Miranda Alvina Marie Hallett was born in 1983 in Trenton, NJ. She is the daughter of Steve and Alvina Hallett. She was raised in Yardley, PA with her four older brothers, Steve, Jr., Jamal, Rashad, and Khaleef. After graduating Pennsbury High School with honors, Miranda attended Spelman College in Atlanta, GA. Miranda graduated in 2006 with a Bachelors of Science degree in Chemistry. Immediately following graduation, she then entered into the Integrated Program in Biomedical Sciences at UTHSC. 